\title{
Determining Airspeed Without a Pitot-Static System for Use in a General Aviation Flight Data Recorder Using an Ardu-Pilot
}

\author{
by \\ James W. Adams \\ A Thesis submitted to \\ the Faculty of Graduate Studies and Research \\ in partial fulfilment of \\ the requirements for the degree of \\ Master of Applied Science \\ Ottawa-Carleton Institute for \\ Mechanical and Aerospace Engineering
}

Department of Mechanical and Aerospace Engineering

Carleton University

Ottawa, Ontario, Canada

December 2016

Copyright (C)

2017 - James W. Adams 
The undersigned recommend to

the Faculty of Graduate Studies and Research acceptance of the Thesis

Determining Airspeed Without a Pitot-Static System for Use in a General Aviation Flight Data Recorder Using an Ardu-Pilot

Submitted by James W. Adams

in partial fulfilment of the requirements for the degree of

Master of Applied Science

Carleton University

2017 


\section{Abstract}

The research was to create the necessary algorithms for airspeed determination without the use of a pitot-static system or weather data. The motivation for this study is due to the large cost associated with integrating into aircraft systems and the uncertainty associated with meteorology. The primary piece of hardware used was the Pixhawk or the Ardu-Pilot Mega (APM) 2.5 by Arduino. The Pixhawk and the APM were powered by either the aircraft's $12 \mathrm{~V}$ power supply or a small battery pack meant for cellphones. Both the Internal logs and the telemetry logs were used in the data acquisition process but focus was placed on the telemetry logs due to ease of data manipulation. The equations used to form the algorithm include the definition of the coefficient of lift, an estimation of the lift-curve slope and various other equations. There were preliminary ground tests performed as well as several flight tests. The flight tests primary consisted of scenic flights and had no aerobatic maneuvers such as stall or spins. The results showed $10 \%$ errors on a turbulent day and $5 \%$ errors on a low-turbulence day. It is possible that the difference in errors was due to turbulence but further investigation is required. The results show promise in steady flight but more work must be done to apply it to stall scenarios. Flaps were not taken into consideration. As it currently stands, the airspeed algorithm would be a good addition to a fuel burn estimation application located on an electronic flight bag. 


\section{Acknowledgments}

The operational support provided by Alexandria Aviation for the flight testing and by Specific Range Solutions Inc. for flight operations app development is gratefully acknowledged. ING Robotic Aviation is also acknowledged for their helpful technical support with the Arduino micro-controllers. Shal Marriott's assistance with MATLAB processing of the dataflash logs is greatly appreciated. 


\section{Table of Contents}

$\begin{array}{ll}\text { Abstract } & \text { ii }\end{array}$

Acknowledgments

Table of Contents $\quad$ iv

List of Tables $\quad$ vii

List of Figures viii

Nomenclature $\quad x$

1 Introduction 1

1.1 Background . . . . . . . . . . . . . . . . . . 4

2 Literature Review 10

2.1 Other Applications of the Non-Invasive Unit with the Airspeed Algorithm . 18

2.1.1 Electronic Flight Bags . . . . . . . . . . . . . . . . . . . . . . . . 19

$2.1 .2 \quad$ Flight Data Streaming . . . . . . . . . . . . . . . 22

2.1 .3 Heads Up Display . . . . . . . . . . . . . . . . . . . . . 22

2.1.4 Low-Cost Research and Flight Testing . . . . . . . . . . . . . . . 23

2.1.5 Flight Services . . . . . . . . . . . . . . . . 24

$\begin{array}{lll}3 & \text { Hardware } & 27\end{array}$

3.1 The APM Microcontrollers: ATMEGA 2560 and ATMEGA 32-U . . . . . 30 
3.2 The Pixhawk Microcontroller: STM32F427 f . . . . . . . . . . . . 30

3.3 The Internal Accelerometer and Gyroscope . . . . . . . . . . . . . . 33

3.4 The Internal Barometer . . . . . . . . . . . . . . . . . . . . 35

3.5 The Internal Compass . . . . . . . . . . . . . . . . . . . 35

3.6 GPS Antenna . . . . . . . . . . . . . . . . . . . 36

3.7 Protective Case . . . . . . . . . . . . . . . . . 36

3.8 3DR Radio . . . . . . . . . . . . . . . . . . . . . . . . . . . 39

4 Software $\quad 41$

4.1 Dataflash Logs . . . . . . . . . . . . . . . . . . 41

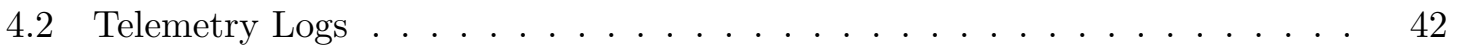

5 Parameters and Algorithms $\quad 45$

5.1 Parameters ................................. 45

5.2 Algorithm . . . . . . . . . . . . . . . . . . . 45

5.2 .1 Definition of Lift . . . . . . . . . . . . . . 45

5.2 .2 Slope of the Lift Curve . . . . . . . . . . . . . . . . . 47

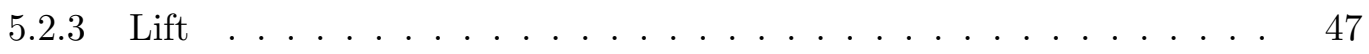

$5.2 .4 \quad$ Air Density . . . . . . . . . . . . . . . . . . 48

5.2 .5 The Airspeed Equation . . . . . . . . . . . . . . 48

5.2 .6 True Airspeed . . . . . . . . . . . . . . . . . . . . . 48

5.2 .7 Groundspeed and Weather Method . . . . . . . . . . . . 50

6 Testing $\quad 52$

6.1 Preliminary Testing $\ldots \ldots \ldots \ldots \ldots \ldots$. . . . . . . . . . . . . . 52

6.1 .1 Preliminary Results . . . . . . . . . . . . . 52

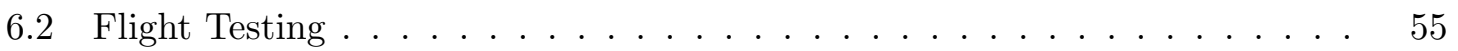

6.2 .1 The Flight Test Aircraft . . . . . . . . . . . . 56

$6.2 .2 \quad$ First Flight Test . . . . . . . . . . . . . . . 56

6.2 .3 Second Flight Test . . . . . . . . . . . . . . . . 60 
6.2 .4 Third Flight Test . . . . . . . . . . . . . . . . . 64

6.2 .5 Fourth Flight Test . . . . . . . . . . . . . . 67

7 Conclusion and Future Work $\quad 77$

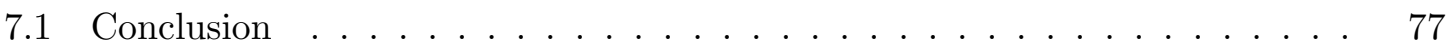

7.2 Future Work . . . . . . . . . . . . . . . . . 79

$7.2 .1 \quad$ Further Testing . . . . . . . . . . . . . . . . . . 79

7.2 .2 Hardware Considerations . . . . . . . . . . . . . 80

7.2 .3 Additions to the Equation . . . . . . . . . . . . . . . 81

List of References $\quad 85$ 


\section{List of Tables}

3.1 List of Hardware and their Function . . . . . . . . . . . . . 29

5.1 List of Parameters and their Sources. . . . . . . . . . . . . . . . 46

5.2 List of Variables, Their Units and Their Sources . . . . . . . . . . . . 50

6.1 Beechcraft Musketeer Details . . . . . . . . . . . . . . . 57

6.2 List of Variables and their Values for Several Data Points from the Second Flight Test . . . . . . . . . . . . . . . . 63

6.3 Third Flight's Recorded Airspeed . . . . . . . . . . . . . . 65

6.4 The Measured Parameters of the Third Flight Test $\ldots \ldots \ldots$. . . . 68

6.5 Calculated Results of the Third Flight Test . . . . . . . . . . . . . 70

6.6 Fourth Flight's Recorded Airspeed . . . . . . . . . . . . . . . 72

6.7 The Measured Parameters of the Fourth Flight Test . . . . . . . . . . . 74

6.8 Calculated Results of the Fourth Flight Test . . . . . . . . . . . 76 


\section{List of Figures}

1.1 Accident Investigation Flow Chart $[2] \ldots \ldots \ldots$

1.2 Glass Cockpit Vs Analog Instruments . . . . . . . . . . . . . . . 6

2.1 Barclay's RPM and Engine Temperature Unit, JEMMA [10] . . . . . . . . . 12

2.2 Nav Canada's Forecast for Atmospheric Conditions Aloft [12] . . . . . . . . 13

2.3 Roll, Pitch, Yaw and the Aircraft Axes $[14] \ldots \ldots$. . . . . . . . . 14

2.4 Current flight data recorders for light aircraft require extensive modifications to the aircraft $[15] \ldots \ldots \ldots \ldots \ldots \ldots$

2.5 Neuhart et al's Flight Test Plan $[15] \ldots \ldots \ldots$

2.6 Configuration of the Previous FDR by the Research Supervisor's and Dr Langlois' Groups $[16] \ldots \ldots$. . . . . . . . . . . . . . . . . . 18

2.7 Different Applications of an Electronic Flight Bag [17] . . . . . . . . . . . 19

2.8 Typical Heads Up Display Information $[19] \ldots \ldots$. . . . . . . . . 23

2.9 A Two-Way Satellite Communication Device $[21] \ldots \ldots$. . . . . . . . 25

2.10 FSS Service $[21] \ldots \ldots \ldots \ldots \ldots \ldots \ldots$

3.1 APM 2.5 Block Diagram $[22] \ldots \ldots \ldots \ldots \ldots \ldots$

3.2 APM 2.5 in it's Protective Shell $[22] \ldots \ldots \ldots \ldots \ldots$

3.3 ATMEGA Block Diagrams $[3] \ldots \ldots \ldots \ldots \ldots \ldots$

3.4 Block diagram of the STM32F427 [28] . . . . . . . . . . . . . . . 32

3.5 Pin layout of the MPU-6000 $[29] \ldots \ldots \ldots \ldots \ldots$

3.6 Block diagram of the barometer $[31] \ldots \ldots \ldots \ldots$

3.7 HMC5883L compass unit $[32] \ldots \ldots \ldots \ldots \ldots \ldots \ldots$

3.8 FGPMMOPA6B GPS Unit $[33] \ldots \ldots \ldots \ldots$ 
3.9 Pelican 1020 Micro Case $[34] \ldots \ldots \ldots$

3.10 The Pixhawk Snugly placed within the Pelican Case . . . . . . . . . . 40

3.11 3DR Radio and Components $[35] \ldots \ldots \ldots$

4.1 Mission Planner Log Graph Output . . . . . . . . . . . . . . . 43

4.2 Dataflash Log Output to Spreadsheet . . . . . . . . . . . . . . . 44

4.3 Telemetry Log Output to Spreadsheet . . . . . . . . . . . . . . . 44

5.1 Indicated and Calibrated Airspeed . . . . . . . . . . . . . . . . 49

5.2 Groundspeed Velocity Triangle . . . . . . . . . . . . . . . 51

6.1 Ground Test Vehicle: 1992 Pontiac Firebird . . . . . . . . . . . . . . . 53

6.2 First Ground Test Preliminary Results . . . . . . . . . . . . . . . 54

6.3 Second Ground Test Preliminary Results . . . . . . . . . . . . . . . . 55

6.4 Flight Test Aircraft . . . . . . . . . . . . . . . . . . . . 57

6.5 Weight and Balance of Beechcraft A-23 C-GBFZ, Formerly Known as N3509R 58

6.6 Flight Path and Altitude of the First Flight Test . . . . . . . . . . . . 60

6.7 Some Noisy Data from the First Flight Test . . . . . . . . . . . . . 61

6.8 Flight Path of the Second Flight Test . . . . . . . . . . . . . . . 62

6.9 Weather During the Third Test Flight $[12] \ldots \ldots \ldots 6$

6.10 The Weight and Balance of the Aircraft for the Third Flight Test . . . . . . 69

6.11 Weather During the Fourth Test Flight $[12] \ldots \ldots$. . . . . . . 71

6.12 The Weight and Balance of the Aircraft for the Fourth Flight Test . . . . . 75

7.1 The Effect of Flaps on an Airfoil [44] . . . . . . . . . . . . . . 82

7.2 Block Digram of a Virtual Flight Data Recorder Using an NNR [45] . . . . 84 


\section{Nomenclature}

\begin{tabular}{|c|c|}
\hline $\mathrm{a}$ & Lift Curve Slope of the Aircraft \\
\hline$a_{0}$ & The Lift Curve Slope of an Infinite Wing $(2 \pi)$ \\
\hline $\mathrm{ADC}$ & Analog to Digital Converter \\
\hline AGL & Above Ground Level \\
\hline $\mathrm{AME}$ & Aircraft Maintenance Engineer \\
\hline $\mathrm{AR}$ & Aspect Ratio of the Wing \\
\hline $\mathrm{APM}$ & ArduPilot Mega \\
\hline AS & Airspeed \\
\hline$C_{L}$ & Coefficient of Lift \\
\hline$C_{L \alpha}$ & Lift Curve Slope of the Aircraft \\
\hline CARs & Canadian Aviation Regulations \\
\hline CVR & Cockpit Voice Recorder \\
\hline $\mathrm{DAC}$ & Digital to Analog Converter \\
\hline Dataflash log & The Ardu-Pilot's Internal Logging Format \\
\hline DC & Direct Current \\
\hline EASA & European Aviation Safety Authority \\
\hline EFB & Electronic Flight Bag \\
\hline FDM & Flight Data Management \\
\hline FDR & Flight Data Recorder \\
\hline FOQA & Flight Operations Quality Assurance \\
\hline GA & General Aviation \\
\hline GAFDR & General Aviation Flight Data recorder \\
\hline
\end{tabular}




\begin{tabular}{|c|c|}
\hline GPS & Global positioning system \\
\hline GS & Groundpeed \\
\hline HUD & Heads Up Display \\
\hline IMU & Inertial measurement unit \\
\hline $\mathrm{I} / \mathrm{O}$ & Input/Output \\
\hline $\mathrm{L}$ & Lift \\
\hline $\mathrm{m}$ & Mass \\
\hline MAV Link & Micro Air Vehicle Link \\
\hline OAT & Outside air temperature \\
\hline $\mathrm{POH}$ & Pilot Operating Handbook \\
\hline $\mathrm{RPM}$ & Revolutions Per Minute \\
\hline Q & Difference Between the Direction of the Wind and the Heading of the Aircraft \\
\hline QAR & Quick Access Recorder \\
\hline $\mathrm{R}$ & Specific Gas Constant for Air \\
\hline$S_{r e f}$ & Surface Area of the Wing and Horizontal Tail \\
\hline SRAM & Static Random-Acess Memory) \\
\hline Telemetry log & The Ardu-Pilot's External Logging Format \\
\hline TSB & Transportation Safety Board \\
\hline UAV & Unmanned Aerial Vehicles \\
\hline USB & Universal Serial Bus \\
\hline UTC & (Coordinated Universal Time) \\
\hline $\mathrm{V}$ & Airspeed \\
\hline VFR & Visual Flight Rules \\
\hline$V_{\text {sound }}$ & Speed of Sound \\
\hline WS & Wind Speed \\
\hline$z_{a}$ & Acceleration in the Z Direction \\
\hline$\alpha$ & Angle of Attack \\
\hline$\alpha_{0}$ & Pitch Mounting Angle of the Data Recorder \\
\hline
\end{tabular}


$\alpha_{L=0}$

$\delta$

$\Lambda$

$\rho$

$\tau$
Zero-Lift Angle of Attack

Induced Drag Factor

Quarter-Chord Sweep Angle of the Wing

Air Density 


\section{Chapter 1}

\section{Introduction}

There are nearly 240,000 active General Aviation (GA) aircraft in the North America alone [1], and most of them are without a Flight Data Recorder (FDR). There are several reasons for the lack of FDRs in GA. The first is cost; the cost of a full modern FDR system can exceed the cost of some aircraft. This cost stems from the required government approval surrounding equipment and the cost of installation by an approved Aircraft Maintenance Engineer (AME). The paperwork for government approval is complicated and tedious which inevitably increases the costs to manufacturers and a licenced AME's time is expensive. By determining the airspeed computationally and using data from sensors which do not require invasive modifications to the aircraft, there is no need for regulatory body approval and the unit may be installed by anyone.

Currently, aircraft accident investigators must use methods which do not require having flight data to determine the cause of an accident of a GA aircraft. These methods can involve reconstructing the aircraft, checking all the switch positions, checking the frequencies of the radio, checking the witness marks of the instrument needles on the instruments caused by impact, attempting to find physical defects in the materials of the aircraft, and various other factor which could lead to an accident. This process of accident investigation can be very tedious, time consuming, and may yield inaccurate results. A flight data recorder offers extra information which can prove invaluable in determining the cause of an accident by giving the investigators information about the aircraft's attitude, flight path and performance in the events leading up to the accident. The aircraft investigators have a clear idea of the 
events which transpired surrounding an accident is important to aviation safety. Their findings help the aviation community learn from their failures and promote new safety recommendations to pilots and air operators. Figure 1.1 shows a flow chart of the accident investigation and documentation process [2].

The research is to create the necessary algorithms for a low-cost FDR with the possibility of improving functions on existing Flight management Systems (FMS). Within this research, FDRs and FMSs are considered together for low-cost applications as the FDR could record the entire flight internally and subsequently provide the data through an FMS. The biggest issue faced with such a project is to determine airspeed without an aircraft modification. Airspeed is a vital piece of information in aviation and has traditionally only been available through an airspeed indicator with a pitot-static system. Without the airspeed information, it is difficult to determine the performance of the aircraft. However, modification to an aircraft or its components requires regulatory approval by the appropriate governing body of aviation and implementation by a licenced Aircraft Maintenance Engineer. In that case, both the approval and the installation are expensive and time consuming. Determining the airspeed without modifications is accomplished by manipulating stability derivatives to computationally approximate airspeed with other known parameters. The other parameters are measured using gyroscopes, accelerometers and GPS (Global Positioning System) through a UAV (Unmanned Aerial Vehicle) autopilot system. There is currently no low-cost FDR or FMS which includes the crucial airspeed parameter. The addition of airspeed on an after-market FMS leads to better performance calculations, indications of stall or near-stall attitudes and a maximum speed warning. The airspeed algorithms have been flight tested. The hardware unit itself may be used as a low-cost flight data recorder. With an FDR using this algorithm, accident or incident investigation can be significantly simplified or the investigators can use the data to validate theories suggested by other means. The FDR could lead to lower insurance costs if the data were available to insurance companies.

There are many other potential, and more profitable, applications to the airspeed algorithm. The other applications of the airspeed algorithm are mostly used within Electronic Flight Bags (EFB) or FMS. An EFB is basically an information application on a mobile 


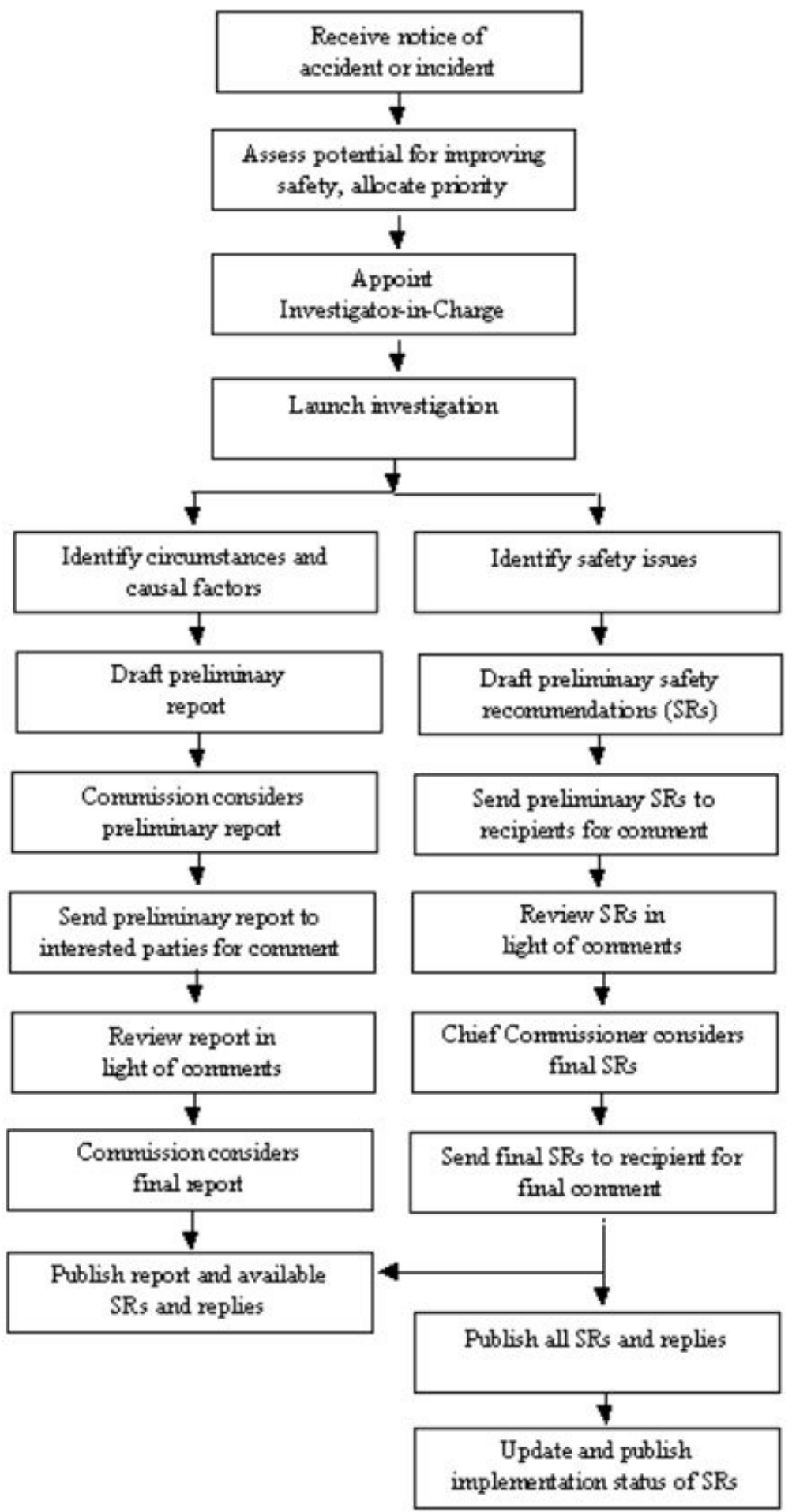

Figure 1.1: Accident Investigation Flow Chart [2] 
electronic device to make pilot calculations easier and faster. An FMS is a program which automates various in-flight tasks that the pilots would otherwise have to do themselves. An FMS with airspeed could reduce other costs for General Aviation because it would lead to a better understanding of the aircraft's attitude and performance, which could in turn help reduce fuel costs with better flight planning.

The Background section outlines the need for FDRs in GA and the literature review describes previous attempts at a GA FDR. The previous attempts shown in the Literature Review section mostly have difficulty with airspeed determination. The Hardware section gives details on the sensors and microcontrollers used for the purposes of measuring the parameters used in the airspeed algorithm. The Software section outlines the software that is typically used with the hardware and explains why it is not the easiest software to use for to determine airspeed. The derivation of the equation and the parameters necessary to the equations are explained in the Parameters and Algorithm section. The Testing and Results section outlines the details of the testing aircraft used and the details of the ground and flight tests. The results and their errors are also shown in the Testing and Results section. Finally, the Conclusion section finishes the paper with a summary of what was achieved, what could be done to further the algorithm and other applications of the airspeed data.

\subsection{Background}

Flight Data Recorders (FDRs) have made it much easier for aircraft accident investigators to understand why accidents have occurred and to validate proposed theories that explain an accident by including information that they would have otherwise been unable to gather. Newer and larger aircraft are equipped with built-in flight data recorders through the glass cockpit or have dedicated FDR systems that are complex and expensive. These FDRs cannot be applied to older or smaller aircraft which still use analog technology. Most of these technologies rely on digital information to be provided to the recorder through direct integration with digital instrumentation. The application of an FDR system to the older analog instrumentation would be a large expense due to the tedious nature of integration 
with the analog instruments. The integration with the instruments must be done by a specialized Aircraft Maintenance Engineer (AME) and must be approved by the regulating bodies such as Transport Canada (TC) or the Federal Aviation Administration (FAA). The installation by specialized AME and the certification by the regulating bodies are very expensive and time consuming.

The newer, high-end general aviation aircraft are equipped with a glass cockpit (a digital dashboard with most relevant flight instrumentation), some models of which can automatically record flight data. Figure 1.2 shows both the glass cockpit configuration and the analog instrument configuration [3]. When an accident occurs with such an aircraft, the investigators are capable of recovering some of the data from the glass cockpit system and the accident investigation benefits from having the recorded data available [4].

O'Callaghan, a national resource specialist of aircraft performance at the National Transportation Safety Board (NTSB) in Washington, explains that one of the major resources which accident investigators have at their disposal is the recorded flight data from any device on the aircraft, thus indicating that a data recorder is invaluable to the investigators [4]. If the orientation, movement and performance of an aircraft are measured and recorded, combined with the weight and balance of the aircraft and the meteorological data during the flight, a clear indication of the events that transpired may be reconstructed. With the information provided by the recorded data, in the case investigated by O'Callaghan, it was possible to determine that the aircraft had stalled, was falling in a stalled configuration until it started a left-handed spin and that the aircraft's parachute system deployed 4 seconds before impact. A stall is when the smooth airflow over the wing becomes too turbulent due to an excessively high angle of attack or excessively low airspeed. Since an aircraft's wing requires smooth airflow over the wing in order to maintain lift, when the airflow over the wing becomes too turbulent the wing no longer produces enough lift to counteract the weight of the aircraft. A spin is a type of stall in which one wing is more stalled than the other which gives it more drag and makes it move slower through the air. This slower movement and less lift on one wing causes the aircraft to descend in a corkscrew pattern. It would be very difficult to determine the events leading up to impact with amount of 


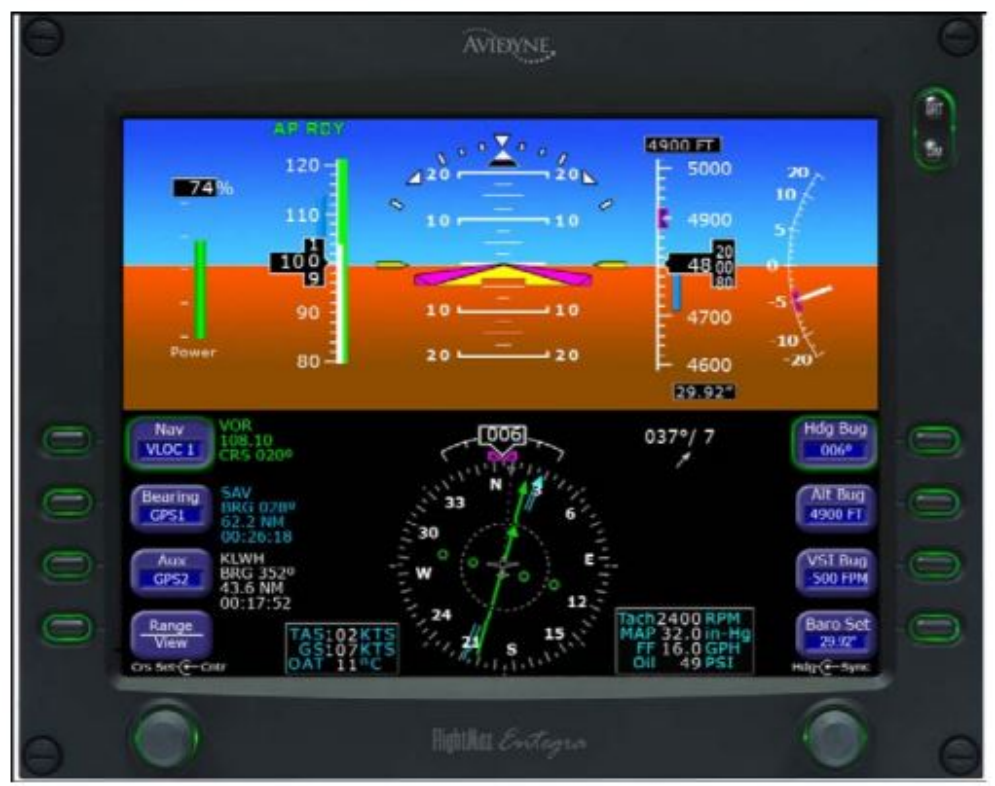

(a) Glass Cockpit Instruments [3]

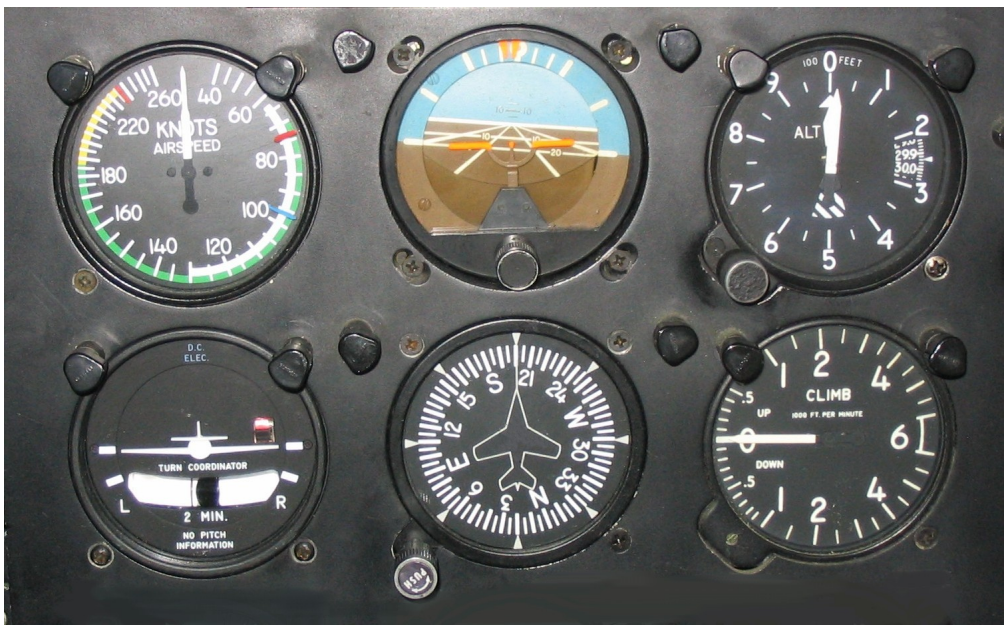

(b) Analog Instruments

Figure 1.2: Glass Cockpit Vs Analog Instruments 
detail listed above without the help of the recorded flight data. Many older aircraft do not have these digital avionics and are therefore unable to benefit from their data-recording capabilities since there are no external recording systems for GA.

Several approaches have been taken for modelling an aircraft using flight data. An early approach developed equations for investigating aircraft accidents that had a limited data set [5]. The Air Traffic Control's (ATC) radar tracking system or an on-board data recorder, combined with meteorological data and known aircraft parameters could provide the necessary information for aircraft accident investigations. The ATC and on-board recorder were only able to record ground speed. Ground speed alone cannot determine aircraft performance because it does not take the meteorological conditions into consideration. The airspeed can be determined using the ground speed only if the wind speed, wind direction, barometric pressure and temperature are known. The issue with such an approach is that the meteorological data, particularly the winds aloft, can be very inaccurate or non-existent in many areas. The equations in this early approach calculate the aircraft motions and forces acting on the vehicle; however, these equations assume that side force and side-slip are negligible. A side-slip is when the aircraft's nose is pointing in the opposite direction of the aircraft's bank angle. This particular attitude is known to increase drag and reduce lift which makes it an inefficient way to fly. Side-slips can happen inadvertently if the pilot is not coordinating aileron and rudder movement or they can be induced the goal is to lose altitude and slow down. Pilots tend to use side-slips when on approach to land if their approach is too high. Side force and side-slip angle are usually negligible in normal operations; however, accidents may be caused by excessive side-slip or side force. This could be due to gusts or poor recovery from a side-slip. In addition, in the Canadian context, the air traffic control data and accurate meteorological data may not be available for small aircraft operating in remote areas. Thus a greater reliance is placed on the flight data recorder to determine the events which transpired leading to an aircraft accident.

Between 2004 and 2014, Canadian air taxi accidents have resulted in 175 deaths [6]. In November of 2014, the Transportation Safety Board (TSB) of Canada launched a probe to 
investigate air taxi accidents. An air taxi, in Canada, is any aircraft which is used to transport passengers or cargo that is single-engine aircraft, multi-engine aircraft which weighs less than 19000 lbs or a multi-engine aircraft with fewer than 10 passenger seats. This type of flight operation is more common in remote areas of the Canada but has become quite popular in the United States. The Canadian TSB recommended that flight data recorders be mandatory on small aircraft because $94 \%$ of commercial air accidents in Canada involve light aircraft [6]. A light aircraft, as defined by Transport Canada is an aircraft weighing maximum gross takeoff weight of 12500 lbs or less. The maximum gross takeoff weight of an aircraft is the maximum weight at which the aircraft is legally allowed to takeoff. There are currently no FDRs available to light aircraft equipped with analog instrumentation. The Canadian TSB recommends that Transport Canada works with industry to make recommended best practices regarding FDRs and Flight Data Management (FDM) systems in light aircraft [7]. These types of best practises are typically adopted into the Canadian Aviation Regulations (CARs) as laws.

In 2014, the European Aviation Safety Authority (EASA) also showed interest in light and inexpensive flight data recorders. EASA created a team to make regulations pertaining to FDRs of light aircraft [8]. Having both the EASA and the TSB announcements in 2014 indicate the possibility of such technologies becoming mandated. An update was released in October of 2016 stating that an action plan by the EASA team is expected to be presented in early 2017 [8]. This update indicates that there is a very high probability of FDRs becoming mandated in light aircraft across Europe. This means that a low-cost FDR will be heavily sought after, especially one that can be installed by the pilots as opposed to the engineers. Another deduction which can be made from this announcement is that North America will not be far behind if the European light aircraft FDR implementation is successful.

In 2011, Bill Cox wrote an article for Plane \& Pilot Magazine which discussed the need for FDRs. He claims that the issues with FDRs are their complexity and cost. Another issue surrounding the adoption of FDRs in general aviation is the fact that they are mostly used after a pilot's death. Many pilots consider an FDR useless because it cannot save their own lives, but instead, only serve to increase safety after they die in an accident. [9]. 
The pilot is then uninterested in spending money on a device which would not accomplish anything for himself. Cox claims that a solution to this lack of enthusiasm would be to make it double as some other device such as a GPS or action camera, which would make people want to have it onboard and recording valuable data. The issue with these types of devices is their destructibility; GPS units and actions cameras are not typically crash-survivable. It would be possible, however, if the data was recorded with a multipurpose device such as an iPad which are frequently used in aviation and have the data transmitted to a robust hard drive either on the ground or in a crash-proof box located somewhere in the aircraft which is less likely to be destroyed in an accident such as the tail section. 


\section{Chapter 2}

\section{Literature Review}

The literature review outlines other attempts at GA FDRs. Several issues are shown pertaining these FDRs such as cost, system integration, uncertainties, weather dependencies and weight. There are several different approached to an FDR system shown in this thesis. A small integrated system was created in 2005 which boasted a low cost but required system integration. A weather-data dependant attempt at an FDR from 2007 is discussed. A fairly complex system without the airspeed parameter was also created in 2007 . There was a large invasive system used to determine many aircraft parameters in oder to be used for flight simulator validation, This system was very invasive, complex and expensive. Finally, a system was developed which recorded most parameters without being invasive but tapped into the pitot-static system in order to measure airspeed.

In 2005, Barclay created a prototype FDR and Cockpit Voice Recorder (CVR) for the purpose of improving flight training, aircraft maintenance, and recording aircraft condition. He states that while there are active efforts to increase the safety of general aviation, that there is little emphasis on FDRs and that current FDRs are too large or expensive to be used in most general aviation aircraft. One of the statistics from 2004 that he lists is that more than 50 percent of active helicopters are small and in the General Aviation (GA) sector. These small GA helicopters account for roughly 50 percent of accidents. This means that there is no flight data for half of the helicopter accidents [10]. This statistic is his primary reason for doing research on FDRs and CVRs. Barclay also lists what he

considers to be basic requirements for CVRs and FDRs in order to reduce the mystery 
surrounding some of these accidents. His requirements for CVRs are that they require 2 hours recording time and 10 minutes of recording time after loss of power. FDRs for his purpose are required to record time, airspeed, altitude, heading, accelerations, altitude, outside air temperature engine speed, rotor speed and cockpit controls. Barclay created two FDRs which were nicknamed EMMA and JEMMA. EMMA is the typical full FDR and CVR which is approximately the size of a shoe box, costs $\$ 1000$ to make and weighs 750 g. JEMMA is used to record rotor RPM, engine RPM and cylinder head temperature; it's about the size of a cigarette pack and weighs $200 \mathrm{~g}$. JEMMA is expected to cost less than $\$$ 500 to manufacture and it can hold up to 50 hours of flight data. The JEMMA device that Barclay prototyped is shown in Figure 2.1. Finally, Barclay raised the concern that without another use or incentive, FDRs will not be used by most GA operators [10]. Alternate uses for his FDR are flight data for maintenance records, and flight-recreation for training purposes. What Barclay does not mention is the cost of installation of such a device. The installation would be a considerable cost due to the fact that the device must tap into the aircraft systems to acquire the engine parameters which means that the installation would have to be performed by a licenced AME. The act of permanently adding a piece of hardware to an aircraft also comes with the added requirement and cost of updating the aircraft's weight and balance. Barclay's unit would require regulatory approval, which would increase the cost of the unit due to the monetary and time costs of dealing with the regulatory body in question.

Slane et al presented a non-invasive flight data recorder [11] in 2007. Their equipment consisted of a GPS and a 3-axis accelerometer. The parameters recorded were position, groundspeed and accelerations in 3 directions and they would calculate the remaining parameters post-flight. The groundspeed, track and vertical velocity were calculated using the GPS position data. Heading and airspeed depended on atmospheric conditions aloft for the calculations. The airspeed was calculated using the groundspeed and atmospheric conditions aloft and the compass was calculated using the conditions aloft and the track data. The roll and flight path angles were then determined from the heading, the vertical velocity and the airspeed. [11] The issue with this approach is that atmospheric conditions 


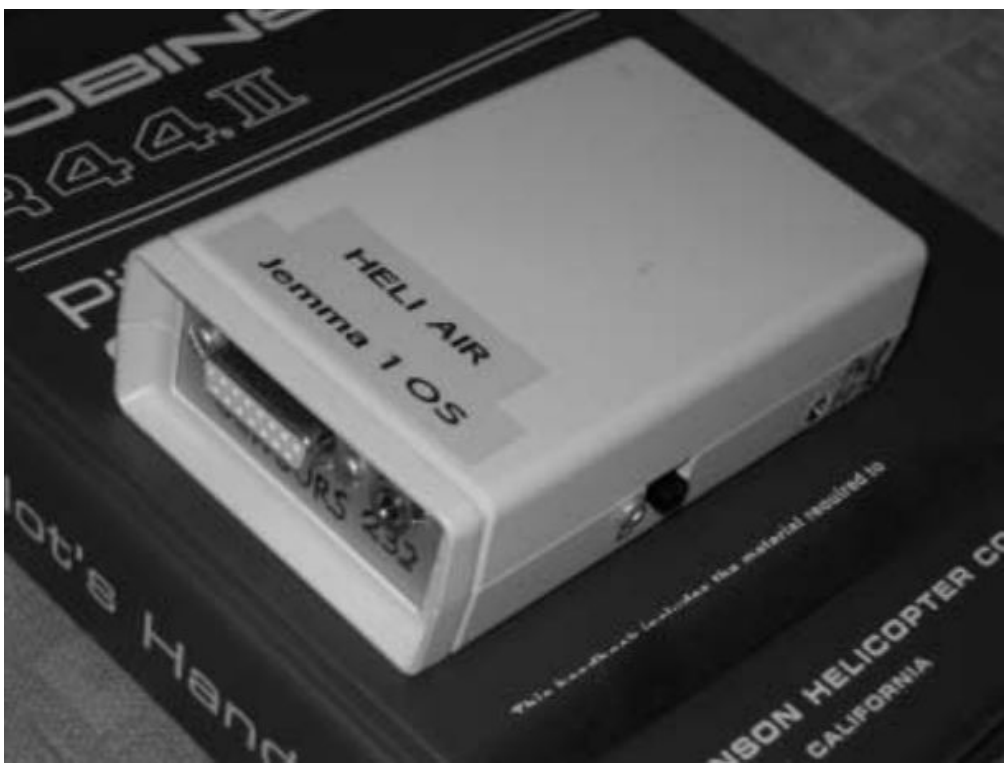

Figure 2.1: Barclay's RPM and Engine Temperature Unit, JEMMA [10]

aloft such as wind speed, wind direction, temperature, and barometric pressure, are not available everywhere and they are forecasted over long periods of time over large volumes of air. Such uncertainty would be compounded when calculating other parameters with the airspeed and heading values. While Slane et al achieved excellent results, this method is not sufficiently accurate when using forecasted conditions aloft. The atmospheric conditions aloft are typically forecasted only above weather stations, which covers a very small area. The conditions aloft are also forcasted over long periods of time with large inaccuracies, especially for wind speed and direction.

An example of the forecasted atmospheric conditions aloft provided by Nav Canada is shown in Figure 2.2. In Figure 2.2, the winds for the Ottawa airport are shown. For example, between 05:00 and 09:00 UTC (Coordinated Universal Time) at three thousand feet above sea level, the wind is expected to be 10 knots coming from $140^{\circ}$. It is shown that the forecasts are only displayed at three thousand foot intervals above the weather station and the wind speed and direction is an average for a four to nine hour period.

Slane et al used a video recording of the cockpit instruments to validate their results from their FDR. It was assumed that the aircraft was constantly in coordinated flight. 


\begin{tabular}{|l|c|c|c|c|c|c|}
\hline STN YOW - OTTAWA. ONT & for use & 3000 & 6000 & 9000 & 12000 & 18000 \\
\hline $\begin{array}{l}\text { FDCN01 CWAO FCST BASED ON 240000 DATA VALID } \\
240600\end{array}$ & $05-09$ & 1410 & $1810+00$ & $2111-03$ & $1415-08$ & $2017-17$ \\
\hline $\begin{array}{l}\text { FDCN02 CWAO FCST BASED ON 240000 DATA VALID } \\
241200\end{array}$ & $\mathbf{0 9 - 1 8}$ & 1710 & $2114-03$ & $2318-06$ & $2123-11$ & $2122-18$ \\
\hline $\begin{array}{l}\text { FDCN03 CWAO FCST BASED ON 240000 DATA VALID } \\
250000\end{array}$ & $\mathbf{1 8 - 0 5}$ & 1814 & $2110-04$ & $2109-07$ & $2620-10$ & $2723-20$ \\
\hline
\end{tabular}

Figure 2.2: Nav Canada's Forecast for Atmospheric Conditions Aloft [12]

Coordinated flight is flight with zero side-slip (it requires coordination between aileron and rudder controls). This assumption is not always the best, especially in an event leading up to an accident situation. Many accidents are caused by the lack of coordination between aileron and rudder controls.

Mitchel et al. conceptually designed a quick access recorder (QAR) as a stand-alone unit for flight operations quality assurance (FOQA) in 2007 [13]. A QAR records data similarly to an FDR but the memory is easily removed to be used for other applications such as maintenance or flight training. FOQA analysis software is available, but it is prohibitively expensive and ergo used by airlines, making it inaccessible to those who pilot smaller aircraft. GA could easily benefit from a FOQA program for flight training and maintenance, were it affordable. The primary factors to the large cost is certification and installation of the system which must be accomplished by a licenced AME and approved by the appropriate regulatory body. Another great barrier to GA is the fact that most FDRs and QARs rely on connecting to a standard data-bus which is found on large transport aircraft. This data-bus is not present on smaller aircraft which makes the QAR system useless to GA aircraft even if the operators were to purchase one [13]. The parameters that Mitchell's conceptual QAR covered were pitch, roll, yaw, accelerations, ground speed, distance, position, cabin temperature and pressure. Engine RPM is proposed to be recorded using a microphone. The roll, yaw and pitch could not be measured directly so they were estimated using accelerometers. The roll, yaw, and pitch, as well as the aircraft axes are depicted in Figure 2.3 [14]. Roll is the rotation around the longitudinal (X) axis, yaw is the rotation around the vertical $(\mathrm{Z})$ axis and pitch is the rotation around the lateral $(\mathrm{Y})$ axis.

Mitchell et al's system is self-contained and secured in the cabin of the aircraft. The 


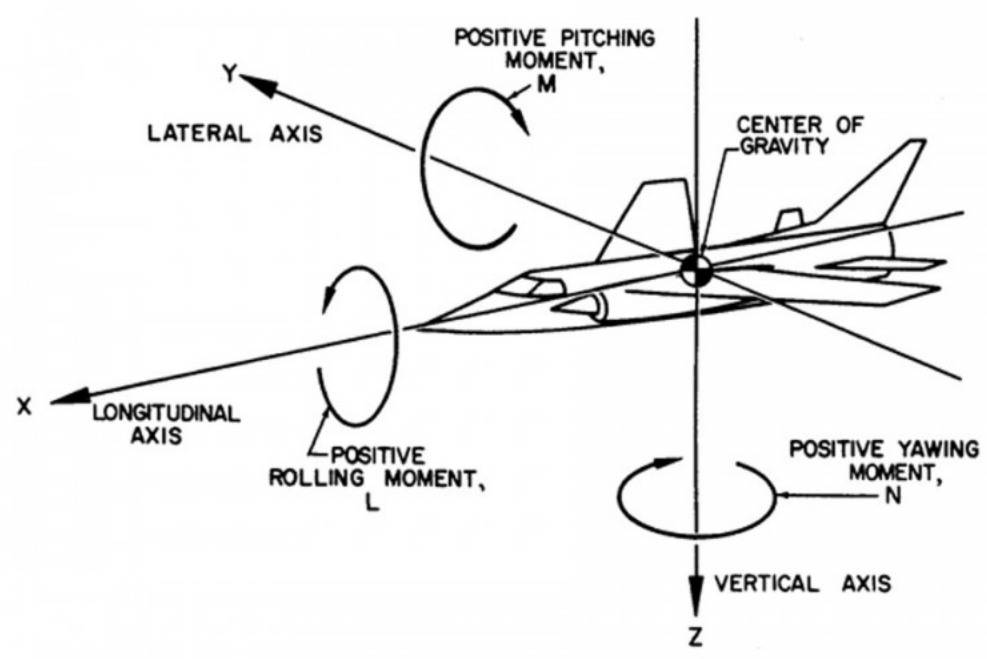

Figure 2.3: Roll, Pitch, Yaw and the Aircraft Axes [14]

cost of their system is dependent on the number of parameters covered and is anticipated to be cheaper than the commercial system. Recording the same parameters as airliners would require a redesign of a GA aircraft simply due to the lack of instrumentation and systems found in small aircraft when compared to airliners. Mitchell et al claim that the potential benefits of a QAR system for general aviation would be to recreate training flights for playback, determine maintenance issues, and give extra information to accident investigators if the QAR is robust enough [13]. GA accident reconstructions can be very tedious without some sort of data recorder to ease the information gathering process. The memory unit is easily removable from the remainder of the QAR to simplify use by maintenance and flight training personnel. Their testing was in a controlled lab setting and in a ground vehicle setting. No flight testing of this QAR was performed. Some of their analog data could not be transferred to digital form easily; analog conditioning was required. The biggest issue with Mitchell et al's system is that airspeed is not mentioned at all [13]; they say that parameters other than the ones listed require for their FDR unit to be directly connected into the aircraft's instrument panel. Aircraft performance and aircraft stress information is directly related to airspeed as opposed to ground speed. The proposed airspeed equation in this thesis would be applicable to Mitchell et al's QAR. This would greatly increase the functionality of the QAR. 
In 2009, Neuhart et al validated a general aviation simulation by recording in-flight data of a real aircraft using a flight data recorder that they had designed [15]. The test was done on a Cessna 172 and the aircraft required experimental certification to fly legally once all the modifications were done to the aircraft. It is fairly straightforward to acquire experimental certification, however the experimental status limits the number of passengers to two and restricts the aircraft from being used for commercial purposes. The experimental certification is not a sustainable solution to the expensive normal certification. The main power source of Neuhart et al's FDR was a deep-cycle marine battery and the main source of data was the Crossbow NAV440 with an approximate cost of $\$ 6000$. The NAV440 is essentially a very expensive attitude indicator and accelerometer; it provides acceleration data and the attitude information of the aircraft [15]. The wingtip was removed and replaced with a cluster of instruments. These instruments measured airspeed, side-slip, outside air temperature (OAT) and it had an inertial measurement unit (IMU) to measure accelerations. The co-pilot's seat was also removed to fit a system which would measure pilot control inputs such as yoke inputs, rudder inputs, throttle position and flap indicator position. A Hall effect sensor was placed under the cowling to measure propeller RPM. String potentiometers were also attached to the control cables of the airplane in order to measure control surface deflections. These potentiometers are capable of detecting linear position changes and from that information, the position of the control surfaces were inferred. The drastic modifications to the aircraft are shown in Figure 2.4 [15]. Clearly, this method of recording flight data was not meant to be sustainable but this demonstrates all the sensors which would be required to retrofit a light GA aircraft to accommodate a full traditional FDR.

Neuhart et al had an extensive flight test plan as shown in Figure 2.5 and they collected accurate and extensive data [15]. However, their approach was very invasive with heavy and expensive equipment. This amount of data, complication and weight is not required to simply determine the cause of an accident or incident. A non-invasive FDR will not have nearly the same level of detail but will still be incredibly helpful to accident investigators.

The research supervisor's group has previously developed a flight data recorder to estimate aerodynamic loads as part of a larger project to estimate the longevity of composite 


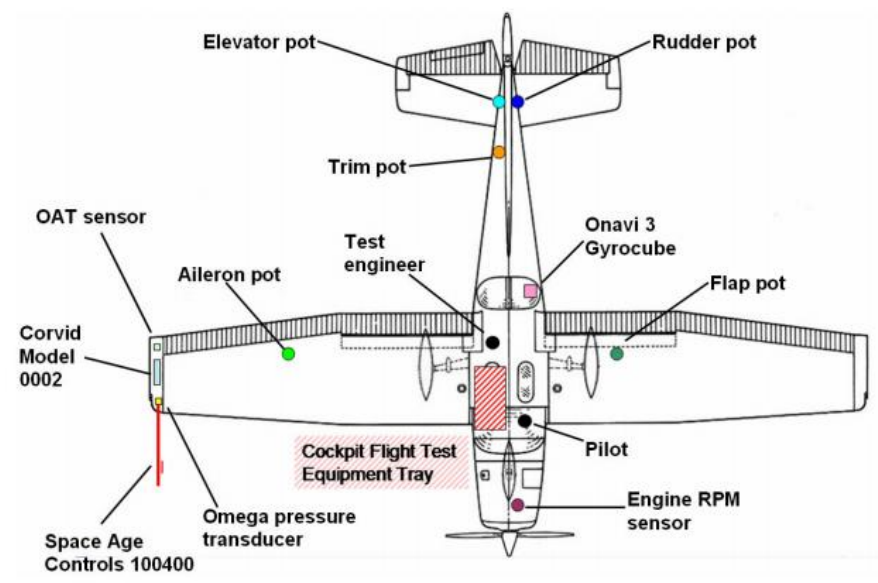

Figure 2.4: Current flight data recorders for light aircraft require extensive modifications to the aircraft $[15]$

\begin{tabular}{ll}
\hline Test & Purpose \\
\hline Takeoff & Ground aceeleration, initial climb performance \\
Rejected Takeoff & Braking performance \\
Glide & Parasite drag \\
Normal Climb Performance & Climb performance \\
Engine Acceleration & Parameter ID and engine thrust characteristics \\
Engine Deceleration & Parameter ID and engine thrust characteristics \\
Throttle Lever Position vs. RPM & Engine performance \\
Power Change Force & Forces and moments created by a change in thrust \\
Power Change Dynamics & Dynamic changes in flight path created by change in thrust \\
Flap Change Force & Forces and moments created by a change in flap deflection \\
Flap Change Dynamics & Dynamic changes in flight path created by change in flap deflection \\
Longitudinal Trim & Steady-state flight conditions \\
Longitudinal Maneuvering Stability & Stick force/g \\
Longitudinal Static Stability & Level of positive static stability \\
Stall (Wings Level) & Stall speed and characteristics \\
Stall (60 deg Bank) & Stall speed and characteristics at 2g \\
Phugoid Dynamics & Dynamic longitudinal stability \\
Short Period Dynamics & Dynamic longitudinal and lateral-directional stability and parameter ID \\
Roll Response (Rate) & Roll rate of aircraft \\
Roll Response to Step Input & Roll overshoot tendencies \\
Spiral Stability & Lateral roll stability \\
Rudder Response & Roll induced by rudder \\
Dutch Roll & Lateral directional coupling \\
Steady State Sideslip & Static directional stability \\
Windup Turns & Longitudinal maneuvering stability \\
Wings-Level Pull-Up & Longitudinal maneuvering stability \\
Spins & Dynamic behavior of aircraft during spin \\
\hline
\end{tabular}

Figure 2.5: Neuhart et al's Flight Test Plan [15] 
aircraft [16]. The equipment used was an Arduino circuit board equipped with a 3 axis gyroscope, a 3 axis accelerometer, a GPS, a barometer and a compass. This Arduino unit is known as the APM (ArduPilot Mega) 2.5, which is also used in this research. The internal gyroscope allowed for angular measurements, the accelerometer could measure the accelerations, the barometer could measure barometric pressure as well as temperature, and the GPS could measure position data and velocity data. The APM was connected to a laptop to gather both internal logs by the APM and external logs on the laptop. A camera was also mounted behind the pilot's seat for redundancy. For the longevity study, the airspeed was acquired using a pressure sensor that tapped into the pitot-static system of a Diamond Katana DA-20 aircraft owned and operated by a local flight training school. The modification to the pitot-static system required a special flight permit from Transport Canada and temporarily removed the aircraft from the school's flight line. The special flight permit required a detailed flight plan, descriptions of the precautions to ensure safety and various other information. Acquiring these special flight permits is not an easy task; without the help of a TC design approval specialist who volunteered to help, the permit would have likely not been obtained [16]. The primary reason to require this special flight permit is due to the method of collecting airspeed data: the recorder was integrated into the pitot-static system in order to record airspeed. The modification was made by a licensed AME but it was not certified by regular use by Transport Canada, thus it resulted in a special flight permit as opposed to a certified piece of equipment. The Arduino was able to retrieve the most data with the least amount of equipment and space requirements compared to previous systems $[11,15]$. Figure 2.6 shows the configuration of the hardware used by the research group; it demonstrates that it requires little space even with the camera, the laptop as additional components [16]. However, due to the modifications to the pitot-static system, the aircraft required an experimental status which restricts the practical use of the FDR unit to experimental aircraft only. Such a restriction makes the unit inapplicable to most aircraft.

The primary difference between an FDR with a computationally derived airspeed and FDRs that came before is the algorithm which calculates airspeed without having to rely 


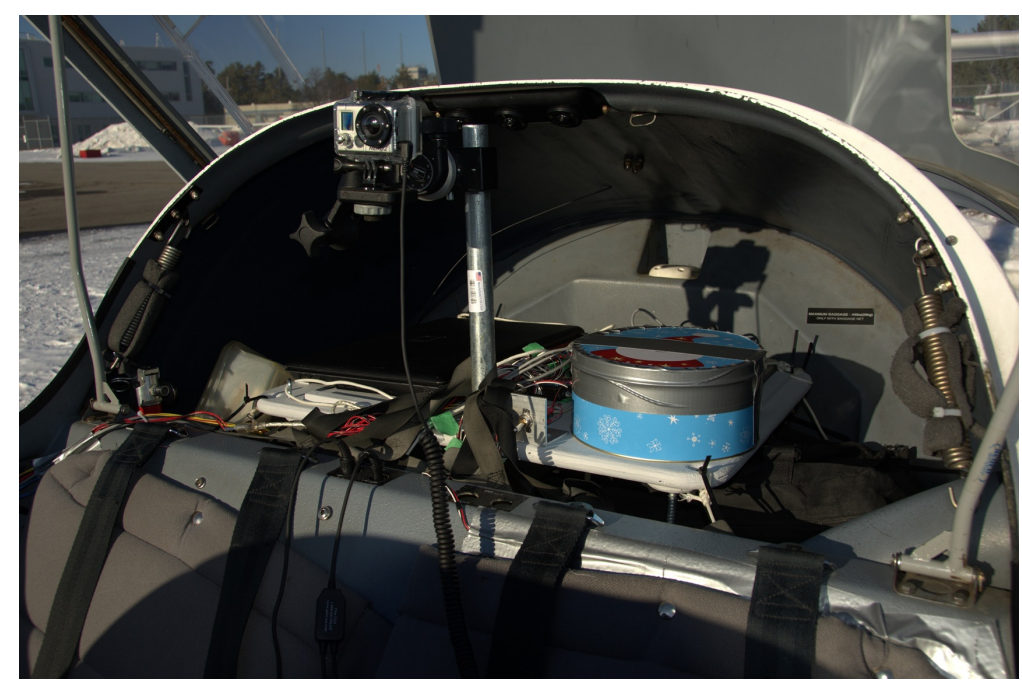

Figure 2.6: Configuration of the Previous FDR by the Research Supervisor's and Dr Langlois' Groups [16]

on outside sources while still being non-invasive. These outside sources could be air traffic control's radar systems or atmospheric conditions aloft. The outside sources are not always available and can be inaccurate to an unacceptable level while the invasive alternatives are costly and time consuming to implement. The airspeed algorithm in this thesis allows for the airspeed to be determined without an invasive modification to the aircraft or relying on outside sources for information. The lack of invasive modification is to avoid the hassle of regulatory body certification and AME costs. The ability to determine airspeed this way will save time and money while still gathering the important data required to help accident investigators or improve the quality of an FMS or EFB.

\subsection{Other Applications of the Non-Invasive Unit with the Airspeed Algorithm}

There are various applications of the airspeed data if it could be obtained in a non-invasive method. The first and most apparent method would be to use the airspeed data in an EFB. This would allow for automated performance calculations using the airspeed parameter. Another potential use of the airspeed data is flight data streaming as opposed to flight 
data recording. With the airspeed parameter, flight data streaming could also be used to enhance flight services. A non-invasive FDR equipped with the airspeed algorithm could also serve to greatly reduce the cost of research and budget flight testing. The following subsections explain various applications of the airspeed algorithm and how it would affect general aviation.

\subsubsection{Electronic Flight Bags}

Other applications could include the implementation of the airspeed data into an electronic flight bag. An EFB is usually a application software on a portable electronic device. EFBs serve to reduce the amount of paper necessary for a flight and automate some of the paperwork associated with aviation. EFBs can hold navigational charts, do performance calculations, do weight and balance calculations, hold POHs, etc. Figure 2.7 shows an EFB with its different applications [17]. These types of electronics were formerly very expensive but they have now reached the affordable stage for most GA uses.

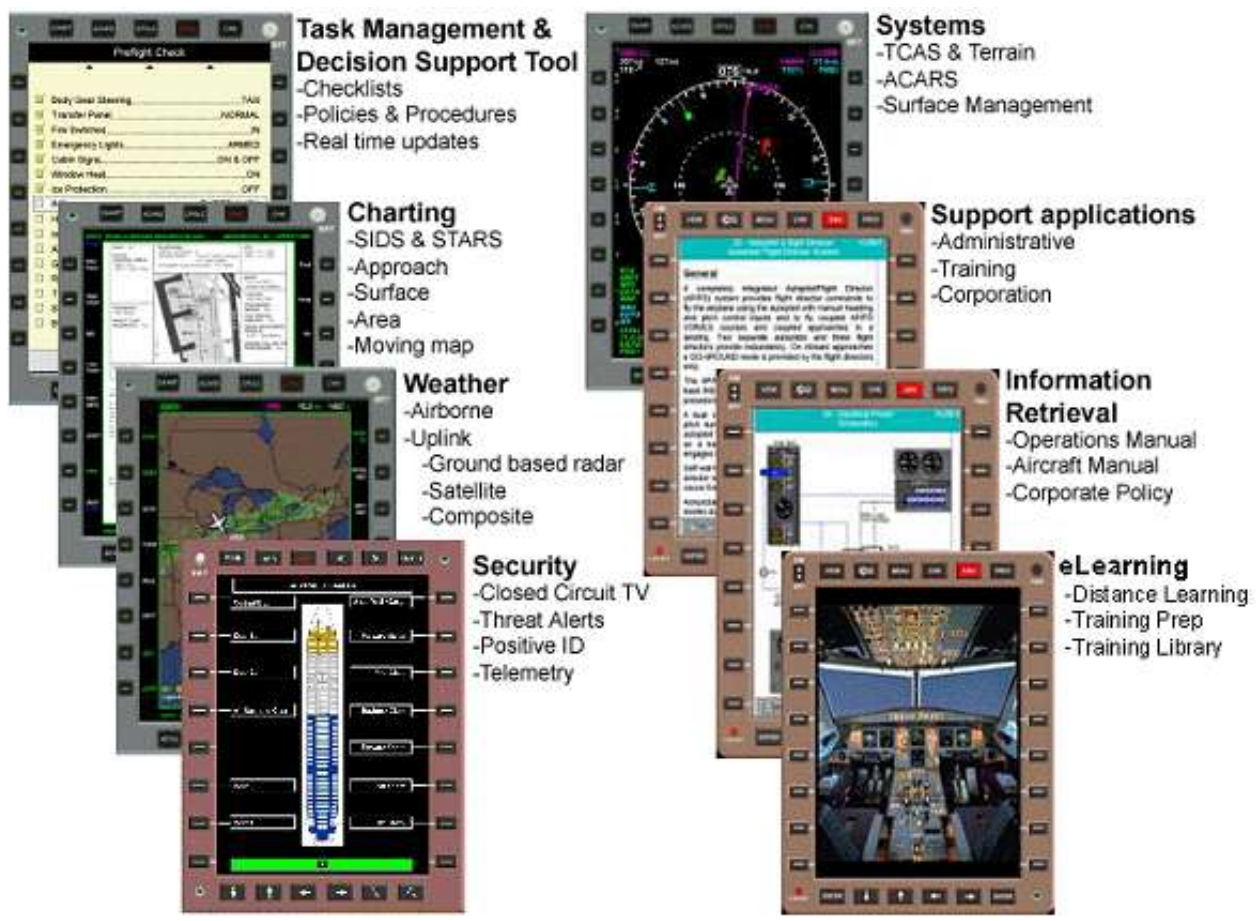

Figure 2.7: Different Applications of an Electronic Flight Bag [17] 
Some EFBs approximate the airspeed to be the same as the groundspeed and other require the pilot to input the airspeed. The airspeed data is used for performance calculations, usually pertaining to fuel burn and flight range. The maximum flying range of an aircraft is usually expressed as a function of airspeed, making the airspeed parameter very valuable in fuel burn calculations. With the ability of having the airspeed as digital information on a preexisting fuel-burn application, it could help significantly reduce the emissions produced by the aircraft, and the cost of flying. With the airspeed algorithm and the appropriate sensors to use it, EFBs could have an automatic input of airspeed data. This would reduce the error caused by assuming that airspeed is equal to groundspeed or increase the automation of the EFB by no longer requiring the pilot to input the airspeed. The increase in automation has been a topic in aviation safety, the less the pilots have to do inside the cockpit, the more they can concentrate on flying the aircraft.

Most aircraft are equipped with a stall speed warning, however, the warning horn may not be heard or could otherwise be faulty. For someone who is already using an electronic flight bag, a low airspeed warning could be programmed in if the application had access to airspeed data. Many people become focused on the paperwork or the electronics in the cockpit. A pop-up warning on the EFB could help reduce the chances of a stall by making the pilot visually aware that the aircraft is in such a configuration while he is looking at the EFB. The electronic flight bag could also include a maximum speed warning programmed in a similar manner to the stall speed warning. Most GA aircraft do not have a maximum speed warning.

While low-speed warning already exist in GA aircraft, unusual attitude warnings do not. Many of the unusual attitudes of the aircraft are determined by airspeed. With the airspeed information, it would be easy to determine if an aircraft was in a spin as opposed to a spiral, etc. Even a simple turn affect the performance of the aircraft; for example, the stall speed increases if the aircraft is in a turn due to the increased lift requirement to maintain centripetal force. An application of this airspeed algorithm combined with other aircraft attitude information could help save lives by determining the unusual attitude that the aircraft is in. The attitude could be determined by the EFB and a pop-up message 
could appear with the method of recovery from that unusual attitude in that particular aircraft. If there was an unusual attitude warning and a message on how to get out of that unusual attitude, it could help prevent accidents by showing pilots their proper emergency checklist for the situation.

In 2001, a design for an intelligent FDR which could provide the pilot with an early warning to a potential hazardous attitude. That particular project focused mainly on large airline FDRs with over 300 recordable parameters. Parameters from hundreds of flight were data-mined in order to form the initial knowledge base. The idea was to create an artificial intelligence which would adapt to the situation and give a warning to the pilot before they entered a specific dangerous situation. [18] This system would also give the pilot details about that situation. This is far beyond the scope of general aviation but a similar early detection and warning system could be implemented using the FDR outlined in this thesis. Using the airspeed and attitude information of the aircraft gathered from the FDR and the airspeed algorithm, a more simple warning system could be implemented. This warning system would have far fewer details than the one for airliners but it may be possible to warn the pilot that they are flying at the wrong altitude or that the type of maneuvers being performed may lead to a loss of control situation such as a stall or spin. Of course, if there were to be a large amount of data mined and a complex algorithm created for a more thorough early warning system based on these parameters, the FDR may be able to be implemented as a part of the system.

Another EFB application that could use the airspeed data is the determination of winds. Electronic flight bags could now have a readout of the winds experienced by the aircraft using the groundspeed, the airspeed, and the yaw as a base of the calculation. The wind information is useful to know if the aircraft has to be in an IFR (Instrument Flight Rules) holding pattern or if the pilot requires to make a landing somewhere without wind information available. 


\subsubsection{Flight Data Streaming}

There has been talk recently about streaming recorded flight data instead of having it in a crash-survivable box. This would help avoid the loss of data if an aircraft were to crash. There have been several instances lately of aircraft going down in the ocean with the components being unretrievable. The movement for streaming the recorded flight data has primarily emerged from those situations. The idea is to help the air operator or the accident investigator determine the cause of the accident as to prevent a similar accident from happening in the future. The Ardu-Pilot used in this research to record flight data is capable of sending information to a tablet or cellular device. The tablet or cell phone could then be programmed to send periodic short-form messages to the ground via cellular network or satellite internet. This information could include the position of the aircraft, the airspeed, the attitude of the aircraft, and various other parameters which could be used to determined what happened if the aircraft were to disappear.

\subsubsection{Heads Up Display}

Private pilots are typically interested in acquiring new add-on technology for their aircraft. Many of these pilots have an older aircraft which primarily uses analog instrumentation. As discussed previously, these aircraft have difficulty outputting information to be used in most digital electronics. The proposed FDR unit with the airspeed algorithm could remedy this lack of digital information. In 1996, a Heads Up Display (HUD) was flight tested in a GA aircraft [19]. A HUD, in this case, is a semi-transparent projection on the windshield of a vehicle which shows relevant information to the operation of that vehicle. Figure 2.8 shows the typical information available on a HUD but in this case, VOR deviation would be substituted for GPS track deviation. A VOR (Very-high-frequency Omni-directional Radio) is a form of radio navigation which is used to guide aircraft from one location to another. Radio navigation is slowly being phased out in favour of satellite navigation such as GPS.

In aviation, the information shown on a HUD would be airspeed, attitude, altitude 


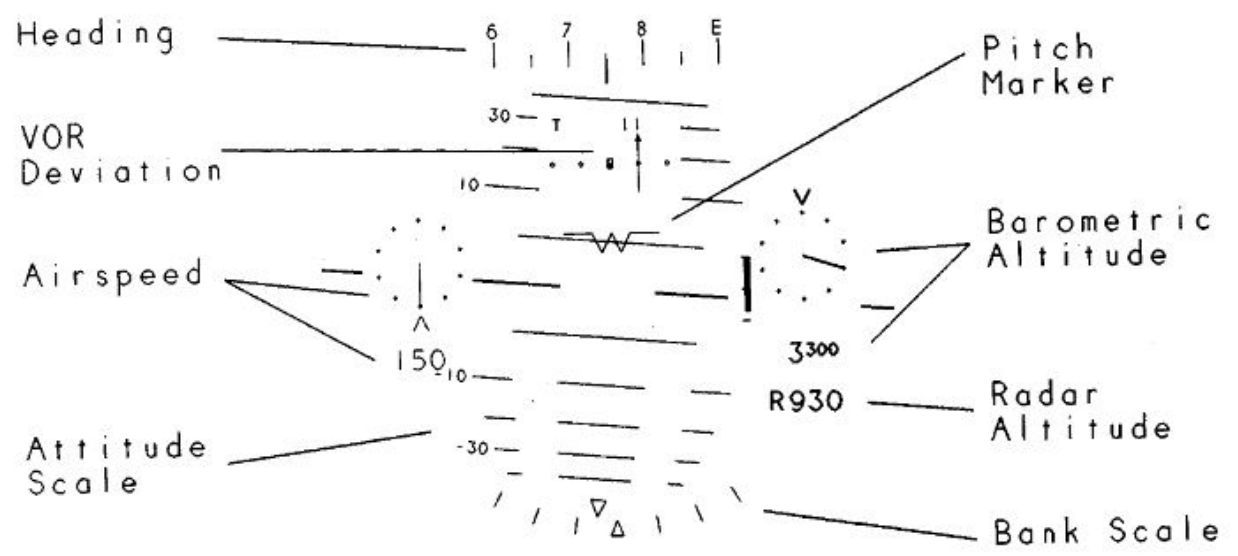

Figure 2.8: Typical Heads Up Display Information [19]

and heading. Position data, such as track and track deviation can usually be selected as a optional display on the HUD [19]. The technology has changed drastically and have become more affordable but the idea remains the same. A HUD could help make general aviation safer by including most of the required flight instrument data on the windshield. This would allow for a VFR (Visual Flight Rules) pilot, who is supposed to primarily be looking outside, to be looking out the windshield more often. Since these technologies would rely on digital information and the proposed FDR is capable of recording the required parameters and calculating the crucial airspeed parameter, a HUD projector could project the data from the FDR on to the windshield of an aircraft which would otherwise be unable to output the appropriate data. This information display on the windshield would cause the pilots to keep their eyes on the window and spend less time looking inside and therefore make it easier to maintain separation with other aircraft or obstacle

\subsubsection{Low-Cost Research and Flight Testing}

The proposed FDR with the airspeed algorithm could help automate testing on homebuilt aircraft. Homebuilt aircraft are becoming more popular due to their low cost and lower licensing requirements. These aircraft are made by amateur builders and are typically built with information from a kit or guide with many rough estimated on most parameters. Many of these aircraft end up doing flight tests in order to determine performance numbers such as 
cruise speed, stall speed, rate of climb, takeoff distance and landing distances. These test are most often done with either the pilot writing down information manually during the flight or taking a video of the flight instruments for post-flight analysis [20]. There are several issues with these recording approaches. If the pilot is writing information down when flying an unknown aircraft, it could lead to potentially dangerous situations due to the distraction of writing time-sensitive information. There could also be a large error associated with writing down the information due to the distraction of flying an unknown aircraft. The post-flight analysis of a video recording is a safer alternative but can be tedious and time consuming. If the proposed FDR with the airspeed algorithm was used in this particular situation, it would allow for the pilot to acquire a large amount of raw numbers as opposed to visual observations. This automatic collection of data would allow for the pilot to concentrate on precision flying and make the post-flight analysis easier than video processing. Another advantage to the FDR is that it is capable of measuring many parameters simultaneously. This particular FDR not requiring to be connected to the instrument panel also reduces the risk of instrumentation failure due to tampering.

\subsubsection{Flight Services}

In 2012 a case was made to implement 2-way satellite communication devices between GA aircraft and Flight Service Stations (FSS) [21]; a system such as this would benefit greatly from FDR data. Figure 2.9 shows the communication device used when they were developing the service for two-way communication between Aircraft and FSS. FSS are responsible for opening and closing flight plans and calling search and rescue units if the aircraft does not arrive some time after the flight plan's estimated time of arrival. They also offer other services such as weather briefings and flight plan assistance. The information delivery from FSS is based on pilot request and the FSS can have difficulty contacting the pilot if they need to. Figure 2.10 depicts the flight services and method of communication with FSS [21]. The idea behind this communication device is to allow FSS to contact the pilot about new adverse flying conditions in the area of the flight, such as SIGMETS or PIREPS while the aircraft is airborne. A SIGMET is significant meterological information that affects the 


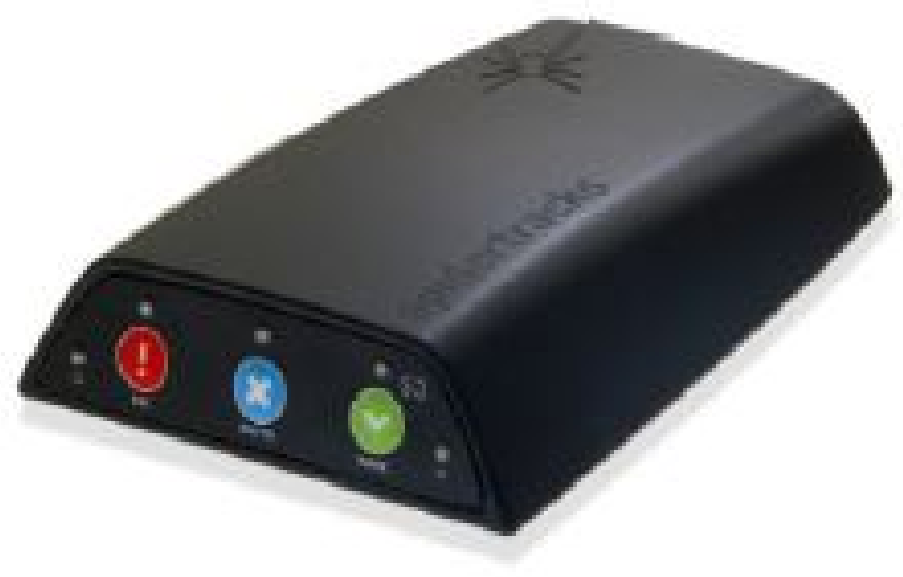

Figure 2.9: A Two-Way Satellite Communication Device [21]

safety of any aircraft in the area and a PIREP is a pilot's report of weather which outlines the difference between the actual weather encountered by the pilot and the forcasted weather.

Another use of the communication device is to have a quicker initiation of search and rescue when required. The device has a built in GPS which would allow the FSS to know if a fixed wing aircraft has remained stationary and is thus, on the ground somewhere it should not be. [21] It also has an emergency button which, when pushed, immediately sends a message to the pilot's spouse and alerts a search and rescue team. The way a device like this could benefit from FDR data is particularly to help determined that the aircraft has indeed had an emergency landing. If the FDR was paired with the communication unit, they could send data-bursts to the FSS unit. These data bursts could alert them to an excessive force acting on the aircraft, such as impact, or other anomalous parameters. Another use of this streamed data could be determining the state of the aircraft while the search and rescue team is en-route. Key parameters such as airspeed, angle of bank and accelerations could help determine if the aircraft was gliding to the ground, if it was in a spin or spiral, etc. This information could benefit the search and rescue team by giving them an idea of how urgent medical care for the pilot may be required. 


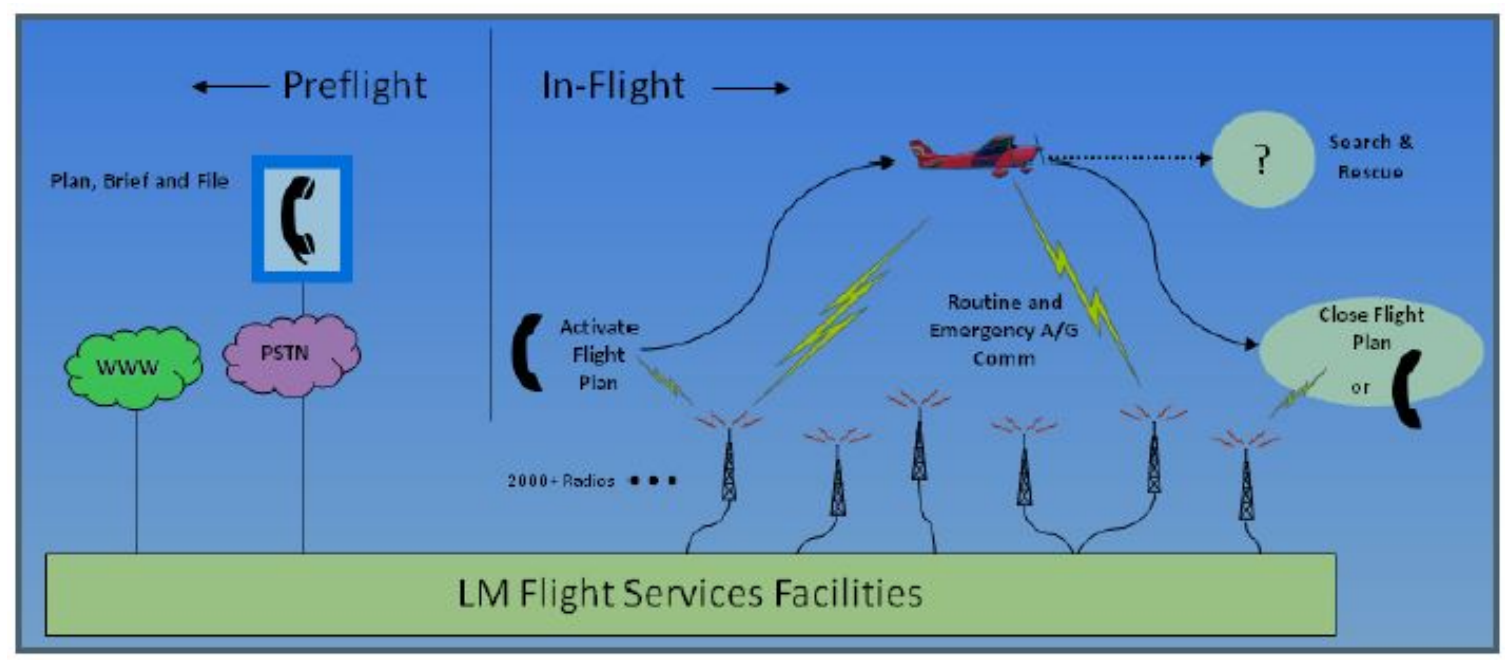

Figure 2.10: FSS Service [21] 


\section{Chapter 3}

\section{Hardware}

This research was conducted with the Ardu-Pilot Mega 2.5 (APM) autopilot for UAVs and the Pixhawk autopilot for UAVs as the primary pieces of hardware. Both of these ArduPilot systems are capable of recording flight data internally (dataflash logs) or streaming data a short distance to the ground station control (telemetry logs). The main difference between the APM and the Pixhawk is that the APM 2.5 uses the ATMEGA2560 and the ATMEGA32-U2 by Atmel as its microcontrollers and the Pixhawk uses the Cortex-M4 by ARM as its primary processor $[22,23]$; the Pixhawk essentially has better sensors, logs at a higher frequency and can hold more information but it comes at a higher cost. Both autopilots are equipped with a 3 -axis accelerometer and a 3 -axis gyroscope, a barometer, a compass, as well as myriad of other onboard sensors which are explained in detail below. Many external sensors can be attached to increase their capabilities such as an airspeed sensor, and GPS. There is also a protective case in which the recorder may be inserted to make is more likely to survive a hard impact.

The entire assembly is low cost. The APM costs approximately $\$ 150$ [24]. The APM's GPS antenna is approximately $\$ 50$ [24]. The Pixhawk and its GPS antenna are $\$ 200$ and $\$ 90$ respectively [25]. This would mean that the total cost for the APM FDR system would be approximately $\$ 200$ and the cost for the Pixhawk version would be approximately $\$ 300$ The protective Pelican case sells for $\$ 25$ [26]. The optional telemetry module for wireless communication costs approximately $\$ 35$ [27]. Figure 3.1 shows the internal block diagram

of the APM 2.5 and Figure 3.2 shows the APM 2.5 in its protective plastic shell [22]. The 


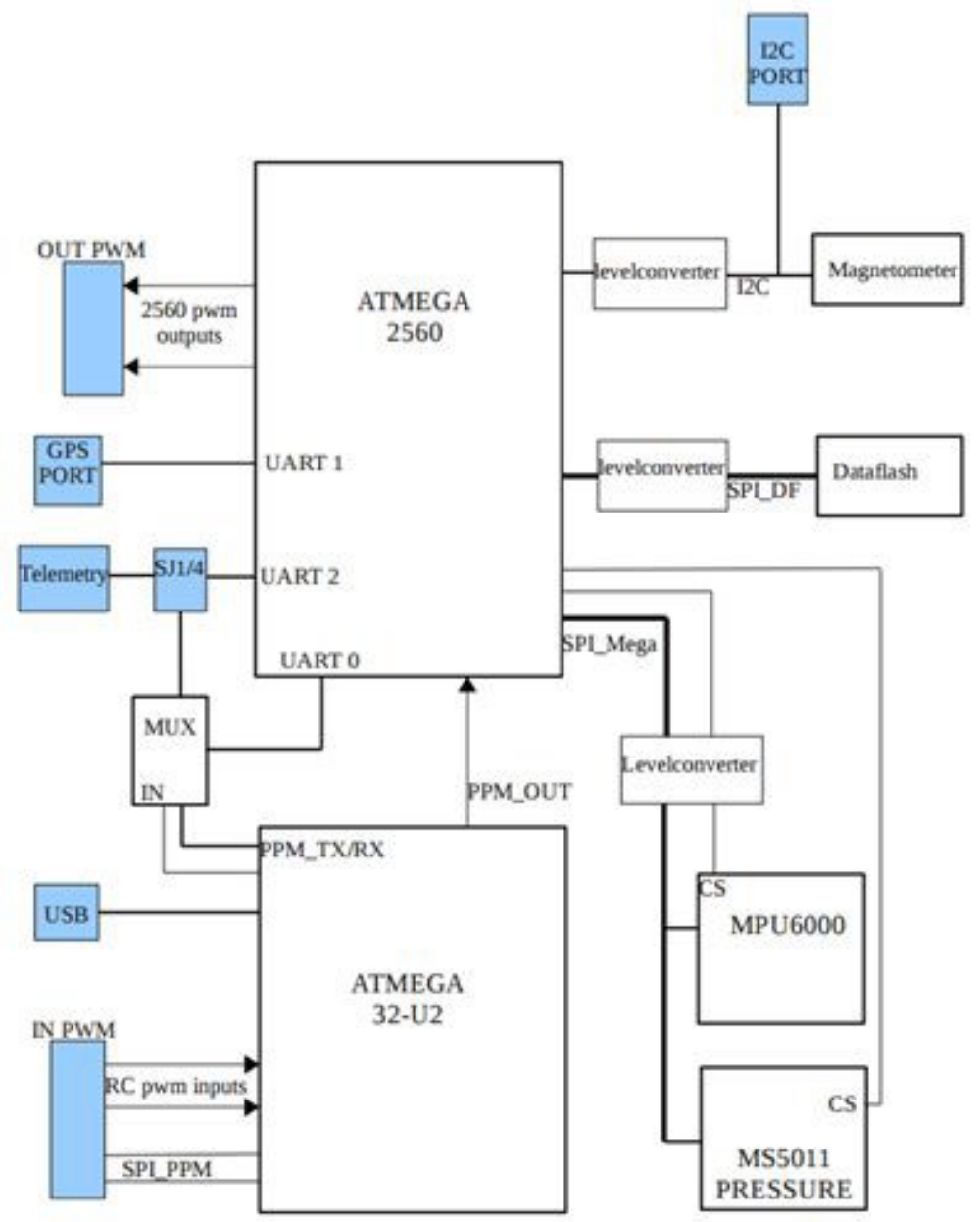

Figure 3.1: APM 2.5 Block Diagram [22]

following subsections describes the components of the micro-controllers, followed by the GPS units, the protective case and the telemetry module.

The following subsections elaborate on the sensors used, what they measure and other various information. Table 3.1 shows a quick overview of the sensors, their names, functions and if they're located in a larger unit. 


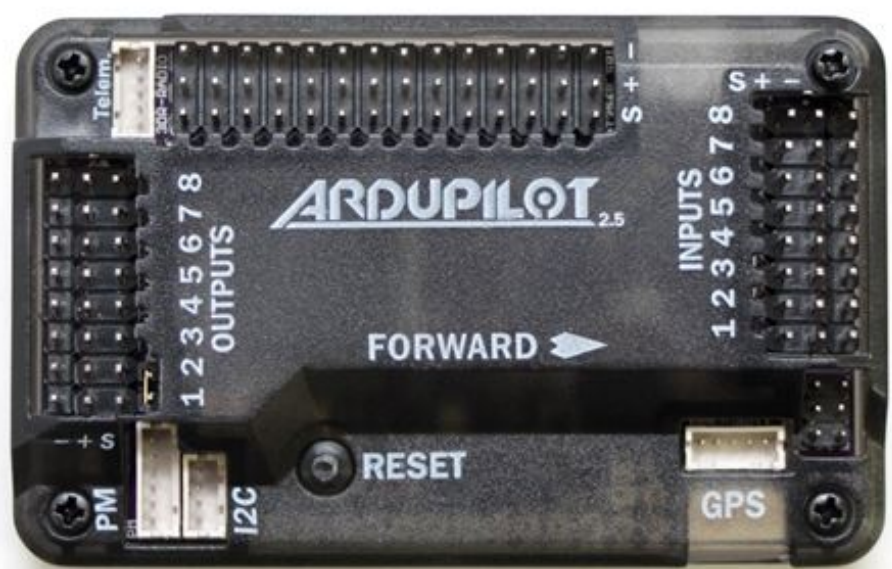

Figure 3.2: APM 2.5 in it's Protective Shell [22]

Table 3.1: List of Hardware and their Function

\begin{tabular}{ccc}
\hline Name & Function & Containing Unit \\
\hline \hline ATMEGA 2560 and 32-U & Microcontroller & APM \\
STM32F427 & Microprocessor & Pixhawk \\
MPU-6000 & Accelerometer and Gyroscope & APM and Pixhawk \\
L3GD20H & Gyroscope & Pixhawk \\
LSM303D & Accelerometer & Pixhawk \\
MS5611-01BA03 & Barometer and Temperature Sensor & APM and Pixhawk \\
HMC5883L & Internal Compass & APM and Pixhawk \\
FGPMMOPA6B & GPS Antenna & N/A \\
\hline
\end{tabular}




\subsection{The APM Microcontrollers: ATMEGA 2560 and ATMEGA 32-U}

The ATMEGA 2560 and ATMEGA 32-U2 are both 8-bit microcontrollers by Atmel which perform most operations of the APM 2.5. The Atmega 2560 features $256 \mathrm{kB}$ of flash memory and $8 \mathrm{kB}$ of random access memory (RAM) as well as a 16 channel, 10-bit Analogto-Digital onverter (ADC). It has 86 general purpose input/output (I/O) pins and 32x8 general purpose working registers. The operation temperatures are $-40{ }^{\circ} \mathrm{C}$ to $85{ }^{\circ} \mathrm{C}$ and the speed grade is $0 \mathrm{MHz}$ to $16 \mathrm{MHz}$ at $4.5 \mathrm{~V}$ to $5.5 \mathrm{~V}$ for both the 2560 and the $32-\mathrm{U}$. The ATMEGA 32-U2 has $32 \mathrm{kB}$ of flash memory and $1 \mathrm{kB}$ of RAM. It also has 22 general purpose I/O pins and 32 general purpose registers. It has a maximum frequency of $16 \mathrm{MHz}$ at $4.5 \mathrm{~V}$. Its operation temperatures are $-40{ }^{\circ} \mathrm{C}$ to $85^{\circ} \mathrm{C}$. The primary difference between the ATMEGA 2560 and the ATMEGA 32-U2 is that the 32-U2 has full speed USB 2.0 data transferring capabilities. The block diagrams for both ATMEGA chips are shown in Figure 3.3 [3]. These microccontrollers are more than enough to function as a basic recorder but the lack of internal memory leaves much to be desired.

\subsection{The Pixhawk Microcontroller: STM32F427}

The STM32F427 by ST Microelectronics is the 32-bit microprocessor within the Pixhawk. It has $2 \mathrm{MB}$ of internal flash memory, $256 \mathrm{~KB}$ of SRAM (Static Random-Acess Memory), and a flexible (variable bit) external memory controller with up to 32-bit data bus. [28] The STM32F427 has three 12-bit ADCs and two 12-bit Digital-to-Analog Converters (DAC). It has $168 \mathrm{I} / \mathrm{O}$ (Input/Output) ports, 164 of which are fast (up to $90 \mathrm{MHz}$ ), and 166 of which are $5 \mathrm{~V}$ tolerant. The operating temperature $-40{ }^{\circ} \mathrm{C}$ and $+105{ }^{\circ} \mathrm{C}$ from a 1.7 to $3.6 \mathrm{~V}$ power supply. It has full USB and Ethernet capabilities. Figure 3.4 shows the block diagram of the STM32F427. This microcontroller, when compared to the APM's has more internal memory and can interact more quickly and more in depth with the other components of the autopilot. 


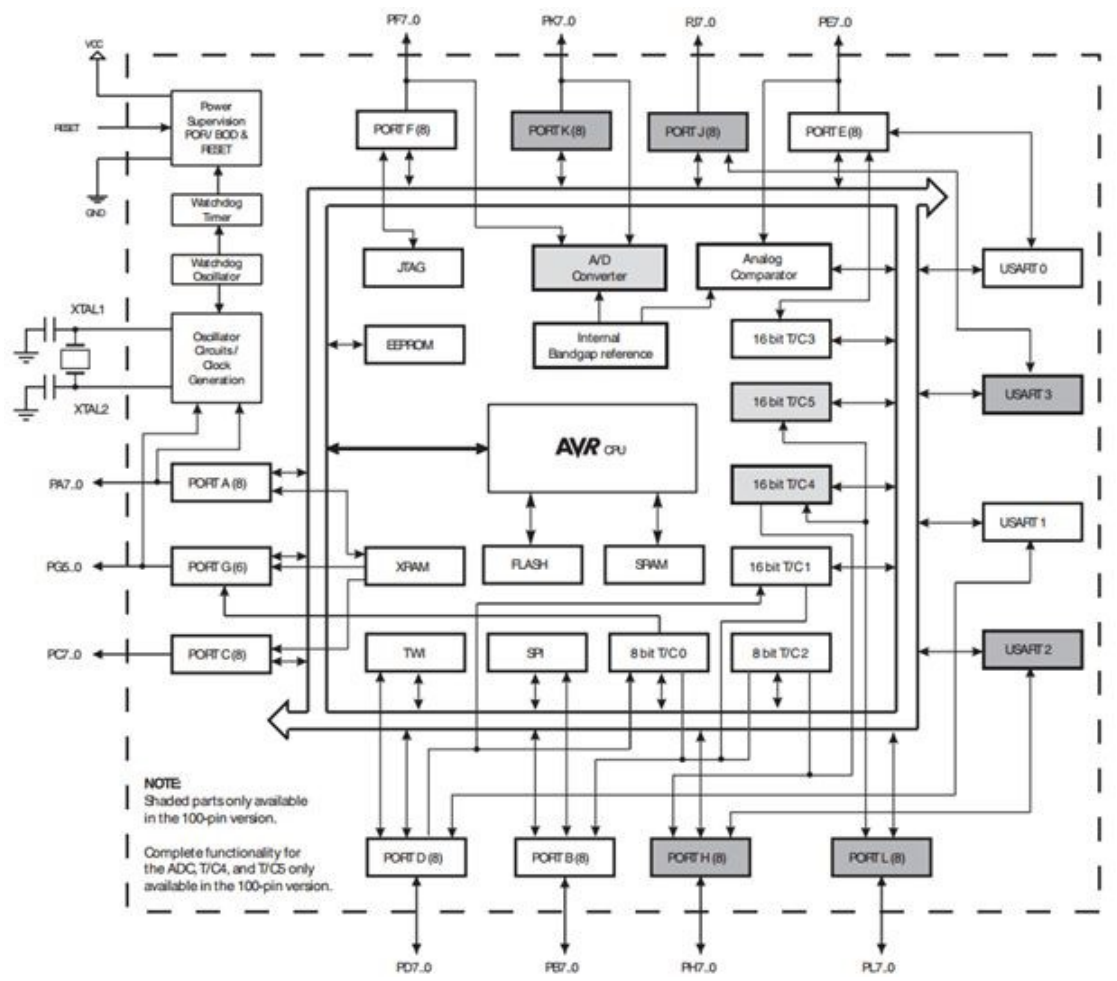

(a) ATMEGA 2560

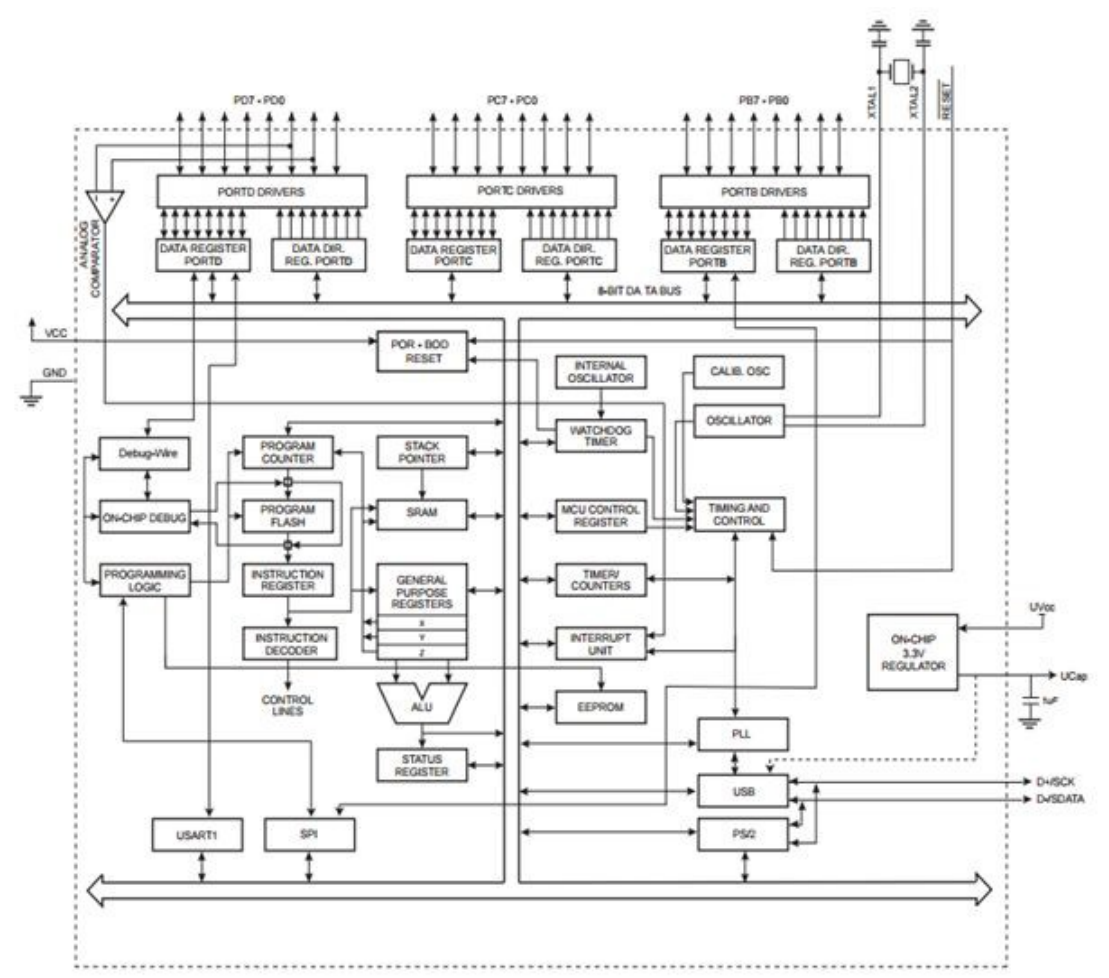

(b) ATMEGA 32-U2

Figure 3.3: ATMEGA Block Diagrams [3] 


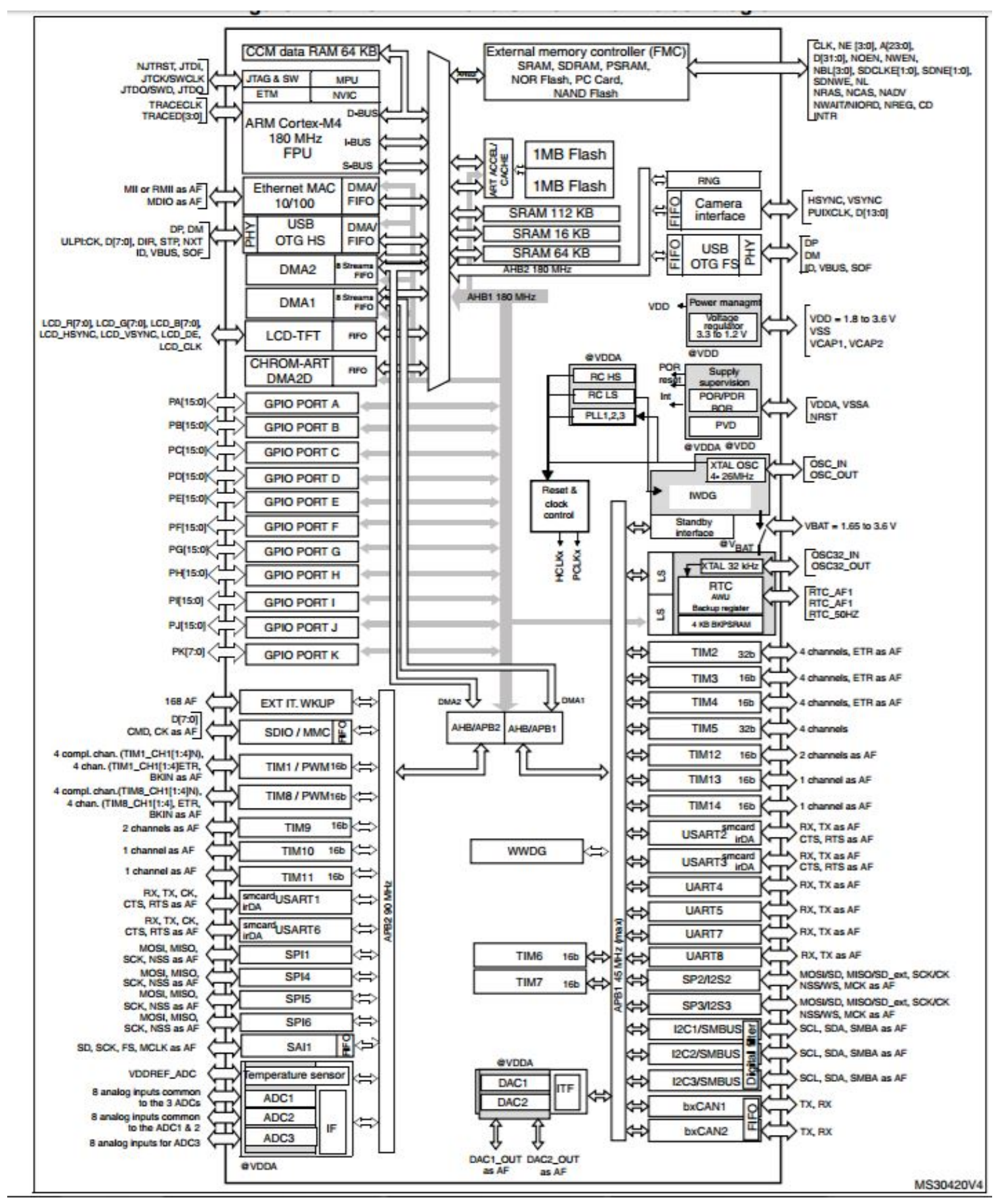

Figure 3.4: Block diagram of the STM32F427 [28] 


\subsection{The Internal Accelerometer and Gyroscope}

The 3-axis accelerometer and 3-axis gyroscope are both found in the MPU-6000 by InvenSense. The MPU-6000 is offered within both the APM and the Pixhawk. In the APM, it is the only accelerometer unit and the only gyroscope unit while the Pixhawk has another accelerometer and another gyroscope. The accelerometer and gyroscope are combined with a Digital Motion Processor and a temperature sensor in a $4 \mathrm{~mm}$ x $4 \mathrm{~mm}$ x $1 \mathrm{~mm}$ package [29]. The MPU has six 16 bit analog-to-digital converters to convert the gyroscopic and accelerometer data to digital form. The ranges of both the gyroscopes and accelerometers can be set by the user. The gyroscopes' ranges are $250 \% / \mathrm{sec}, 500^{\circ} / \mathrm{sec}, 1000 \% / \mathrm{sec}$, and $2000^{\circ} / \mathrm{sec}$ and the accelerometers' ranges are $2 \mathrm{~g}, 4 \mathrm{~g}, 8 \mathrm{~g}$, and $16 \mathrm{~g}$. The operating temperature range for the MPU-6000 is $-40^{\circ} \mathrm{C}$ to $105^{\circ} \mathrm{C}$. The MPU-6000 can communicate with the rest of the APM with a frequency of $400 \mathrm{kHz}, 1 \mathrm{MHz}$ or $20 \mathrm{MHz}$ depending on the application. The data output rate is $8 \mathrm{kHz}$ for the gyroscope and $1 \mathrm{kHz}$ for the accelerometer. The MPU-6000 has a 10,000 g shock tolerance. More specifically, when the gyroscopes are rotated, they cause a vibration which is detected by a capacitive pickoff that signal is then amplified, filtered and converted into a digital signal [29]. The accelerometers work with proof masses; when there is acceleration in a direction, the proof mass is displaced which is detected by capacitive sensors and is then converted to a digital signal. The MPU-6000 gives the acceleration information and the pitch information necessary for the airspeed equation. Figure 3.5 shows a schematic of the MPU-6000 [29].

The Pixhawk, as opposed to the APM, has a second gyroscope and a second accelerometer [23]. The second gyroscope unit is the L3GD20H by ST Micro. It is listed as an angular rate sensore and has three selecatable full scales which are $245 \mathrm{deg} / \mathrm{s}, 500 \mathrm{deg} / \mathrm{s}$, $2000 \mathrm{deg} / \mathrm{s}$ [30]. It has an operating temperature of $-40{ }^{\circ} \mathrm{C}$ to $85{ }^{\circ} \mathrm{C}$ and an 8 bit temperature output. The dimensions of this chip are $3 \mathrm{~mm} \times 3 \mathrm{~mm} \times 1 \mathrm{~mm}$. The L3GD20H has a non-linearity of $0.2 \%$ of the full scale. The second Accelerometer is the LSM303D by ST Micro. 


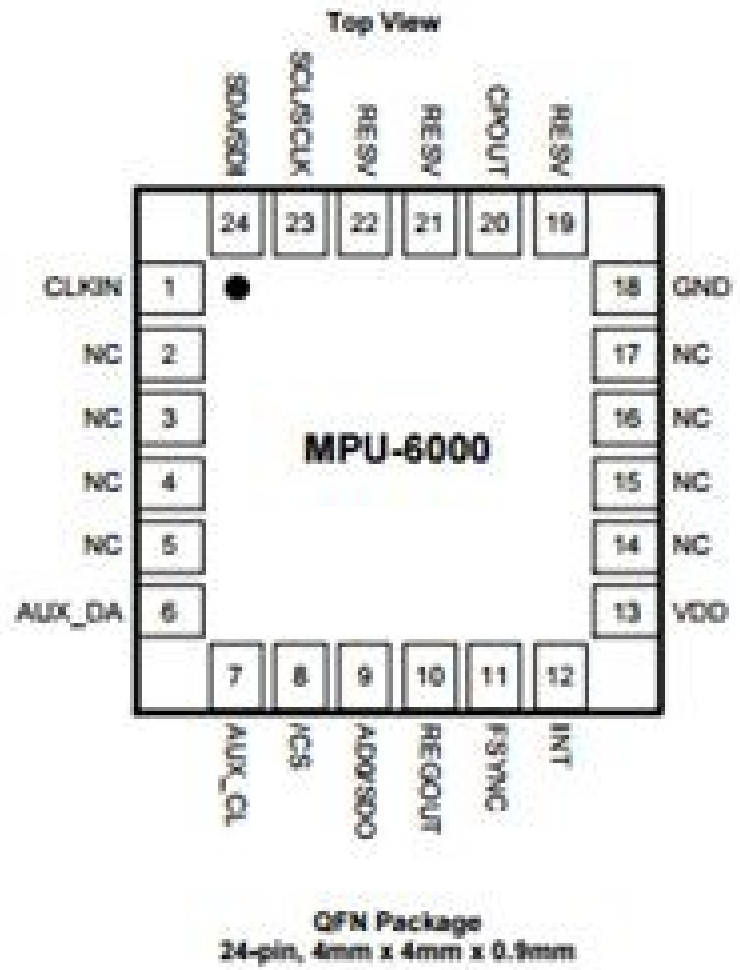

Figure 3.5: Pin layout of the MPU-6000 [29] 


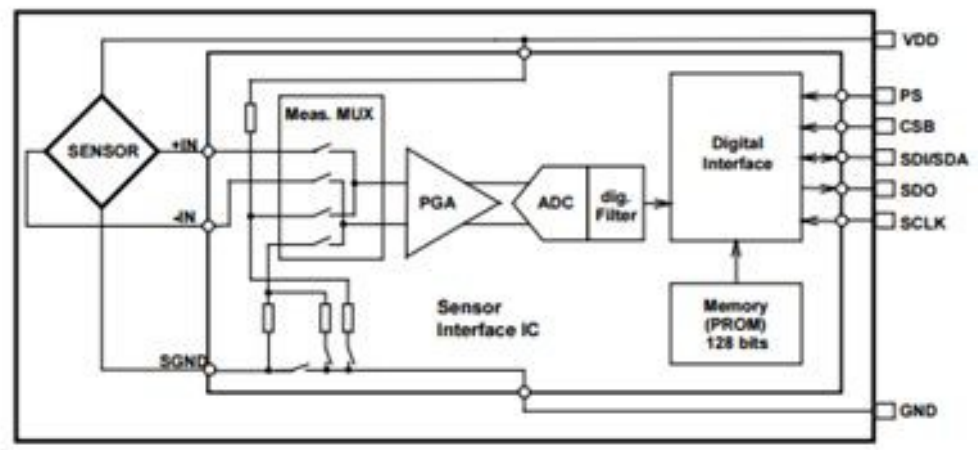

Figure 3.6: Block diagram of the barometer [31]

\subsection{The Internal Barometer}

The barometer in both the APM and the Pixhawk is the MS5611-01BA03 by Measurement Specialities. The dimensions of the barometer are $5 \mathrm{~mm} \times 3 \mathrm{~mm} \times 1 \mathrm{~mm}$ and it is capable of measuring pressure and temperature. The measurable pressure range is 10 mbar to 1200 mbar with an accuracy of $1.5 \mathrm{mbar}$. The resolution is variable between 0.065 mbar, 0.042 mbar, 0.027 mbar, 0.018 mbar and 0.012 mbar. The response time is dependant on the resolution and is $0.5 \mathrm{~ms}, 1.1 \mathrm{~ms}, 2.1 \mathrm{~ms}, 4.1 \mathrm{~ms}, 8.22 \mathrm{~ms}$ respectively [31]. The operating temperature range is from $-40^{\circ} \mathrm{C}$ to $85^{\circ} \mathrm{C}$ with a $0.8^{\circ} \mathrm{C}$ of accuracy and a resolution of $0.01^{\circ} \mathrm{C}$. The MS5611-01BA03 has a 24-bit analog to digital converter which is used to convert both pressure and temperature data into digital form . Figure 3.6 shows a block diagram of the barometer [31]. The temperature and pressure information provided by the internal barometer are necessary to determine density, which is used in the airspeed equation.

\subsection{The Internal Compass}

The APM and Pixhawk both have an onboard compass which is the HMC5883L by Honeywell. The compass has a 3-axis magno-resistive sensor and a 12-bit analog to digital converter to record the heading and convert it to a digital signal respectively. The compass heading accuracy is $2^{\circ}$. The output rate is $0.75 \mathrm{~Hz}$ to $75 \mathrm{~Hz}$ in continuous mode and a $160 \mathrm{~Hz}$ single measurement mode output rate [32]. Intuitively, in continuous measurement 
mode, the device continuously makes measurements at the user-defined rate and in single measurement mode, it makes only one measurement and then remains idle. The operating temperature of this compass is $-30^{\circ} \mathrm{C}$ to $85^{\circ} \mathrm{C}$. Figure 3.7 shows the I/O pin layout the internal schematic of the compass unit [32]. The internal compass was most useful for determining the orientation of the sensors.

\subsection{GPS Antenna}

The GPS antenna unit is a stand-alone unit which is the FGPMMOPA6B by GlobeTop. The size of the unit is $16 \mathrm{~mm} \times 16 \mathrm{~mm} \times 6 \mathrm{~mm}$ and it has position accuracy of $3 \mathrm{~m}$ and velocity accuracy of $0.1 \mathrm{~m} / \mathrm{s}$. The FGPMMOPA6B has a maximum altitude reading of 18000 feet, a maximum velocity reading of $515 \mathrm{~m} / \mathrm{s}$ and maximum acceleration reading of 4 $\mathrm{g}$ [33]. The operating temperatures are $-40^{\circ} \mathrm{C}$ to $85^{\circ} \mathrm{C}$ and an operating humidity of $5 \%$ to 95\% with no condensing. Figure 3.8 illustratesthe unit's block diagram and the size of the GPS unit without its protective packaging [33]. The GPS unit was useful for determining the flight path and date/time information. Without the date/time information, gathering the proper information in the spreadsheet would be extremely tedious.

\subsection{Protective Case}

The protective case in which contains the APM during this study is the Pelican 1020 Microcase as shown in Fig 3.9. The case is constructed out of copolymer, sealed with a neoprene o-ring [34] and has a purge valve which allows for changes in pressure. The 1020 Microcase is certified with a IP67 level of protection. This means that the contents are completely protected against dust as well as $1 \mathrm{~m}$ submersion in water. The interior dimensions of the case are $13.5 \mathrm{~cm} \times 9 \mathrm{~cm} \times 4.3 \mathrm{~cm}$ and its exterior dimensions are 17.3 $\mathrm{cm} \times 12.1 \mathrm{~cm}$ x $5.4 \mathrm{~cm}$. While not completely indestructible, the Pelican 1020 should be sufficient protection for a light aircraft accident. The crash-survivability thankfully wasn not an issue for these particular tests; however, the case was used to keep the FDR unit in 


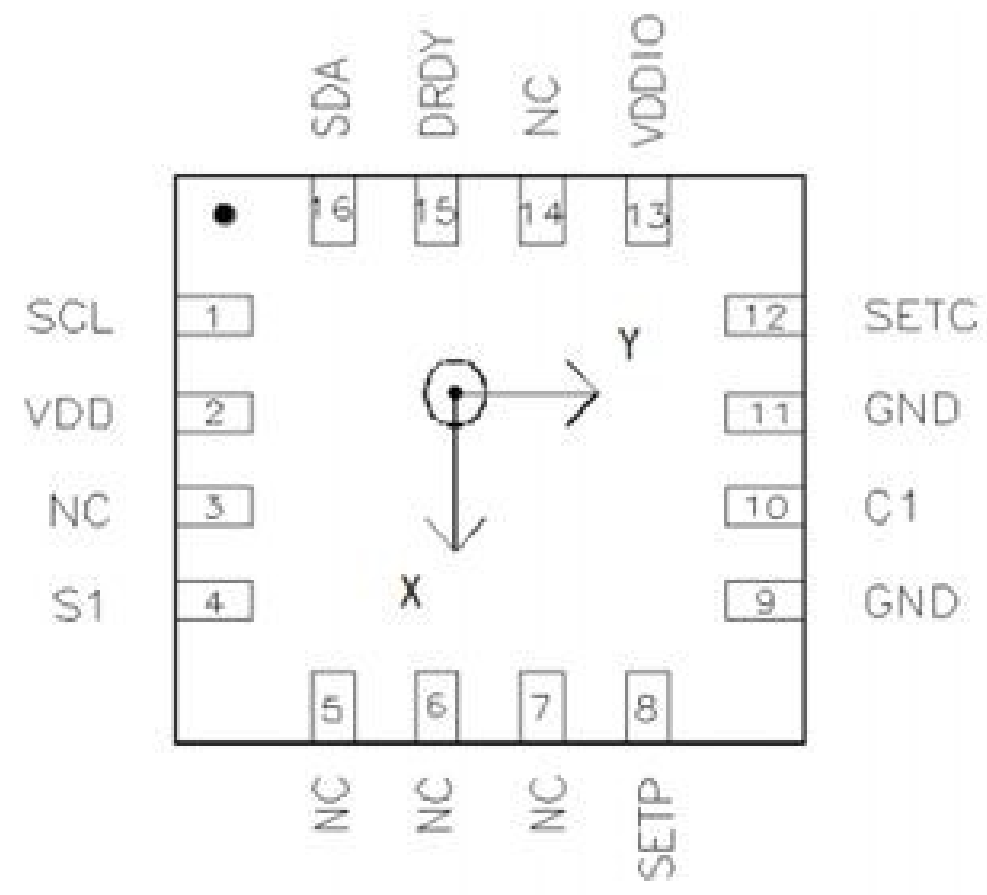

TOP VIEW (looking through)

(a) I/O pin layout

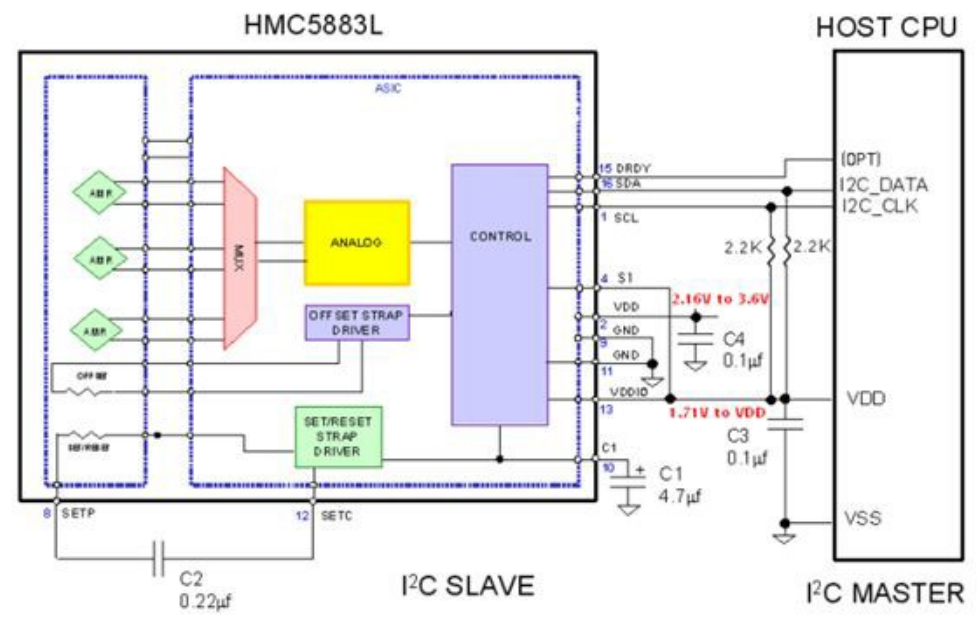

(b) Internal Schematic

Figure 3.7: HMC5883L compass unit [32] 

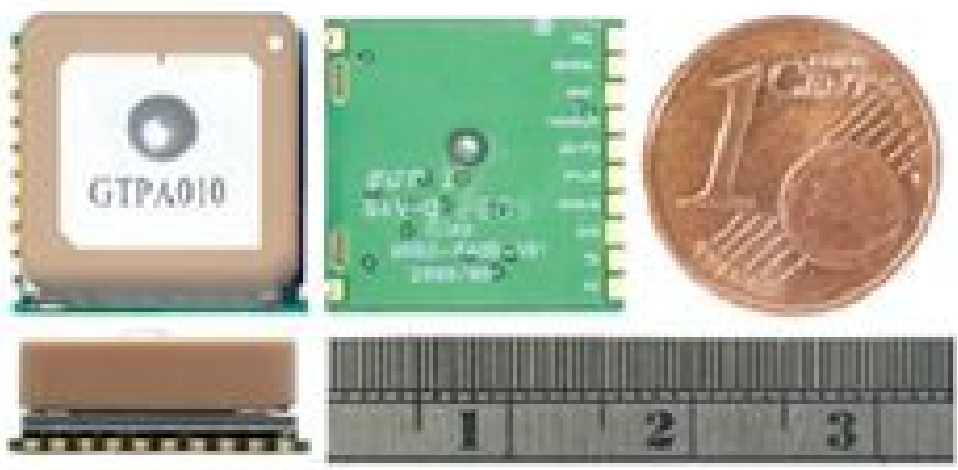

(a) Unprotected GPS Unit

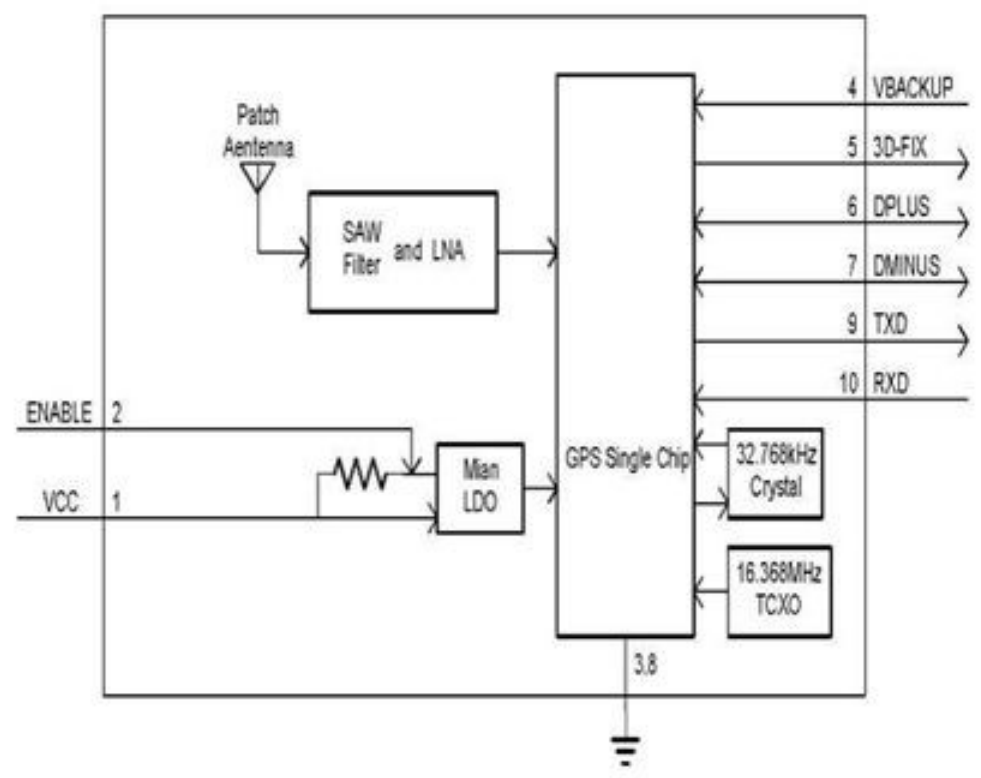

(b) Block Diagram

Figure 3.8: FGPMMOPA6B GPS Unit [33] 


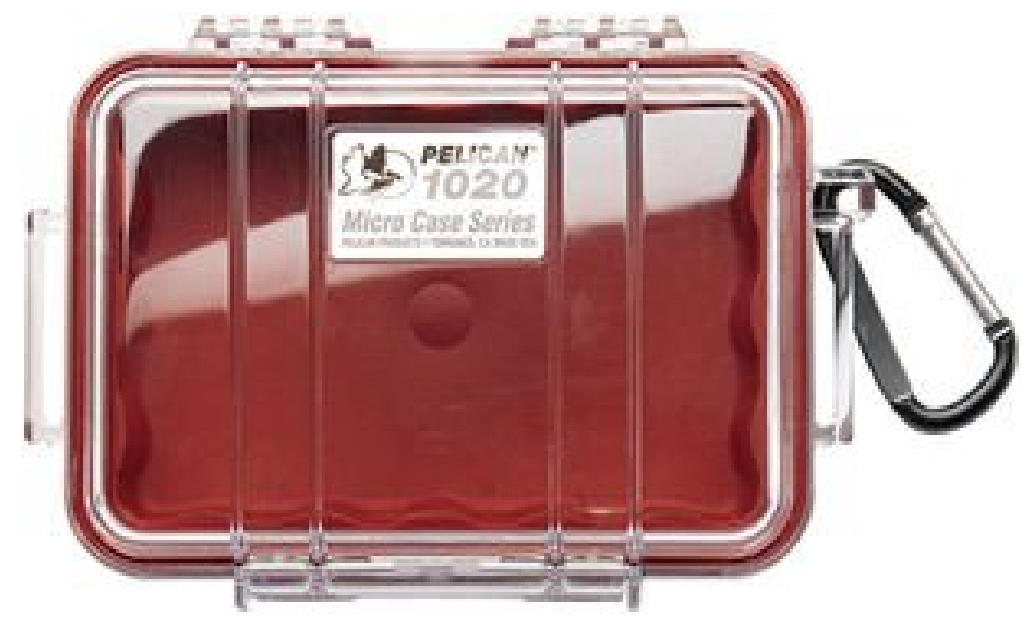

Figure 3.9: Pelican 1020 Micro Case [34]

one solid position. The rubber layering the interior of the case was also ideal for vibration dampening. Figure 3.10 show the Pixhawk and its GPS unit solidly place in the Pelican case. This placement is tight and does not allow for the Pixhawk or the GPS unit to move around within the case.

\subsection{DR Radio}

3D Robotics has a radio specifically designed for two way communication between the Arduino-based autopilot and the ground control station which is typically a laptop or mobile device. The radio comes in either $915 \mathrm{MHz}$ or $433 \mathrm{MHz}$. It is capable of being powered through the APM or via micro-USB cable. The dimensions of the $3 \mathrm{DR}$ radio are $5 \mathrm{~cm} \mathrm{x}$ $2.6 \mathrm{~cm} \times 1.3 \mathrm{~cm}$ in addition to the $10.8 \mathrm{~cm}$ antenna. Figure 3.11 shows the $3 \mathrm{DR}$ radio and its various parts. This is not primarily used for the flight data recorder but is useful for testing and monitoring the APM [35]. This can also lead to the use of the APM for other applications once it is installed in the aircraft. For the purposes of this thesis, the radio link proved most useful to connect the FDR to the computer in order to log more data when the maximum internal memory was reached. 


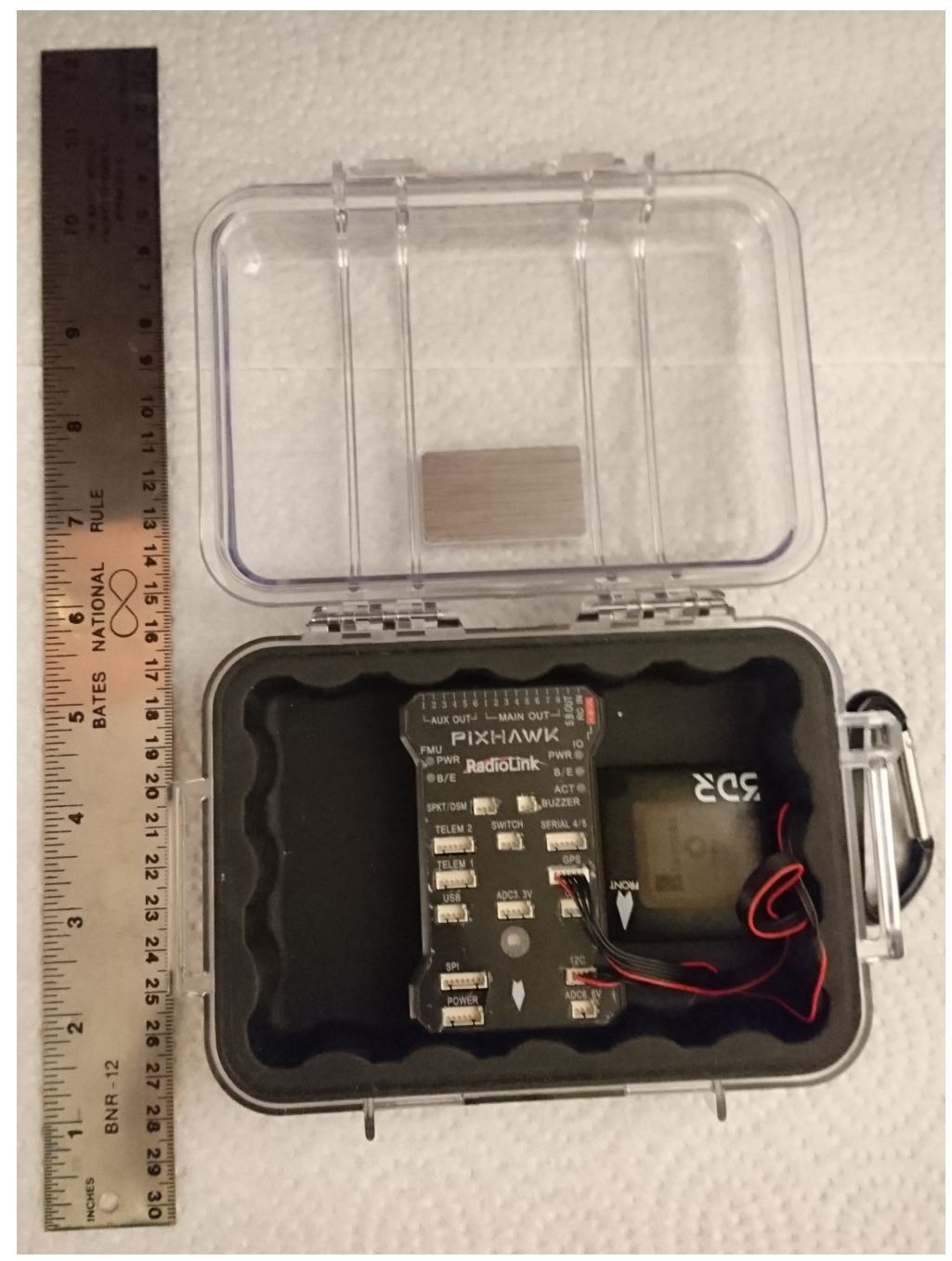

Figure 3.10: The Pixhawk Snugly placed within the Pelican Case
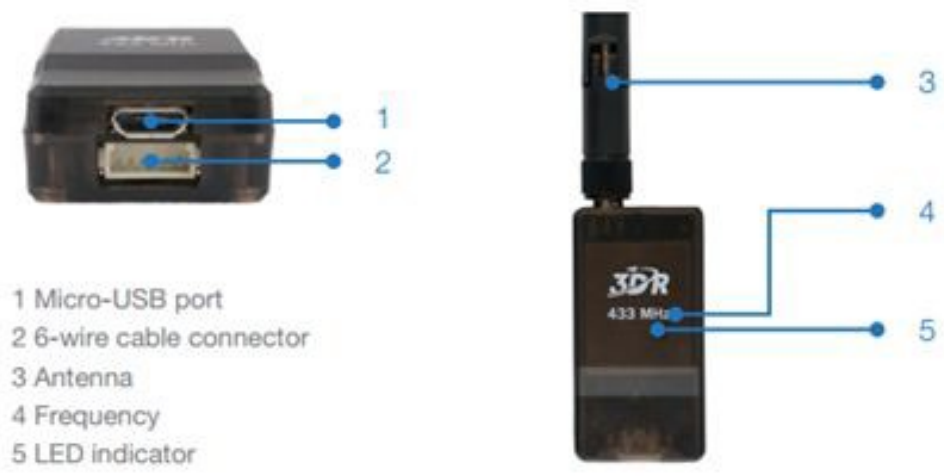

Figure 3.11: 3DR Radio and Components [35] 


\section{Chapter 4}

\section{Software}

The primary software used is the Mission Planner freeware ground station for Arduino-based UAVs, which is everything one could need for use of a private UAV and some commercial UAVs. The program has a versatile package; though few of its features are required for the flight data recorder it is still the most ideal software for the application. Mission Planner is capable of interpreting dataflash logs stored on the APM as well as recording the dataflash logs sent by the APM. Mission Planner is available for computers as well as mobile devices.

\subsection{Dataflash Logs}

Dataflash logs are files of recorded flight paramaters which are saved to the ArduPilot internally. To download the dataflash logs, the APM must be connected via USB (universal serial bus) cable or wirelessly using the APMs Micro Air Vehicle Link (MAVLink). The logs can then be analysed in Mission Planner itself; however, Mission Planner's log analysis is less than ideal for many reasons. The software is incapable of calculations with its recorded parameters and most of the measurements are with reference to line of code as opposed to time (Figure 4.1a). Within the Mission Planner settings, it is possible to adjust the program to use time instead of line of code, but it provides unreliable results. 4.1b highlights the discrepancies within the program when the option, "Use Time," is selected. The software creates an outlier of unknown source at the beginning and connects it to the

end, presumably related to the power-up and power-down cycles of the Arduino. Other 
than the graphs, the data as presented in Mission planner is difficult to interpret and can occasionally be misleading. Due to the difficult layout of the data within Mission Planner, it is more practical to export the data to a spreadsheet where it can be manipulated and interpreted with comparative ease. The native form of the data from the dataflash logs is difficult to use for analysis; this is shown in Figure 4.2. Each column in a row of the dataflash $\log$ has a different parameter based on the identifier representing a sensor in column A. The biggest issue that this type of log is time stamped with time in microseconds beginning from the last value of the previous log. This means that most of the parameters are not with reference to a specific time of day. While this is not impossible to work with, it can make the process tedious.

\subsection{Telemetry Logs}

A telemetry $\log$ is a file of recorded flight data which was recorded on a device that is not the ArduPilot. For the telemetry logs to be created, the Pixhawk or APM must be connected to the computer. While the micro-controller is connected to the computer, the telemetry $\operatorname{logs}$ are created in real time. These telemetry logs are save in a much clearer format because they do not need to be compressed to save into a tiny memory chip. Both types of logs essentially hold the same data but the telemetry logs are much easier to work with. Ever single piece of information in the telemetry log is referenced to time and the variables are easier to identify when the log is exported to a spreadsheet. Figure 4.3 shows the output of a telemetry log into a spreadsheet. The time is listed in column A and the sensor is listed in column J. After column J, parameters are listed in columns with their values listed in the following column of the same row. An example of this is, in the first row of Figure 4.3, column $\mathrm{O}$ has pitch and column $\mathrm{P}$ has 0.198 , which means that the pitch at this time was 0.198 radians. This is the log type that was used to get the parameter data for the airspeed algorithm. 


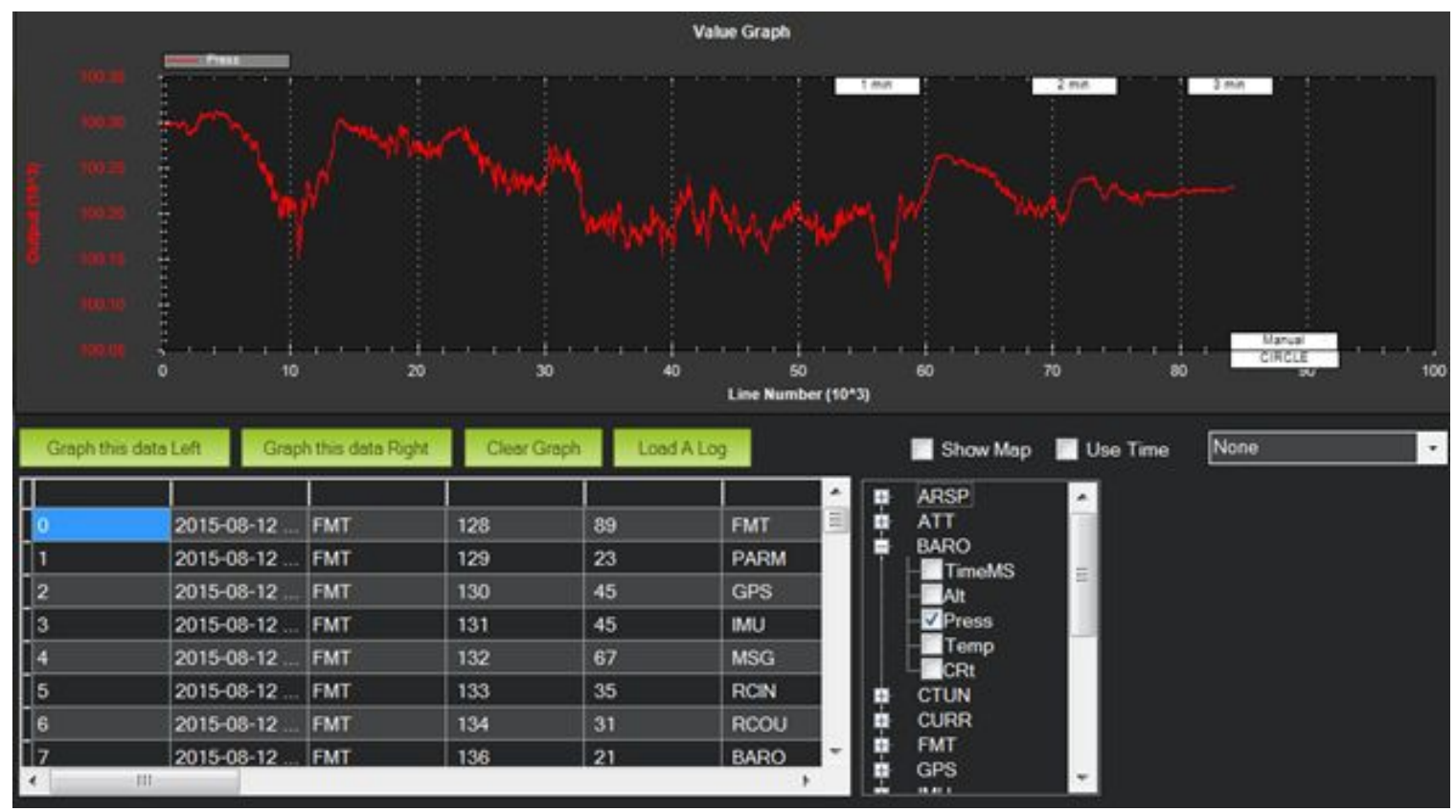

(a) Pressure vs Line of Code. The $\mathrm{y}$ axis is barometric pressure and the $\mathrm{x}$ axis is the line of code in which it is located in the log.

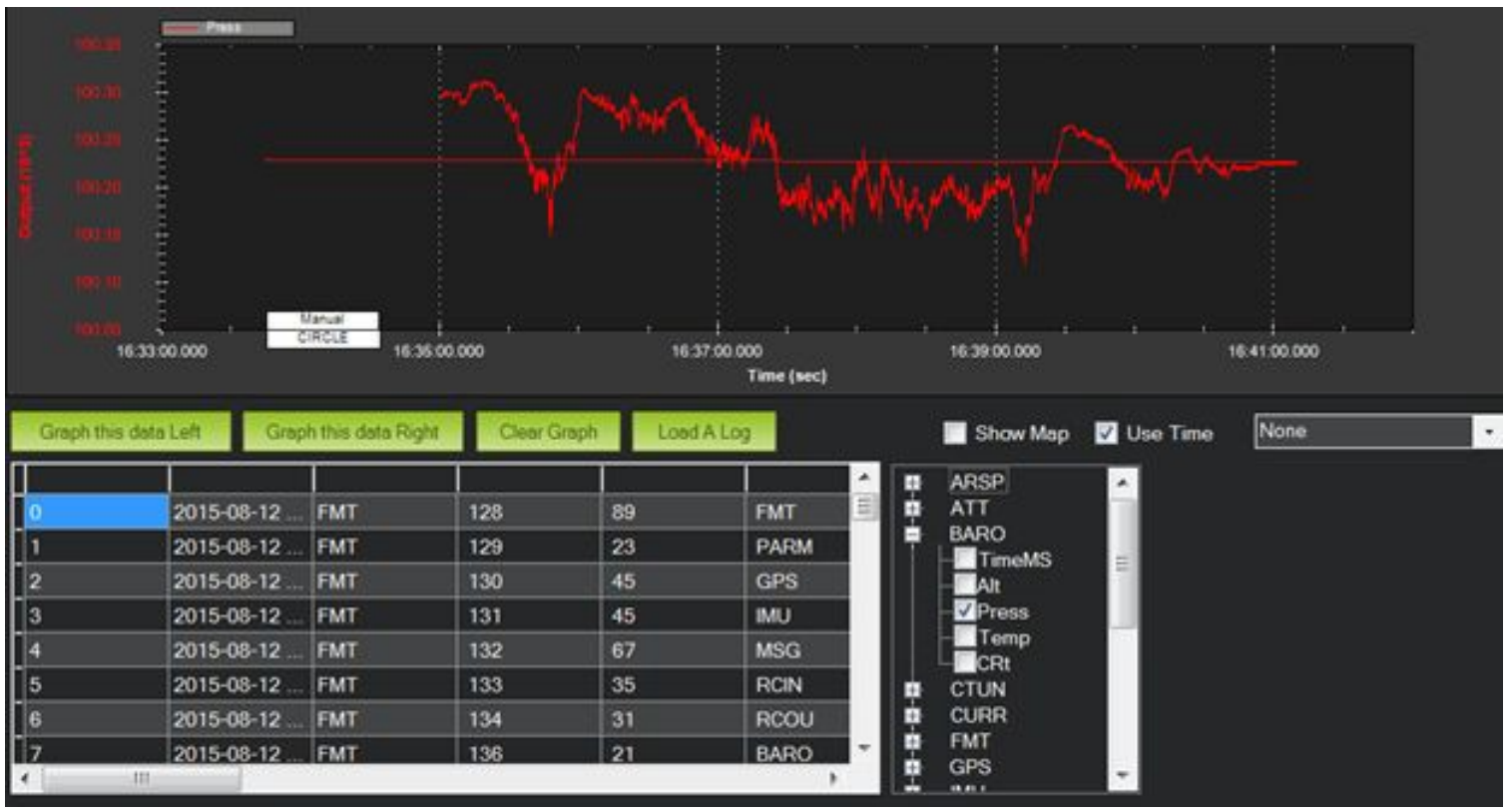

(b) Pressure vs Time in Mission Planner.

Figure 4.1: Mission Planner Log Graph Output 


\begin{tabular}{|c|c|c|c|c|c|c|c|c|c|c|}
\hline 4 & A & B & C & D & $\mathrm{E}$ & $\mathrm{F}$ & G & $\mathrm{H}$ & 1 & J \\
\hline 90670 & IMU & 334110366 & 0.117169 & -0.17428 & -0.17214 & 5.703071 & 0.932997 & -7.44272 & 0 & 0 \\
\hline 90671 & IMU2 & 334110366 & 0.120362 & -0.16314 & -0.18529 & 6.095605 & 1.433305 & -6.20207 & 0 & 0 \\
\hline 90672 & CURR & 334130405 & 0 & 0 & 0 & 4516 & 0 & 0 & & \\
\hline 90673 & POWR & 334130409 & 4.51 & 0.69 & 5 & & & & & \\
\hline 90674 & MAG & 334130432 & 171 & 454 & 278 & 0 & 0 & 0 & 0 & 0 \\
\hline 90675 & MAG2 & 334130436 & -229 & -61 & 383 & 0 & 0 & 0 & 0 & 0 \\
\hline 90676 & BARO & 334130474 & 8.848984 & 100494 & 38.41 & 0.66409 & & & & \\
\hline 90677 & CTUN & 334130484 & 0 & 0 & 0 & 0 & 8.683316 & 8.84 & 0 & 0 \\
\hline 90678 & ATT & 334130528 & 0 & -4.93 & 0 & 40.1 & 302.78 & 302.78 & 0.02 & 0.42 \\
\hline 90679 & EKF1 & 334130547 & -4.93 & 40.1 & 302.78 & 0.051759 & 0.106346 & -0.04371 & 0 & 0 \\
\hline 90680 & EKF2 & 334130553 & 50 & -36 & 68 & 0 & 0 & 279 & 0 & 406 \\
\hline 90681 & EKF3 & 334130558 & 0 & 0 & 0 & 0.01 & 0.04 & 0.01 & -133 & -219 \\
\hline 90682 & EKF4 & 334130580 & 0 & 0 & 0 & 0.57 & 0.95 & 0.66 & 0 & 0 \\
\hline 90683 & AHR2 & 334130624 & -7.55 & 44.99 & 260.94 & 8.84 & 0 & 0 & & \\
\hline 90684 & RATE & 334130634 & 133.0597 & 133.0597 & 40 & -2094.28 & -2094.28 & 36 & -187.098 & -187.098 \\
\hline 90685 & PIDR & 334130645 & 257.8346 & 18.71623 & 0 & 21.66676 & 0 & 0 & & \\
\hline 90686 & PIDP & 334130649 & -1940.08 & 23.12944 & 0 & 13.04903 & 0 & 0 & & \\
\hline 90687 & PIDY & 334130653 & -366.673 & -12.6596 & 0 & 0 & 0 & 0 & & \\
\hline 90688 & PIDA & 334130657 & 0 & 0 & 0 & 0 & 0 & 0 & & \\
\hline 90689 & RCIN & 334130661 & 0 & 0 & 0 & 0 & 0 & 0 & 0 & 0 \\
\hline 90690 & $\mathrm{RCOU}$ & 334130766 & -1 & -1 & -1 & -1 & 0 & 0 & 0 & 0 \\
\hline 90691 & VIBE & 334130783 & 0.576925 & 0.753062 & 0.300538 & 0 & 0 & 0 & & \\
\hline
\end{tabular}

Figure 4.2: Dataflash Log Output to Spreadsheet

\begin{tabular}{|c|c|c|c|c|c|c|c|c|}
\hline & A & $\mathrm{J}$ & K & $\mathrm{L}$ & M & $\mathrm{N}$ & 0 & $\mathrm{P}$ \\
\hline 52589 & 2016-09-02Т14:17:43.570 & mavlink_attitude_t & time_boot_m & 879413 & roll & -0.07656 & pitch & 0.198237 \\
\hline 52590 & 2016-09-02Т14:17:43.570 & mavlink_ahrs2_t & roll & -0.09039 & pitch & 0.170664 & yaw & 1.512177 \\
\hline 52591 & 2016-09-02Т14:17:43.571 & mavlink_vfr_hud_t & airspeed & 54.36 & groundspe & 54.36 & alt & -1.01 \\
\hline 52592 & 2016-09-02Т14:17:43.746 & mavlink_heartbeat_ & custom_modt & & type & & autopilot & 3 \\
\hline 52593 & 2016-09-02Т14:17:43.771 & mavlink_raw_imu_1 & 1 time_usec & $8.8 \mathrm{E}+08$ & xacc & 172 & yacc & 77 \\
\hline 52594 & 2016-09-02Т14:17:43.771 & mavlink_scaled_imı & Itime_boot_m & 879613 & xacc & 219 & yacc & 121 \\
\hline 52595 & 2016-09-02Т14:17:43.772 & mavlink_scaled_pre & time_boot_m & 879613 & press_abs & 972.1129 & press_diff & -6.13383 \\
\hline 52596 & 2016-09-02Т14:17:43.772 & mavlink_sys_status & onboard_con & 6356015 & onboard_c & 6298671 & onboard_c & 6356014 \\
\hline 52597 & 2016-09-02Т14:17:43.773 & mavlink_power_sta & Vcc & 4511 & Vservo & 642 & flags & 5 \\
\hline 52598 & 2016-09-02Т14:17:43.773 & mavlink_meminfo_- & brkval & & freemem & 22208 & freemem 3 & 0 \\
\hline 52599 & 2016-09-02Т14:17:43.774 & mavlink_mission_cl & seq & 0 & & sig & Len & 10 \\
\hline 52600 & 2016-09-02Т14:17:43.774 & mavlink_gps_raw_i & I time_usec & $8.79 \mathrm{E}+08$ & lat & $4.53 E+08$ & Ion & $-7.5 \mathrm{E}+08$ \\
\hline 52601 & 2016-09-02Т14:17:43.774 & mavlink_nav_contr & nav_roll & 0 & nav_pitch & 0 & alt_error & -57.9103 \\
\hline 52602 & 2016-09-02Т14:17:43.775 & mavlink_global_pos & stime_boot_m & 879468 & lat & $4.53 E+08$ & Ion & $-7.5 E+08$ \\
\hline 52603 & 2016-09-02Т14:17:43.775 & mavlink_servo_out| & time_usec & $8.8 \mathrm{E}+08$ & servo1_ra' & 65535 & servo2_ral & 65535 \\
\hline 52604 & 2016-09-02Т14:17:43.775 & mavlink_rc_channe & time_boot_m & 879613 & chan1_rav & 0 & chan2_ran & 0 \\
\hline 52605 & 2016-09-02Т14:17:43.776 & mavlink_ahrs_t & omegalx & -0.00743 & omegaly & -0.03682 & omegalz & 0.035478 \\
\hline 52606 & 2016-09-02Т14:17:43.776 & mavlink_hwstatus_ & Vcc & 4511 & 12Cerr & 0 & & sig \\
\hline 52607 & 2016-09-02Т14:17:43.776 & mavlink_system_tir & time_unix_use & $1.47 \mathrm{E}+15$ & time_boot & 879613 & & sig \\
\hline 52608 & 2016-09-02Т14:17:43.777 & mavlink_terrain_re! & & $4.53 E+08$ & lon & $-7.5 E+08$ & terrain_he & 84.62914 \\
\hline 52609 & 2016-09-02Т14:17:43.777 & mavlink_ekf_status & velocity_varia & 0 & pos_horiz_. & 7.63E-07 & pos_vert_' & 0.003761 \\
\hline 52610 & 2016-09-02Т14:17:43.778 & mavlink_vibration_ & time_usec & $8.8 \mathrm{E}+08$ & vibration_ & 1.449295 & vibration_' & 2.085263 \\
\hline
\end{tabular}

Figure 4.3: Telemetry Log Output to Spreadsheet 


\section{Chapter 5}

\section{Parameters and Algorithms}

\subsection{Parameters}

A list of parameters has been devised for the flight data recorder and they are listed in Table 5.1. These parameters can be combined to show most of the information the pilot of one of these aircraft would have access to. The parameters are selected based on the information that a post-accident investigation would require. The key parameter and most important factor in aviation is airspeed. Since airspeed cannot be directly measured in the cockpit, it is to be calculated using the other parameters.

\subsection{Algorithm}

This section outlines the algorithm for determining the airspeed using the available data and sensors in the Ardu-Pilot systems. The different subsections outline the different equations used and how they were algebraically manipulated to eventually determine the airspeed.

\subsubsection{Definition of Lift}

The definition of the lift coefficient is used and is shown in Equation 5.1. Knowing the relationship between the coefficient of lift, the angle of attack and the lift-curve slope in Equation 5.2, it is possible to isolate for variables that are mostly recordable by the system. [36] 
Table 5.1: List of Parameters and their Sources.

\begin{tabular}{cc}
\hline Parameter & Source \\
\hline \hline Time & GPS \\
Altitude 2 & GPS \\
Climb \& Descent Rate & GPS \\
Track & GPS \\
Ground Speed & GPS \\
Position & GPS \\
Yaw & Accelerometers \& Gyroscopes \\
Pitch & Accelerometers \& Gyroscopes \\
Roll & Accelerometers \& Gyroscopes \\
3D Forces (Including Impact) & Accelerometers \\
Heading & Compass \\
Airspeed & Calculations \\
\hline
\end{tabular}

$$
\begin{gathered}
C_{L}=\frac{L}{0.5 \rho\left(V_{\text {true }}\right)^{2} S_{\text {ref }}} \\
C_{L}=a\left(\alpha-\alpha_{L=0}\right)
\end{gathered}
$$

Where $C_{L}$ is the coefficient of lift and $\mathrm{L}$ is the lift. The symbol $\rho$ is the air density in $\mathrm{kg} / \mathrm{m}^{3}$ and is measured by the internal barometer of the micro controller. $V_{\text {true }}$ is the true airspeed of the aircraft in $\mathrm{m} / \mathrm{s}$ and the symbol a is the slope of the lift curve. $S_{r e f}$ is the reference area of the wing in $m^{2}$. The angle of attack is approximated by the pitch which measured by the internal gyroscopes of the Arduino units, its symbol is $\alpha$ and its units are in radians and $\alpha_{L=0}$ is the angle of attack where lift is equal to zero. Equations 5.1 and 5.2 can be equated to each other to form Equation 5.3

$$
a\left(\alpha-\alpha_{L=0}\right)=\frac{L}{0.5 \rho\left(V_{\text {true }}\right)^{2} S}
$$

Equation 5.3 can be isolated for true airspeed which gives Equation 5.4 or Equation 5.5. 


$$
\begin{aligned}
& \left(V_{\text {true }}\right)^{2}=\frac{L}{0.5 \rho S_{\text {ref }} a\left(\alpha-\alpha_{L=0}\right)} \\
& V_{\text {true }}=\sqrt{\frac{L}{0.5 \rho S_{\text {ref }} a\left(\alpha-\alpha_{L=0}\right)}}
\end{aligned}
$$

\subsubsection{Slope of the Lift Curve}

The slope of the lift curve of a finite wing, a, can be approximated using Equation 5.6 [37].

$$
a=\frac{a_{0}}{1+\left(\frac{a_{0}}{\pi A R}\right)(1+\tau)}
$$

Where the lift-slope for an infinite wing, $a_{0}$, can be approximated constant at $2 \pi$ and $\tau$ is a function of Fourier coefficients [37]. AR is the aspect ratio of the aircraft's wing.

\subsubsection{Lift}

Lift $(\mathrm{L})$ can approximated by the acceleration in the $\mathrm{Z}$ direction (which is recorded by the Arduino) and the mass of the aircraft as shown in Equation 5.7.

$$
L=\left(z_{a}+z_{g}\right) m
$$

Where $z_{a}$ is acceleration in the $\mathrm{z}$ direction (up on the vertical axis of the aircraft) in $\mathrm{m} / \mathrm{s}^{2}$ and $\mathrm{m}$ is the mass of the aircraft in $\mathrm{kg}$. Lift in this case is defined by what the wing produces and is body fixed. The variable $z_{g}$ is the force of gravity acting on the sensor unit. For any pitch angle that is not zero, the force opposing aircraft lift needs to be adjusted accordingly. This pitch adjustment is shown in Equation 5.8. Equations 5.8 and 5.7 can be combined to form Equation 5.9

$$
\begin{gathered}
z_{g}=g \operatorname{Cos}(\alpha) \\
L=\left(z_{a}+g \operatorname{Cos}(\alpha)\right) m
\end{gathered}
$$




\subsubsection{Air Density}

The density of the air must also be considered. The Arduino is capable of measuring both temperature and pressure. With a simple calculation shown in Equation 5.10, density can be found. Where $\mathrm{K}$ is the temperature in Kelvin, $\mathrm{T}$ is the temperature in degrees Celsius, $\mathrm{p}$ is the pressure in Pascals and $\mathrm{R}$ is the specific gas constant for air which is approximately $287 \mathrm{~J} / \mathrm{kgK}$.

$$
\rho=\frac{p}{R K}=\frac{p}{R(T+273)}
$$

\subsubsection{The Airspeed Equation}

Equations 5.5, 5.9, 5.10 and ?? are finally combined to create Equation 5.11.

$$
V_{\text {true }}=\sqrt{\frac{2\left[z_{a}+g \operatorname{Cos}(\alpha)\right] m}{\left(\frac{p}{R(T+273)}\right) S_{\text {ref }}\left(\frac{a_{0}}{1+\left(\frac{a_{0}}{\pi A R}\right)(1+\delta)}\right)\left(\alpha-\alpha_{L=0}\right)}}
$$

It was realized upon the beginning of the flight testing that the FDR would almost always have a non-zero angle of incidence. Due to this realization, Equation 5.11 required slight modification. The modification was to include an angle of incidence of the FDR to compensate for a pitch difference between the unit and the angle of incidence of the wing. Equation 5.12 is the result of such a change, where $\alpha_{0}$ is the difference in incidence angle between the FDR and the wing.

$$
V_{\text {true }}=\sqrt{\frac{2\left[z_{a}+g \operatorname{Cos}\left(\alpha-\alpha_{0}\right)\right] m}{\left(\frac{p}{R(T+273)}\right) S_{\text {ref }}\left(\frac{a_{0}}{1+\left(\frac{a_{0}}{\pi A R}\right)(1+\delta)}\right)\left(\alpha-\alpha_{L=0}\right)}}
$$

\subsubsection{True Airspeed}

Eventually, the result from Equation 5.12 was compared to an airspeed recorded by a visual observer of the airspeed indicator within the test aircraft. This required the indicated airspeed to be converted to true airspeed using Equation 5.13. Where $V_{\text {equivalent }}$ is the equivalent airspeed and $\rho_{0}$ is the standard density of air of $1.225 \mathrm{~kg} / \mathrm{m}^{3}$ [38]. In this 
situation, the equivalent airspeed is equal to the calibrated airspeed due to the lack of compressibility error at the flown airspeed and altitude [39]. The calibrated airspeed is usually not the same as the indicated airspeed, however, in the Beechcraft Musketeer Pilot's Operating Handbook (POH), it is listed as equal [40], as seen in Figure 5.1. So, essentially, for the purposes of these tests, the equivalent airspeed is equal to the indicated airspeed and Equation 5.13 becomes Equation 5.14.

$$
V_{\text {true }}=V_{\text {equivalent }} \sqrt{\frac{\rho_{0}}{\rho}}
$$

\begin{tabular}{|c|c|c|c|c|c|}
\hline \multicolumn{3}{|c|}{$\begin{array}{l}\text { SectionII } \\
\text { Limitations }\end{array}$} & \multicolumn{3}{|c|}{$\begin{array}{r}\text { BEECHCAAFT } \\
\text { MusketeerA23, A23A }\end{array}$} \\
\hline \multicolumn{6}{|c|}{-AIRSPEED INDICATOR MARKINGS } \\
\hline \multirow{2}{*}{$\begin{array}{c}\text { MARK } \\
\text { ING }\end{array}$} & \multicolumn{2}{|c|}{ CAS } & \multicolumn{2}{|c|}{ IAS } & \multirow{2}{*}{$\begin{array}{l}\text { SIGNIF- } \\
\text { ICANCE }\end{array}$} \\
\hline & KTS & MPH & KTS & $\mathrm{MPH}$ & \\
\hline $\begin{array}{l}\text { White } \\
\text { Arc }\end{array}$ & $\begin{array}{l}\text { (1) } 51-96 \\
\text { (2) } 52-96\end{array}$ & $\begin{array}{l}59-110 \\
60-110\end{array}$ & $\begin{array}{l}51-96 \\
52-96\end{array}$ & $\begin{array}{r}59-110 \\
60-110\end{array}$ & $\begin{array}{l}\text { Full Flap } \\
\text { Operating } \\
\text { Range }\end{array}$ \\
\hline $\begin{array}{l}\text { Green } \\
\text { Arc }\end{array}$ & (1) $63-135$ & $\begin{array}{r}72.153 \\
72.155\end{array}$ & $\begin{array}{c}63-133 \\
63-135\end{array}$ & $\begin{array}{r}72-153 \\
72-155\end{array}$ & $\begin{array}{l}\text { Normal } \\
\text { Operating } \\
\text { Range }\end{array}$ \\
\hline $\begin{array}{l}\text { Yellow } \\
\text { Arc }\end{array}$ & $\begin{array}{l}\text { (1) } 33-152 \\
\text { (2) } 35-152\end{array}$ & $\begin{array}{l}153-175 \\
155-175\end{array}$ & $\begin{array}{l}133 \cdot 152 \\
135 \cdot 152\end{array}$ & $\begin{array}{l}153-175 \\
155-175\end{array}$ & $\begin{array}{l}\text { Operate With } \\
\text { Caution, Only } \\
\text { in Smooth Air }\end{array}$ \\
\hline $\begin{array}{l}\text { Red } \\
\text { Line }\end{array}$ & 152 & 175 & 162 & 175 & $\begin{array}{l}\text { Maximum } \\
\text { Speed } \\
\text { For All } \\
\text { Operations }\end{array}$ \\
\hline $\begin{array}{l}\text { - The lin } \\
\text { CAS Vi } \\
\text { DM-3, } \\
\text { (2) M-901 }\end{array}$ & $\begin{array}{l}\text { mits of the } \\
\text { values. } \\
\text { M-555 thru } \\
1 \text { thru M-10 }\end{array}$ & $\begin{array}{l}\text { ares on th } \\
\text { M.900 } \\
094\end{array}$ & he airspee & ad indicatc & or are marked in \\
\hline
\end{tabular}

Figure 5.1: Indicated and Calibrated Airspeed

$$
V_{\text {true }}=V_{\text {indicated }} \sqrt{\frac{\rho_{0}}{\rho}}
$$

Finally, to put Equation 5.14 in terms of measured variables, it is converted to Equation 
5.15 which can be rewritten as Equation 5.16.

$$
\begin{gathered}
V_{\text {true }}=V_{\text {indicated }} \sqrt{\frac{\rho_{0}}{\left(\frac{p}{R(T+273)}\right)}} \\
V_{\text {true }}=V_{\text {indicated }} \sqrt{\frac{\rho_{0} R(T+273)}{p}}
\end{gathered}
$$

For ease of reference, all of the variables used in Equations 5.12 and 5.16 are listed in Table 5.2 with their units and sources.

Table 5.2: List of Variables, Their Units and Their Sources

\begin{tabular}{cccc}
\hline Variable & Symbol & Unit & Source \\
\hline \hline True Airspeed & $V_{\text {true }}$ & $\mathrm{m} / \mathrm{s}$ & Equation 5.11 or 5.16 \\
Acceleration in the Z Direction & $z_{a}$ & $\mathrm{~m} / \mathrm{s}^{2}$ & Accelerometer \\
Acceleration due to Gravity & $\mathrm{g}$ & $\mathrm{m} / \mathrm{s}^{2}$ & Constant at $9.81 \mathrm{~m} / \mathrm{s}^{2}$ \\
Angle of Attack & $\alpha$ & Radians & Gyroscopes \\
FDR Incidence Angle & $\alpha_{0}$ & Radians & Measured on the Aircraft \\
Mass & $\mathrm{m}$ & kilograms & Weight and Balance Sheet \\
Pressure & $\mathrm{p}$ & Pascals & Barometer \\
Specific Gas Constant for Air & $\mathrm{R}$ & $\mathrm{J} / \mathrm{kgK}$ & Constant at $287 \mathrm{~J} / \mathrm{kgK}$ \\
Temperature & $\mathrm{T}$ & Degrees Celsius & Internal Thermometer \\
Conversion from Celsius to Kelvin & 273 & Degrees Celsius & Constant at $273 \mathrm{Degrees}$ \\
Reference Area & $S_{r e f}$ & $\mathrm{~m}^{2}$ & Measured on the Aircraft \\
Airfoil Efficiency & $\eta$ & none & Estimated to be $0.95[?]$ \\
Speed of Sound & $V_{\text {sound }}$ & $\mathrm{m} / \mathrm{s}$ & Constant at $343 \mathrm{~m} / \mathrm{s}$ \\
Standard Air Density & $\rho_{0}$ & $\mathrm{~kg} / \mathrm{m}^{3}$ & Constant at $1.225 \mathrm{~kg} / \mathrm{m}^{3}$ \\
\hline
\end{tabular}

\subsubsection{Groundspeed and Weather Method}

The airspeed algorithm results will be compared to the groundspeed method which uses the law of cosines to determine the airspeed velocity vector. Figure 5.2 shows the velocity triangle which depicts, the groundspeed (GS), the airspeed (AS), the wind speed (WS) and 
the difference in angle between the wind and the heading of the aircraft (Q). Equation 5.17 shows the law of cosines when used to determine airspeed from groundspeed.

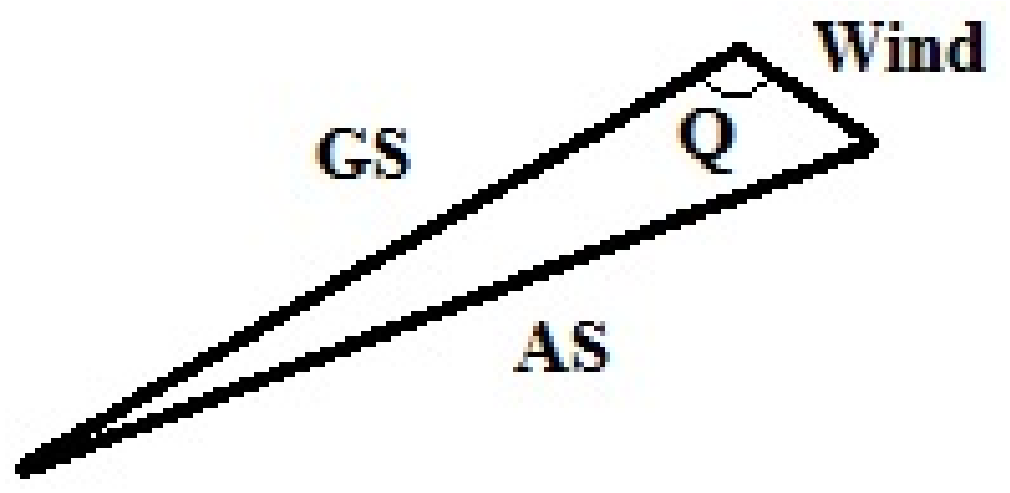

Figure 5.2: Groundspeed Velocity Triangle

$$
A S=\sqrt{G S^{2}+W S^{2}-2(G S)(W S) \cos (Q)}
$$




\section{Chapter 6}

\section{Testing}

\subsection{Preliminary Testing}

Preliminary testing involved using the FDR in a land vehicle to determine its measuring capabilities and begin the process of software troubleshooting. This has also lead to beginning some calculations as well. The ground tests were done as a way to save the expenditure of flying an aircraft while troubleshooting the hardware of the FDR unit. The test consisted of a fairly standard drive mostly to see if the APM would behave appropriately. The expected behaviour was for pitch to change as the vehicle goes up and down hills and the GPS data to accurately measure speed, position. There were many parameters which were expected to remain constant during these tests such as pressure, temperature, and roll. The accelerometers measured acceleration when the car was accelerating, braking or turning. The gyroscopes measured pitch when the car went up and down hills as well as yaw when the car was turning. GPS measured altitude, track, position and ground speed while the compass measured heading. The data was expected to be substantially noisy due to the car used in these tests. The only car available for these tests was the author's muscle car with a rough riding suspension; the car was a 1992 Pontiac Firebird, shown in Figure 6.1.

\subsubsection{Preliminary Results}

As previously mentioned, the proposed FDR system was taken for preliminary testing in a car to test basic functionality and qualitatively determine if the results are logical. Figure 


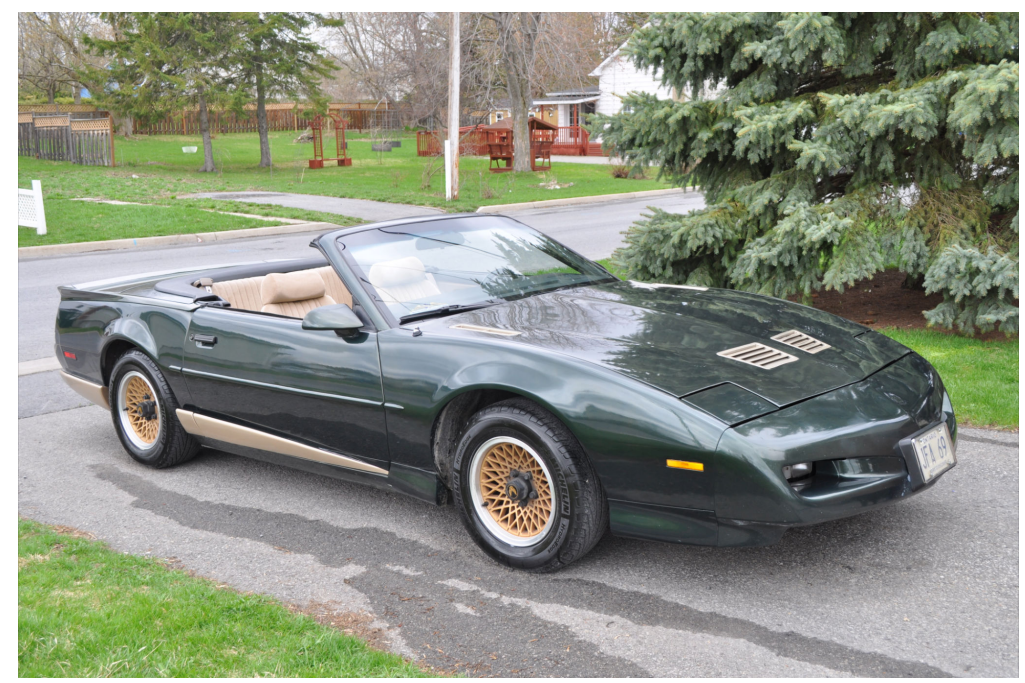

Figure 6.1: Ground Test Vehicle: 1992 Pontiac Firebird

6.2 illustrates data taken during a drive which involved going up and down two hills. Figure 6.2a somewhat shows the three hills: the first one being a small but steep hill around line number 10,000, the second one being approximately the same height but more gradual slopes and a longer plateau shown between the lines 25000 and 60000 . There were two stop signs during this drive, one just after the first hill and another just before climbing the second hill. These stops are shown in Figure $6.2 \mathrm{~b}$ as abrupt negative acceleration. Figure 6.2c shows that the temperature remained constant at $35^{\circ} \mathrm{C}$ during the drive, as expected. Figure $6.2 \mathrm{~d}$ shows acceleration in the $\mathrm{Z}$ direction which mostly stays near the force of gravity but is very noisy due to the rough riding nature of the vehicle used for the preliminary tests.

There was a second ground test which was performed because the GPS was not functional during the first preliminary test. During this test, the vehicle moved down a long, steadily declining hill. The GPS took some time to acquire satellite reception, and therefore did not begin recording until half way down the hill. However the GPS altitude in Figure 6.3a shows the steady decline as the vehicle goes down the hill. The speed, shown in Figure $6.3 \mathrm{~b}$ demonstrates a fairly steady velocity until the vehicle comes up to the two stop signs just after the lines of 60000 and 70000 . The sensors in the APM were not designed for land vehicles and therefore have difficulty with the rough riding nature of ground vehicles compared to air vehicles. Regardless, the information received from the drives correspond 


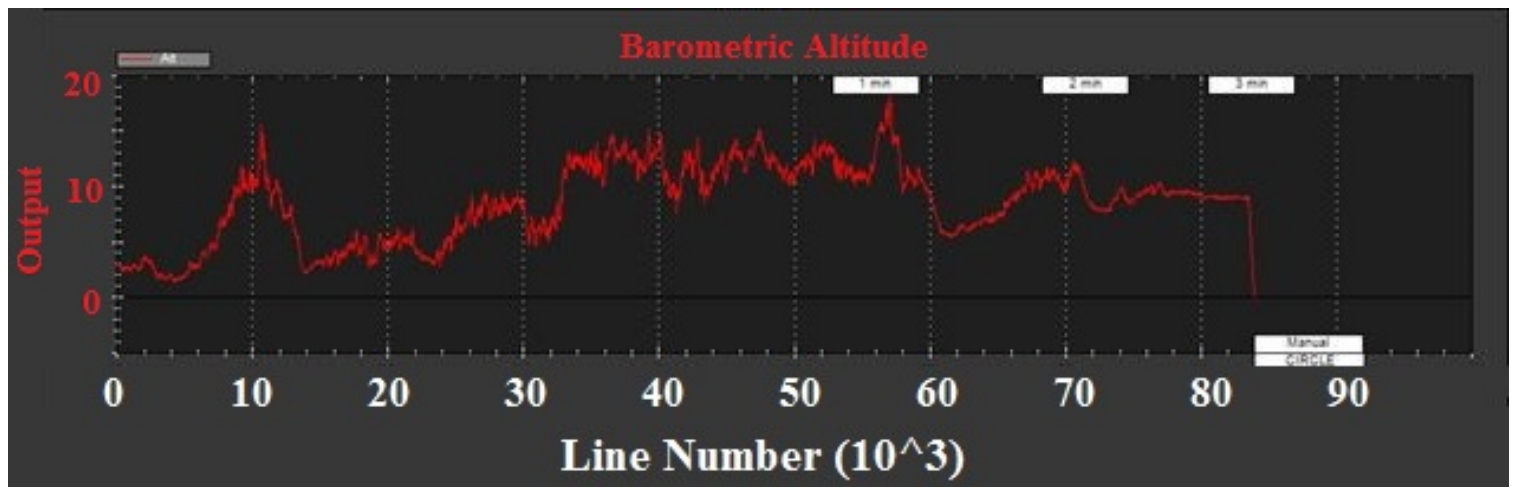

(a) Barometric Altitude

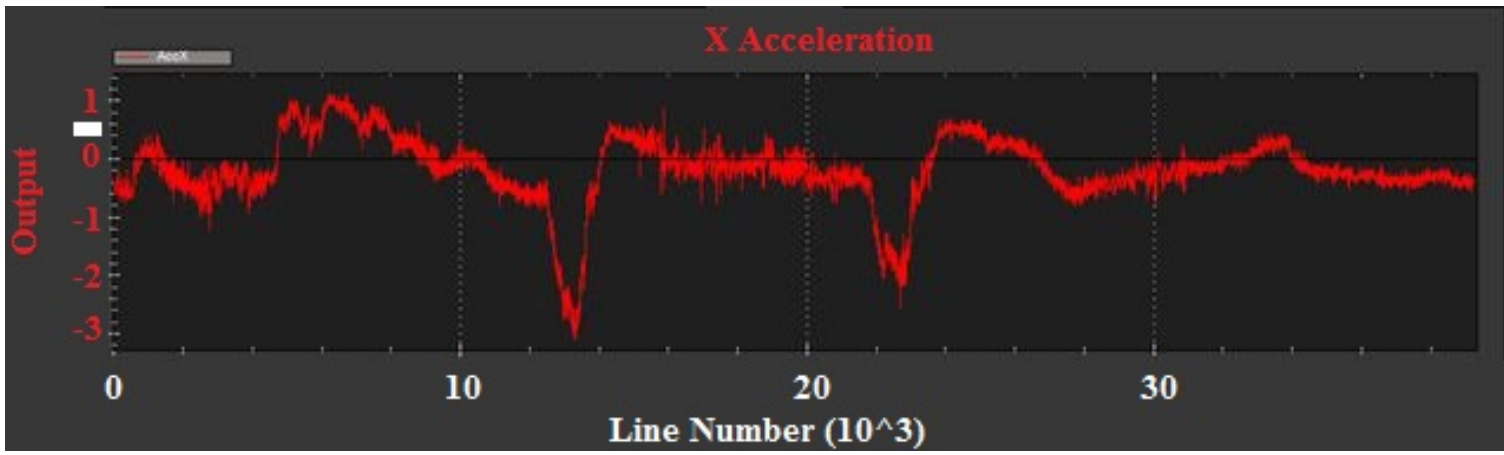

(b) Acceleration in the X Direction

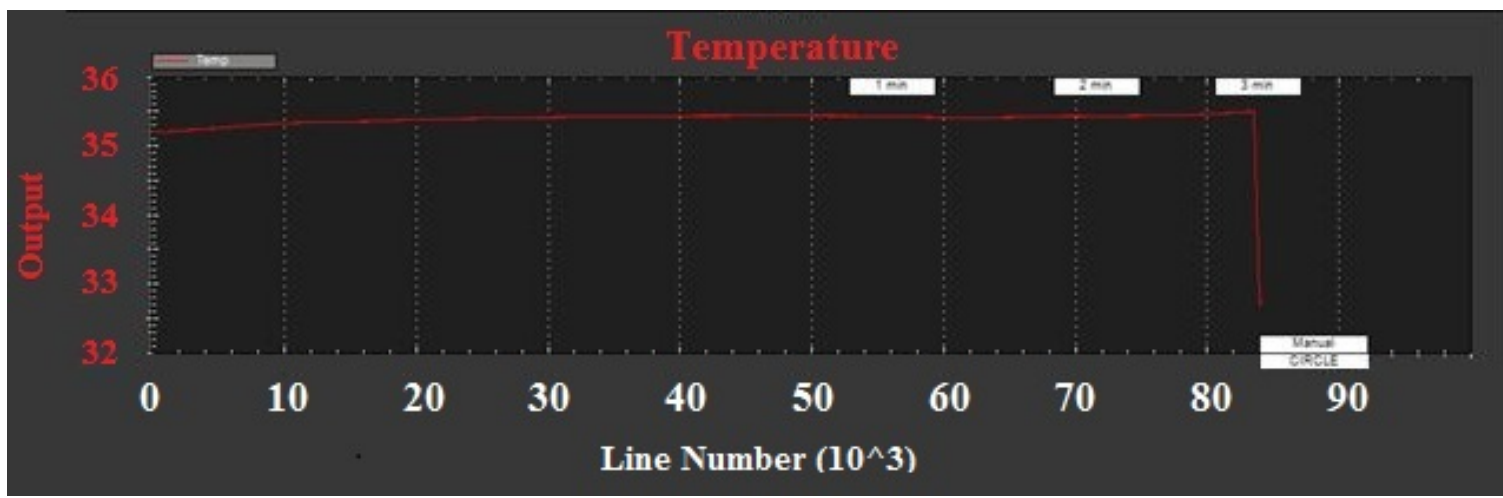

(c) Temperature

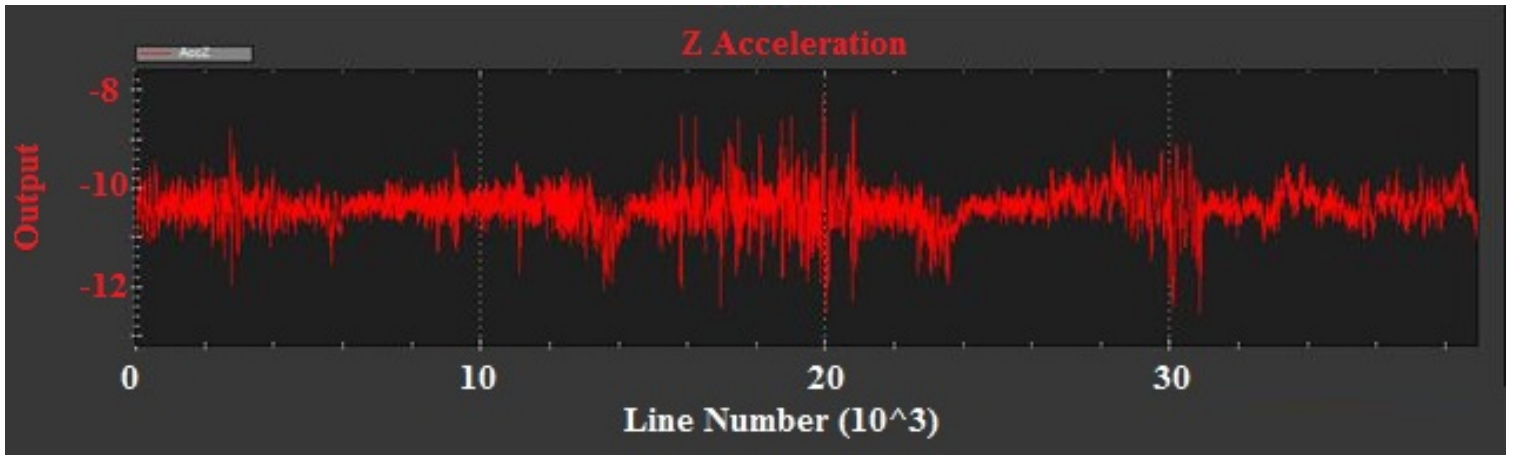

(d) Acceleration in the $\mathrm{Z}$ direction

Figure 6.2: First Ground Test Preliminary Results 


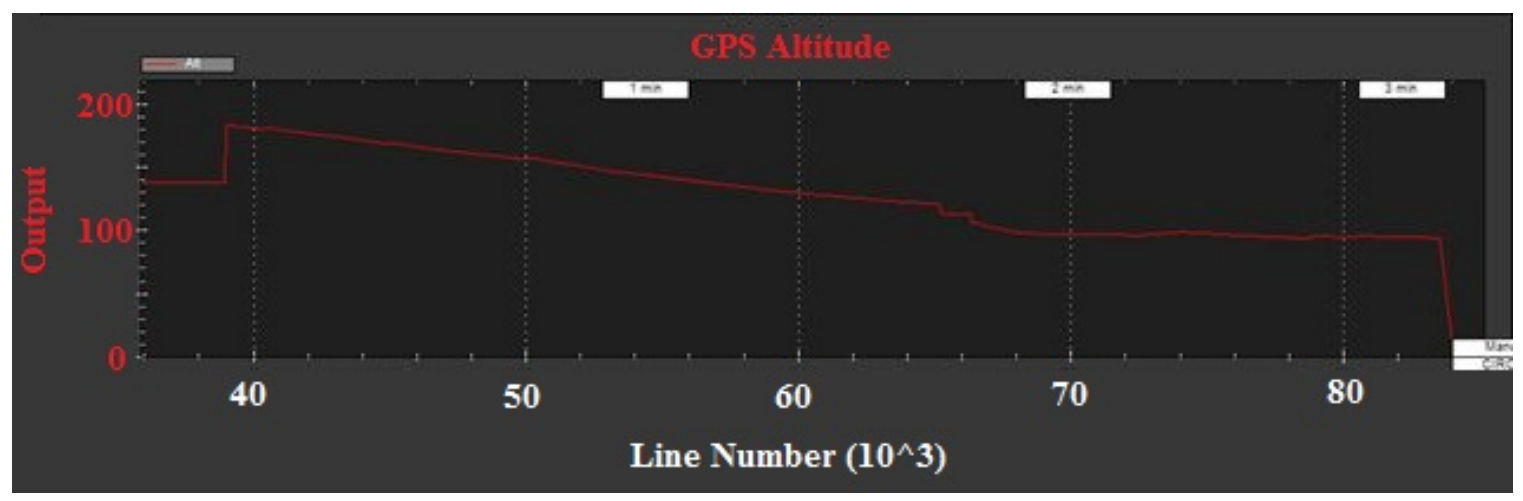

(a) GPS Altitude

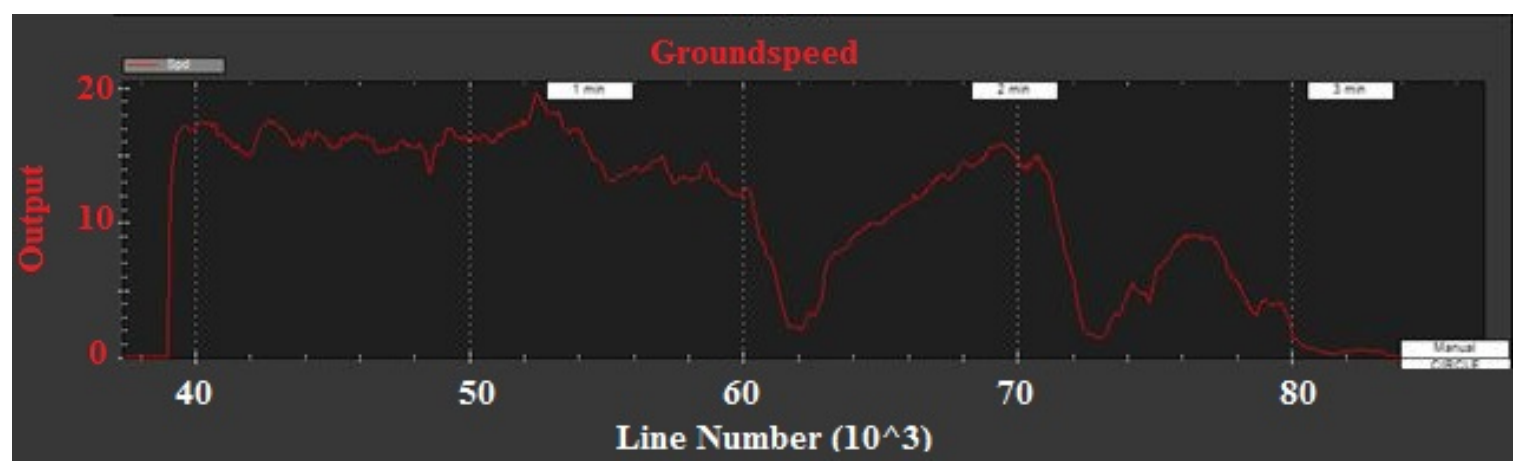

(b) Groundspeed

Figure 6.3: Second Ground Test Preliminary Results

to what would be expected from those sensors. There were no anomalies which could be seen in the recorded data but as stated previously, the resulting data format is less than ideal. At this point, work began on a code to organize the dataflash log data into a more ideal format for the determination of airspeed.

\subsection{Flight Testing}

Several flight tests were conducted in order to gather data and perform some light validation the the airspeed algorithm. The flight tests performed and their results are outlined in the following subsections. There were four flight tests in total, each one of the tests had a different objective. 


\subsubsection{The Flight Test Aircraft}

The aircraft available for flight testing was a 1965 Beechcraft Musketeer A23A Registered as C-GBFZ. Figure 6.4 shows the aircraft in question at the Alexandria airport where the test flights took place. It is a fairly standard low-wing, four passenger, single-engine aircraft. Relevant aircraft details can be found in Table 6.1. The $\tau$ values listen in this table assumes that the aspect ratio is 6 as opposed to 6.4 [41]. The Airfoil used by the Beechcraft Musketeer is the NACA 63A415 [42]. This particular aircraft is not rated for aerobatics; as such, stalls, spins and spirals were not performed as part of the flight testing. The empty weight and fuel consumption were read from the $\mathrm{POH}$ of the aircraft. The empty weight of the aircraft is $1421 \mathrm{lbs}(646 \mathrm{~kg})$ and the fuel consumption is 9 U.S. gallons per hour. Figure 6.5 shows the most recent weight and balance of the aircraft. The latest weight and balance was done before the aircraft was imported to Canada from the United States so the registration listed is N3509R. The Aspect Ratio was calculated from the measured span and

chord of the wing. The $S_{\text {ref }}$ was measured as the surface area of the wings. The dihedral angle was measured using the scale diagram of the aircraft in its $\mathrm{POH}$. The initial angles of the FDR in the aircraft were determined by setting the FDR in the aircraft and using its internal sensors to read the angles. For all tests outlined in this thesis, the FDR unit was placed in the Pelican case on the rear seat of the aircraft in order to reduce vibrations. This placement also places the FDR unit close to the center of gravity. It was determined that the $\alpha_{0}$ was $5^{\circ}$ and that the yaw ad roll angles at rest were zero. This was determined using the internal sensors of the Arduino and knowing that the angle of incidence of the wings is zero with respect to the body of the aircraft according to the $\mathrm{POH}$.

\subsubsection{First Flight Test}

The next step was in-flight testing. The first flight test was a fairly simple flight. It involved takeoff, climb, cruise, slow flight, approach and landing. While all of the parameters are recorded during the entire length of the flight, the maneuvers each have their own crucial measurements. The takeoff allows for ground acceleration measurements, and the initial 


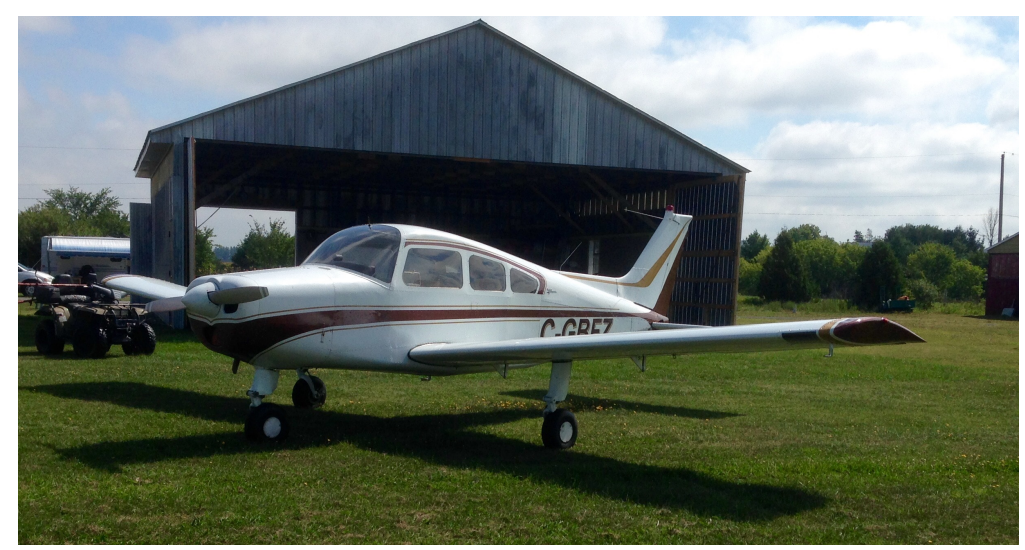

Figure 6.4: Flight Test Aircraft

Table 6.1: Beechcraft Musketeer Details

\begin{tabular}{cc}
\hline Detail & Value \\
\hline \hline Sweep Angle & 0 \\
Taper Ratio & 0 \\
$S_{\text {ref }}$ & $12.5 \mathrm{~m}^{2}$ \\
$\tau$ & 6.4 \\
Aspect Ratio (AR) & $0.163[41]$ \\
$\alpha_{L=0}$ & 0.061 radians $[43]$ \\
Roll Angle of FDR at Rest & 0 \\
Yaw Angle of FDR at Rest & 0 \\
$\alpha_{0}$ & $5^{\circ}$ \\
Empty Weight & $646 \mathrm{~kg}$ \\
Dihedral Angle & $7^{\circ}$ \\
Fuel Consumption (US gallons) & 9 Gallons per Hour \\
Fuel Consumption (kg) & 0.41 kilograms per minute \\
\hline
\end{tabular}




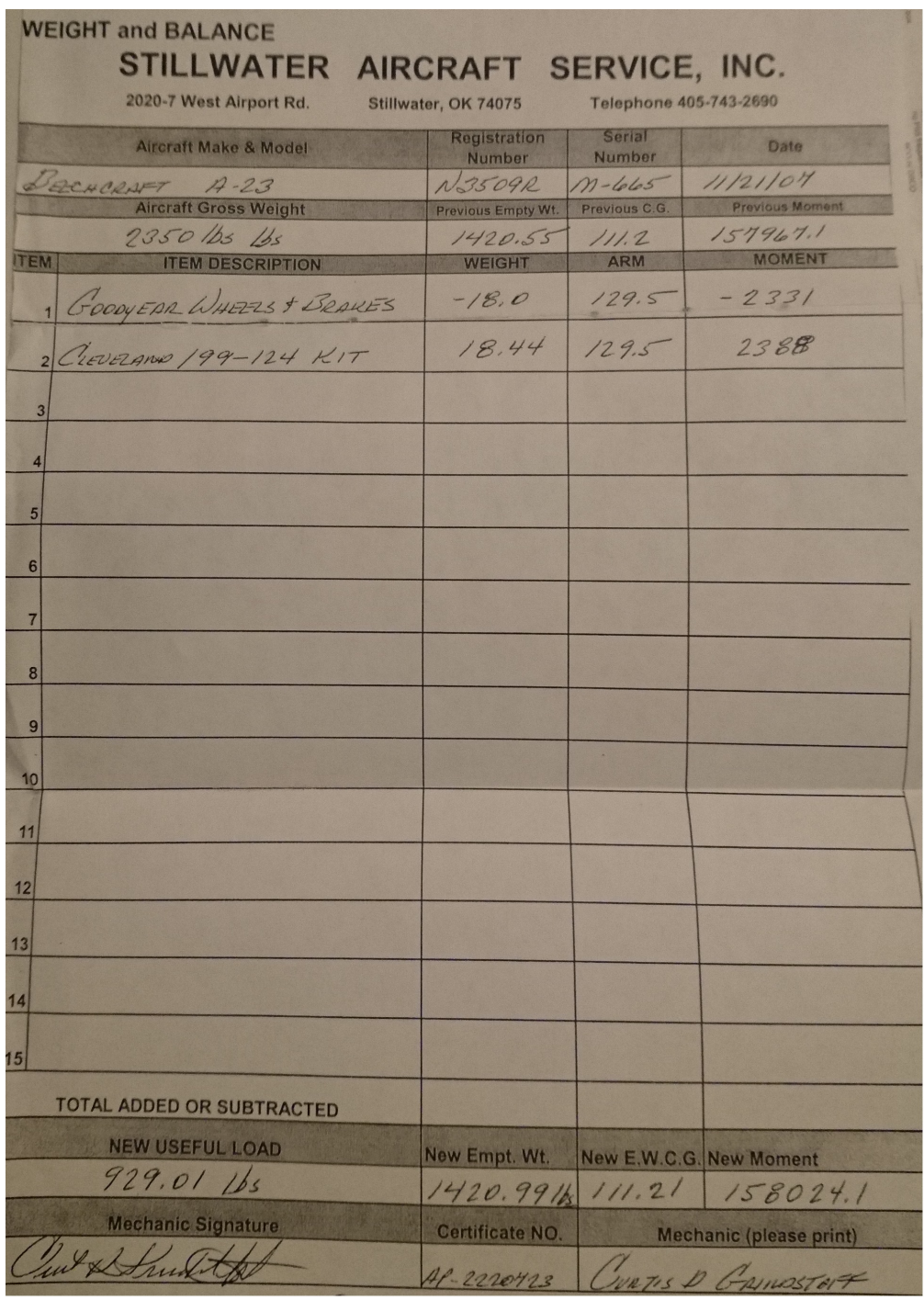

Figure 6.5: Weight and Balance of Beechcraft A-23 C-GBFZ, Formerly Known as N3509R 
climb leads to the measurement of lift and rate of climb when these parameters would normally be the greatest. Cruise is the phase of flight which most aircraft spend the majority of their time, so it is important to determine that all parameters are functioning properly during this phase. Slow flight data measures lift and angle of attack at the back side of the aircraft's power curve. During the slow-flight phase of the flight, it is expected that the equation will fail. This is because there is no compensation for the critical angle of attack in the equation and during this phase of flight a lower angle of attack yields more lift. The approach and landing is an important part of every flight and a common time for which aircraft have had accidents. During the approach and landing, it is expected that the airspeed equation will fail due to the use of flaps being necessary on the short runway. The flaps change the shape of the airfoil, the size of the airfoil, and its angle of attack and this was not taken into consideration in the equation yet. The telemetry system mentioned in the hardware section can also be used in air testing to ensure that the Arduino unit is functioning properly by having it connected to a laptop for an instant readout of parameters. The telemetry system was not used for this flight. It was a fairly standard flight involving takeoff, climb, steep turns, slow flight, circuit pattern and landing. During this flight, the APM was powered using a portable power pack meant for recharging cellphones.

\section{First Flight Test Results}

During the post-flight analysis of the first flight test, it was determined that the APM's internal memory for the dataflash log files was only 10 minutes long with the logging configuration used. The logging configuration used was the "log all while disabled" selection, which take a large amount of data for this particular piece of hardware. This is to say that the APM can only log 10 minutes worth of data at a time. The last 10 minutes of the flight were recorded, during which the approach and circuit pattern were observed. The APM unit produces a .kmz file which shows the flight path overlaid on Google Earth. Figure 6.6 is a screenshot of this .kmz file; it shows the flight path and altitude of the aircraft. The bottom of the red bar represents the geographical location of the aircraft and the top of the red bar is the relative altitude. The required parameters for the airspeed equation seemed 


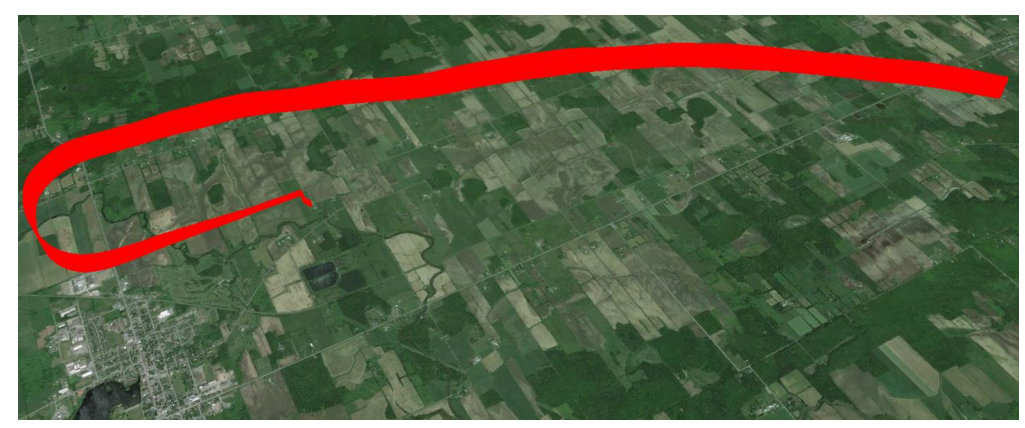

Figure 6.6: Flight Path and Altitude of the First Flight Test

to be within reasonable limits but they seemed very noisy. Figure 6.7 shows the noisy pitch data and the noisy z acceleration data depicted by the Mission Planner software. The pitch data in Figure $6.7 \mathrm{a}$ is in radians so the values on the y axis are near zero. The acceleration data in Figure 6.7b includes the force of gravity so the values on the $\mathrm{Y}$ axis of the graph are all near negative 10. A second flight test was scheduled to record the entire flight and determine if the parameters were within reasonable limits for the length of the flight. The fact that the APM could only hold 10 minutes worth of data and that the format of the dataflash logs was difficult to work with made for an easy decision to conduct the next flight test with the APM connected to a laptop computer. This connection allows for the data to be directly saved on the computer and the format in which the data is saved on the laptop is much easier to use in calculations. Due to these conclusions, the calculations were not attempted on this set of data but in stead, would be first attempted after the next flight.

\subsubsection{Second Flight Test}

The second flight test was done with the APM connected wirelessly to a laptop computer to compensate for the lack of internal memory using the telemetry system. During this flight, the APM was powered using the 12 Volt DC (Direct Current) outlet in the aircraft. This connection allowed for the APM to send the recorded information to the laptop in order to store more flight data. The same Beechcraft A-23 aircraft was used for the test and the same restrictions on flight maneuvers were applied; there were no stalls, spins, or spirals. The flight was a scenic flight, during which a photographer was to take pictures 


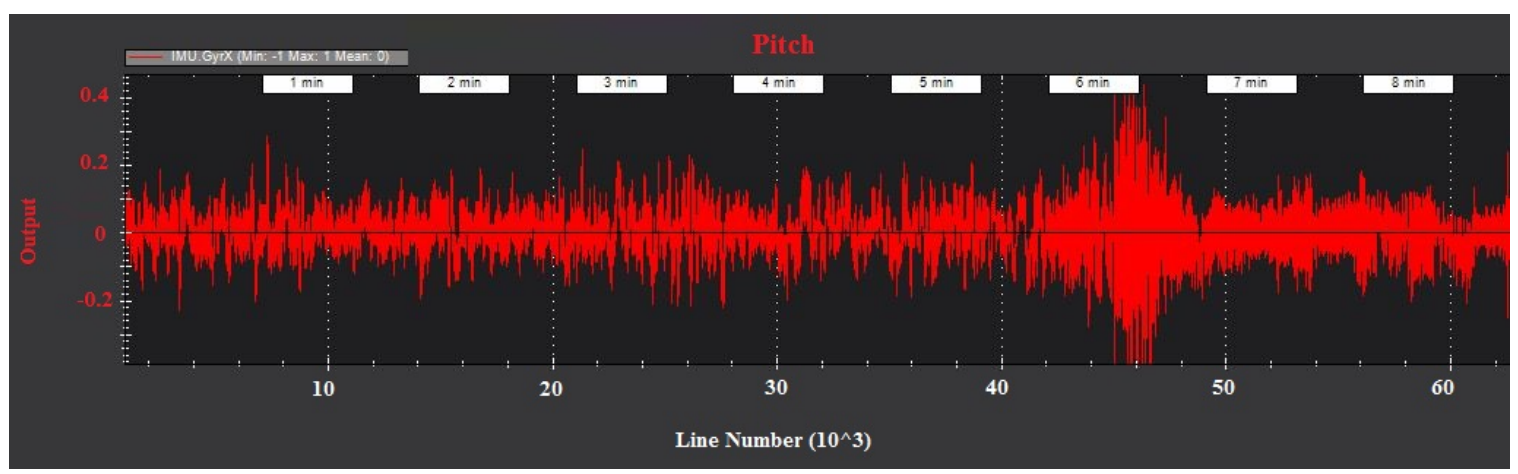

(a) Pitch Data

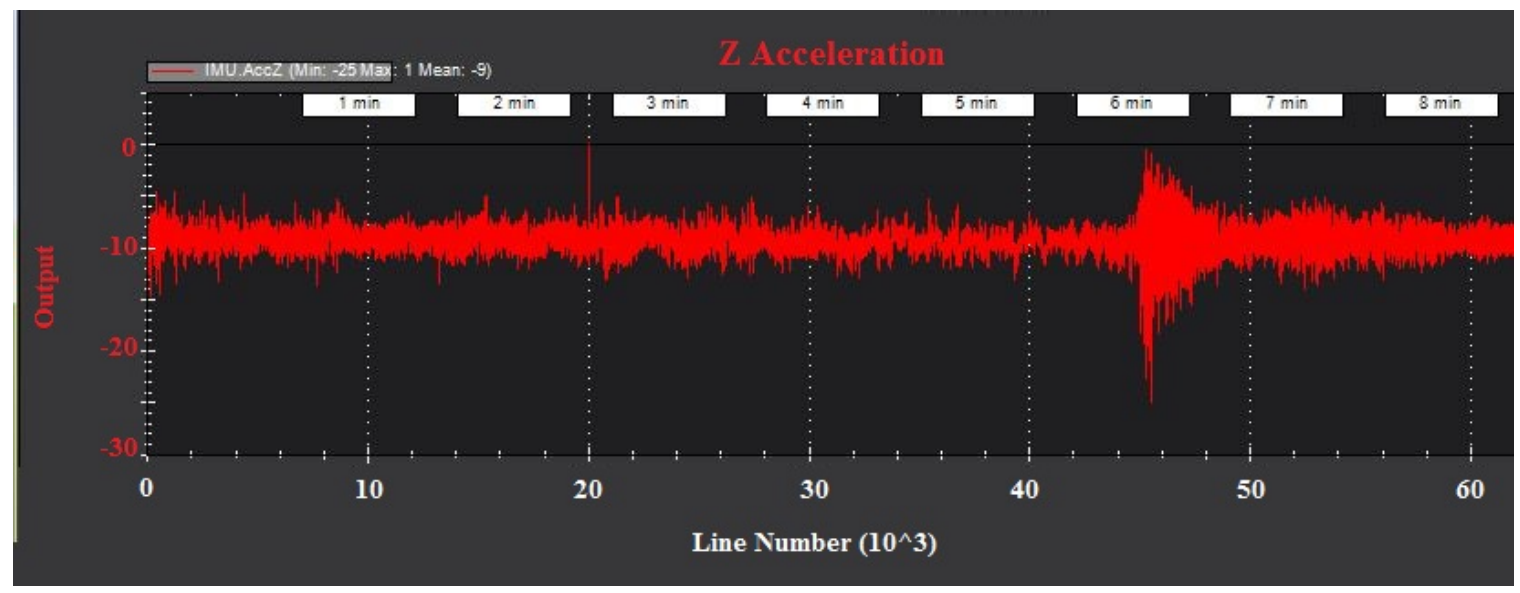

(b) z Acceleration Data

Figure 6.7: Some Noisy Data from the First Flight Test 


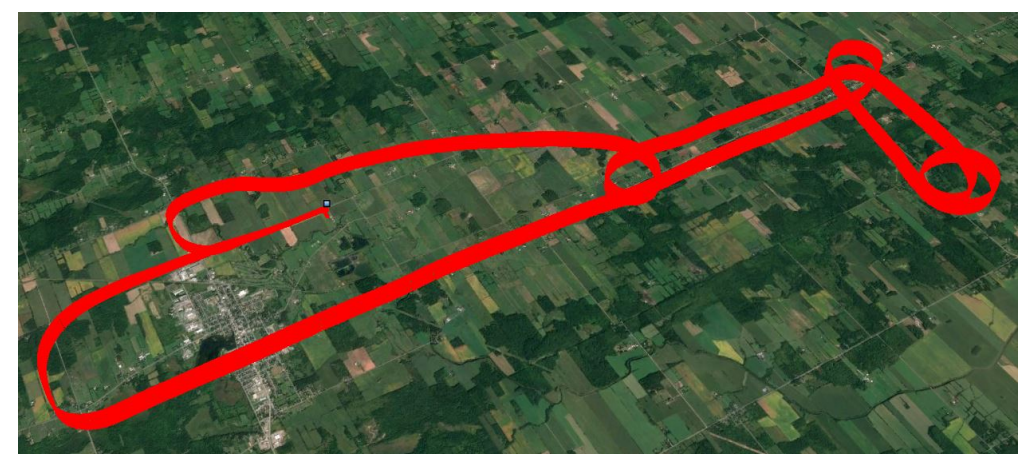

Figure 6.8: Flight Path of the Second Flight Test

of the local area; this multitasking reduced the effective cost of the flight. Since the slowflight phase of the flight was assumed to cause the airspeed equation to fail, it was omitted from this particular flight test plan in order to focus on the data points that should work with the current equation. The flight included takeoff, climb, cruise, circling around several points, approach and landing. The flight path of this flight test is shown in Figure 6.8 and the altitude of the flight was approximately 1000 feet AGL (Above Ground Level) or 1300 feet MSL (Mean Sea Level). The purpose of this test was to qualitatively determine if the airspeed equation showed values within reasonable limits of the aircraft's airspeed. The airspeed was to be calculated using Equation 5.12 and the goal was to see if the speeds calculated were within the normal flight characteristics of the aircraft.

\section{Second Flight Test Results}

The results of the second flight test showed that the parameters for the airspeed equation and the result of the airspeed equation were within reasonable limits. A few data points were taken to test the equation and they show that there is reasonable possibility of success based on the approximate airspeed of the aircraft. The approximate airspeed of the aircraft during this flight was $105 \mathrm{mph}$ or $46.9 \mathrm{~m} / \mathrm{s}$. The data points were chosen at random and spot calculations of the airspeed were performed at those data points. Table 6.2 shows the values of the variables used in a few of the calculations. The results from this test were fairly successful. The main focus of this flight test was to calculate a resulting airspeed which was within the realm of the aircraft's operating speed. The results of the airspeed 
Table 6.2: List of Variables and their Values for Several Data Points from the Second Flight Test

\begin{tabular}{ccccc}
\hline Unit & Data Line & Data Line & Data Line & Data Line \\
& 18014 & 23285 & 30464 & 34736 \\
\hline \hline$z_{a}$ & $-9.46 \mathrm{~m} / \mathrm{s}^{2}$ & $-10.55 \mathrm{~m} / \mathrm{s}^{2}$ & $-10.01 \mathrm{~m} / \mathrm{s}^{2}$ & $-8.19 \mathrm{~m} / \mathrm{s}^{2}$ \\
$\mathrm{~g}$ & $9.81 \mathrm{~m} / \mathrm{s}^{2}$ & $9.81 \mathrm{~m} / \mathrm{s}^{2}$ & $9.81 \mathrm{~m} / \mathrm{s}^{2}$ & $9.81 \mathrm{~m} / \mathrm{s}^{2}$ \\
$\alpha$ & $0.185 \mathrm{rad}$ & $0.133 \mathrm{rad}$ & $0.163 \mathrm{rad}$ & $0.121 \mathrm{rad}$ \\
$\alpha_{0}$ & $0.0872 \mathrm{rad}$ & $0.0872 \mathrm{rad}$ & $0.0872 \mathrm{rad}$ & $0.0872 \mathrm{rad}$ \\
$\mathrm{m}$ & $925.0 \mathrm{~kg}$ & $913.0 \mathrm{~kg}$ & $898.6 \mathrm{~kg}$ & $889.0 \mathrm{~kg}$ \\
$\mathrm{p}$ & $97482 \mathrm{~Pa}$ & $97957 \mathrm{~Pa}$ & $97577 \mathrm{~Pa}$ & $97637 \mathrm{~Pa}$ \\
$\mathrm{R}$ & $287 \mathrm{~J} / \mathrm{kgK}$ & $287 \mathrm{~J} / \mathrm{kgK}$ & $287 \mathrm{~J} / \mathrm{kgK}$ & $287 \mathrm{~J} / \mathrm{kgK}$ \\
$\mathrm{T}$ & $37.69{ }^{\circ} \mathrm{C}$ & $38.52{ }^{\circ} \mathrm{C}$ & $39.42{ }^{\circ} \mathrm{C}$ & $39.87{ }^{\circ} \mathrm{C}$ \\
$S_{\text {ref }}$ & $12.516 \mathrm{~m}{ }^{2}$ & $12.516 \mathrm{~m}{ }^{2}$ & $12.516 \mathrm{~m}{ }^{2}$ & $12.516 \mathrm{~m}$ \\
$\eta$ & 0.95 & 0.95 & 0.95 & 0.95 \\
$V_{\text {true }}($ Approx $)$ & $46.9 \mathrm{~m} / \mathrm{s}$ & $46.9 \mathrm{~m} / \mathrm{s}$ & $46.9 \mathrm{~m} / \mathrm{s}$ & $46.9 \mathrm{~m} / \mathrm{s}$ \\
$V_{\text {sound }}$ & $343 \mathrm{~m} / \mathrm{s}$ & $343 \mathrm{~m} / \mathrm{s}$ & $343 \mathrm{~m} / \mathrm{s}$ & $343 \mathrm{~m} / \mathrm{s}$ \\
\hline$V_{\text {true }}$ (Result) & $47.9 \mathrm{~m} / \mathrm{s}$ & $45.7 \mathrm{~m} / \mathrm{s}$ & $42.6 \mathrm{~m} / \mathrm{s}$ & $43.5 \mathrm{~m} / \mathrm{s}$ \\
$V_{\text {true }}$ (Result) & $107 \mathrm{mph}$ & $102 \mathrm{mph}$ & $95.2 \mathrm{mph}$ & $97 \mathrm{mph}$ \\
\hline
\end{tabular}

calculations at these data points were between $90 \mathrm{mph}$ and $110 \mathrm{mph}$, which is well within the aircraft's usual speeds. After the results of this test were calculated, a third flight test was scheduled while attempting to determine a low-cost method of validating the results. As opposed to th previous flight the entirety of this flight's data was recorded via telemetry logging, so the next flight will also have the microcontroller connected to the computer. The data was much more manageable in the telemetry log's format and so the work to convert the dataflash log to a more usable format was abandoned in favour of concentrating on the development of the airspeed algorithm using the telemetry logs. 


\subsubsection{Third Flight Test}

The third flight test was conducted using the Pixhawk autopilot as opposed to the APM 2.5. The Pixhawk is known to be very similar to the APM but with more accurate sensors and a higher sampling rate. This flight test was similar to the second flight test; the Pixhawk was connected to a computer so the computer could log a larger amount of data and there were no stalls, spins, or spirals during the flight test. The Pixhawk was powered by a USB cable to the computer for the length of this test. In this particular test, the airspeed was manually recorded by an observer reading the airspeed indicator to acquire airspeed data in order to validate the airspeed equation. The airspeed was recorded every 60 seconds by the observer. These observations were recorded in a spreadsheet and the values are shown in Table 6.3 along with the maneuver the aircraft was performing at the time. The airspeed was recorded in MPH before being converted to $\mathrm{m} / \mathrm{s}$. There were hardware issues at the beginning of the flight so the Pixhawk only started recording once the aircraft was airborn. There were some difficulties with the calculations due to the gusty conditions during the day of the flight test. The most recent Meteorological Terminal Aviation Routine Weather Reports (METARs) preceding the flight are shown in Figure 6.9. A METAR is a weather observation done at a particular weather station in which the winds, visibility, clouds and other meteorological conditions are observed and recorded every hour; the METARs are one of the most common weather resources used by pilots. The METAR for the Montreal airport (CYUL) and the Ottawa airport (CYOW) are both shown because the flight test took place in Alexandria, Ontario, which is half way in between the two airport weather stations. Due to the gusty conditions, this flight test yielded less than adequate results which are discussed in the next chapter.

\section{Third Flight Test Results}

The third flight test, as previously mentioned, was largely an attempt to validate the airspeed equation. At this point the yielded results with an average error of $20 \%$ when compared to the visual observations of the airspeed indicator. The parameters recorded by 
Table 6.3: Third Flight's Recorded Airspeed

\begin{tabular}{cccc}
\hline Local Time & Maneuver & Indicated Airspeed $(\mathrm{mph})$ & Indicated Airspeed $(\mathrm{m} / \mathrm{s})$ \\
\hline \hline $14: 04$ & Straight and Level Bank & 105 & 46.9 \\
$14: 05$ & $10^{\circ}$ Bank & 103 & 46.0 \\
$14: 06$ & $10^{\circ}$ & 105 & 46.9 \\
$14: 07$ & $15^{\circ}$ Bank & 104 & 46.4 \\
$14: 08$ & Straight and Level & 110 & 49.2 \\
$14: 09$ & Straight and Level & 115 & 51.4 \\
$14: 10$ & Straight and Level & 120 & 53.6 \\
$14: 11$ & $20^{\circ}$ Bank & 115 & 51.4 \\
$14: 12$ & Straight and Level & 110 & 49.2 \\
$14: 13$ & $15^{\circ}$ Bank & 110 & 49.2 \\
$14: 14$ & Straight and Level & 110 & 49.2 \\
$14: 15$ & $10^{\circ}$ Bank & 115 & 51.4 \\
$14: 16$ & Straight and Level & 100 & 44.7 \\
$14: 17$ & $20^{\circ}$ Bank & 110 & 49.2 \\
$14: 18$ & $10^{\circ}$ Bank & 110 & 49.2 \\
$14: 19$ & Descent & 120 & 53.6 \\
$14: 20$ & Descent & 125 & 55.9 \\
$14: 21$ & Climb & 100 & 44.7 \\
$14: 22$ & Climb & 100 & 44.7 \\
\hline
\end{tabular}




\begin{tabular}{|c|c|c|}
\hline $\begin{array}{l}\text { METAR CYUL } 02180 \\
\text { 400FT }=\end{array}$ & $5007 \mathrm{KT}$ 230V310 30SM BKN040 20/10 A3016 RN & U6 SLP215 DENSITY ALT \\
\hline METAR & $\begin{array}{c}\text { LOCATION } \\
\text { CYUL - MONTREAL/PIERRE-ELLIOTT-TRUDEAU } \\
\text { INT }\end{array}$ & $\begin{array}{c}\text { DATE - TIME } \\
02 \text { SEPTEMBER } 2016 \text { - } \\
1800 \text { UTC }\end{array}$ \\
\hline $\begin{array}{c}\text { WIND } \\
250 \text { TRUE @ } 7 \\
\text { KNOTS } \\
\text { VARIATION } \\
230<-310 \text { DEG }\end{array}$ & $\begin{array}{c}\text { VISIBILITY } \\
30 \text { STAT. MILES }\end{array}$ & RUNWAY VISUAL RANGE \\
\hline WEATHER & $\begin{array}{c}\text { CLOUDINESS } \\
\text { BROKEN CLOUDS }(5 / 8-7 / 8) 4000 \text { FT }\end{array}$ & $\begin{array}{l}\text { TEMP / DEWPOINT } \\
20 \mathrm{C} / 10 \mathrm{C}\end{array}$ \\
\hline $\begin{array}{l}\text { ALTIMETER } \\
30.16 \text { IN HG }\end{array}$ & $\begin{array}{ll}\text { RECENT WEATHER } \\
\end{array}$ & WIND SHEAR \\
\hline
\end{tabular}

METAR CYOW 021800Z 32012G18KT 300V030 15SM FEW040 20/09 A3021 RMK CU1 SLP233 DENSITY ALT 600FT=

\begin{tabular}{|c|c|c|}
\hline METAR & $\begin{array}{l}\text { LOCATION } \\
\text { CYOW - OTTAWA/MACDONALD-CARTIER } \\
\text { INTL/ON }\end{array}$ & $\begin{array}{c}\text { DATE - TIME } \\
02 \text { SEPTEMBER } 2016- \\
1800 \text { UTC }\end{array}$ \\
\hline $\begin{array}{c}\text { WIND } \\
320 \text { TRUE @ } 12 \\
\text { KNOTS } \\
\text { VARIATION } \\
300<->30 \text { DEG } \\
\text { GUSTS } \\
18 \text { KNOTS }\end{array}$ & $\begin{array}{c}\text { VISIBILITY } \\
15 \text { STAT. MILES }\end{array}$ & RUNWAY VISUAL RANGE \\
\hline WEATHER & $\begin{array}{c}\text { CLOUDINESS } \\
\text { FEW CLOUDS }(1 / 8-2 / 8) 4000 \text { FT }\end{array}$ & $\begin{array}{l}\text { TEMP / DEWPOINT } \\
20 \mathrm{C} / 9 \mathrm{C}\end{array}$ \\
\hline $\begin{array}{l}\text { ALTIME TER } \\
30.21 \text { IN HG }\end{array}$ & RECENT WEATHER & WIND SHEAR \\
\hline
\end{tabular}

Figure 6.9: Weather During the Third Test Flight [12] 
the FDR and the mass of the aircraft are shown in 6.4. To reduce errors attributed to vibrations, the measurements of the parameters by the Pixhawk were taken as an average over 10 seconds. These 10 secconds were essentially the time of the recorded airspeed plus or minus 5 seconds. The Pixhawk has two gyroscopes so the average of the two pitch values were used in the calculation. The Pixhawk also has two accelerometers so the average of the two z acceleration values was also used. The mass was calculated using the POH's weight and balance sheet as seen in Figure 6.10. The starting mass was calculated then the one gallon for startup, run up, taxi and takeoff were subtracted. The aircraft has a known fuel burn of 9 gallons per hour which translated to approximately 0.41 kilograms per minute. These values and rates were used to calculate the mass of the aircraft at each relevant data point of the flight.

The calculated results of the airspeed and it's error from the third flight test are shown in Table 6.5. The larger errors may be due to the gusty conditions during the day of the flight test. Gusts near the ground create turbulence and drastically change the airspeed of the aircraft and the forces acting on the aircraft. The meteorological conditions are shown in Figure 6.9. Since the wind was such a large variable in this flight, a fourth flight test was organized for a less gusty day in an attempt to determine if the error would significantly decrease under better weather conditions. It was determined after this flight test that the Pixhawk has enough internal memory to be used as a flight data recorder. It has over one hour of logging memory and it will automatically loop over itself in order to keep the most recent logs. This amount of log time is more than enough to determine the cause of most accidents.

\subsubsection{Fourth Flight Test}

This flight test was similar to the third in various ways. The Pixhawk and its GPS unit were the hardware used for this test. While the Pixhawk could easily record enough data for the length of this flight in it's dataflash log, it was connected to a laptop computer in order to generate the more convenient telemetry logs. There were, once again, no aerobatic maneuvers due to the restrictions of the aircraft. The Pixhawk was powered using a USB 
Table 6.4: The Measured Parameters of the Third Flight Test

\begin{tabular}{|c|c|c|c|c|c|c|}
\hline Time & $\begin{array}{c}\text { Pitch } \\
\text { (Radians) }\end{array}$ & $\begin{array}{c}\text { Pressure } \\
\qquad(\mathrm{Pa})\end{array}$ & $\begin{array}{l}\text { Temperature } \\
\qquad\left({ }^{\circ} C\right)\end{array}$ & $\begin{array}{l}\mathrm{Z} \text { acceleration } \\
\qquad\left(\mathrm{m} / s^{2}\right)\end{array}$ & $\begin{array}{l}\text { Mass } \\
(\mathrm{kg})\end{array}$ & $\begin{array}{l}\text { Heading } \\
\text { Degrees }\end{array}$ \\
\hline 14:04 & 0.216 & 97718 & 42.3 & -9.36 & 932.8 & 12 \\
\hline $14: 05$ & 0.380 & 97537 & 42.0 & -9.60 & 932.4 & 100 \\
\hline $14: 06$ & 0.339 & 97314 & 41.7 & -9.54 & 932.0 & 85 \\
\hline $14: 07$ & 0.217 & 97148 & 41.4 & -9.10 & 931.6 & 135 \\
\hline $14: 08$ & 0.216 & 97225 & 41.2 & -9.37 & 931.2 & 117 \\
\hline $14: 09$ & 0.187 & 97029 & 41.0 & -9.05 & 930.7 & 110 \\
\hline $14: 10$ & 0.282 & 97263 & 40.7 & -10.87 & 930.3 & 68 \\
\hline $14: 11$ & 0.252 & 97235 & 40.5 & -9.90 & 929.9 & 261 \\
\hline $14: 12$ & 0.204 & 97247 & 40.3 & -9.40 & 929.5 & 111 \\
\hline $14: 13$ & 0.169 & 97738 & 40.2 & -9.50 & 929.1 & 92 \\
\hline $14: 14$ & 0.232 & 97500 & 40.2 & -9.98 & 928.7 & 66 \\
\hline $14: 15$ & 0.215 & 97762 & 40.0 & -9.53 & 928.3 & 56 \\
\hline $14: 16$ & 0.306 & 97466 & 39.9 & -10.10 & 927.9 & 32 \\
\hline $14: 17$ & 0.154 & 96967 & 39.8 & -9.38 & 927.5 & 105 \\
\hline $14: 18$ & 0.182 & 96865 & 39.7 & -9.39 & 927.1 & 108 \\
\hline $14: 19$ & 0.153 & 97369 & 39.6 & -9.66 & 926.7 & 102 \\
\hline $14: 20$ & 0.126 & 99433 & 39.5 & -9.62 & 926.2 & 230 \\
\hline $14: 21$ & 0.292 & 99464 & 39.5 & -9.46 & 925.8 & 62 \\
\hline $14: 22$ & 0.219 & 98274 & 39.6 & -9.38 & 925.4 & 302 \\
\hline
\end{tabular}




\section{BEECHCRAFT}

Musketeer A23, A23A

Section VI

Wt and Bal/Equip List

WEIGHT AND BALANCE LOADING FORM

MODEL $\frac{\text { A23A }}{\text { SERIAL NO. C-GBFZ }}$ REG NO. NXXX

\begin{tabular}{|l|l|l|}
\hline \multicolumn{1}{|c|}{ ITEM } & WEIGHT & MOM/100 \\
\hline 1. BASIC EMPTY CONDITION & $\mathbf{1 4 2 0 . 9 9}$ & $\mathbf{1 5 8 0}$ \\
\hline 2. FRONT SEAT OCCUPANTS & $\mathbf{2 2 0}$ & $\mathbf{2 4 2}$ \\
\hline 3. 3rd \& 4th SEAT OCCUPANTS & $\mathbf{1 5 0}$ & $\mathbf{2 1 3}$ \\
\hline 4. BAGGAGE OR CARGO & $\mathbf{3 0}$ & $\mathbf{5 0}$ \\
\hline $\begin{array}{l}\text { 5. SUB TOTAL } \\
\text { ZERO FUEL CONDITION }\end{array}$ & $\mathbf{1 8 2 0 . 9 9}$ & $\mathbf{2 0 8 5}$ \\
\hline 6. FUEL LOADING (41GAL) & $\mathbf{2 4 6}$ & $\mathbf{2 8 8}$ \\
\hline $\begin{array}{l}\text { 7. SUB TOTAL } \\
\text { RAMP CONDITION }\end{array}$ & $\mathbf{2 0 6 7}$ & $\mathbf{2 3 7 3}$ \\
\hline $\begin{array}{l}\text { 8. *LESS FUEL FOR START, } \\
\text { TAXI, AND TAKE-OFF }\end{array}$ & $\mathbf{6}$ & $\mathbf{7}$ \\
\hline $\begin{array}{l}\text { 9. SUB TOTAL } \\
\text { TAKE-OFF CONDITION }\end{array}$ & $\mathbf{2 0 6 1}$ & $\mathbf{2 3 6 6}$ \\
\hline $\begin{array}{l}\text { 10. LESS FUEL TO } \\
\text { DESTINATION ( GAL) }\end{array}$ & $\mathbf{2 5}$ & $\mathbf{2 9}$ \\
\hline 11. LANDING CONDITION & $\mathbf{2 0 3 6}$ & $\mathbf{2 3 3 7}$ \\
\hline
\end{tabular}

* Fuel for start, taxi and take-off is normally $5 \mathrm{lbs}$ at an average $\mathrm{mom} / 100$ of 6 .

Figure 6.10: The Weight and Balance of the Aircraft for the Third Flight Test 
Table 6.5: Calculated Results of the Third Flight Test

\begin{tabular}{|c|c|c|c|c|c|}
\hline \multirow[t]{2}{*}{ Time } & TAS $(\mathrm{m} / \mathrm{s})$ & TAS $(\mathrm{m} / \mathrm{s})$ & Error (\%) & TAS (m/s) & Error (\%) \\
\hline & Observed & Algorithm & Algorithm & GS Method & GS Method \\
\hline $14: 04$ & 48.03 & 45.45 & 5.38 & 41.50 & 13.61 \\
\hline $14: 05$ & 47.16 & 35.92 & 23.84 & 42.11 & 10.71 \\
\hline $14: 06$ & 48.13 & 37.79 & 21.48 & 55.91 & -16.16 \\
\hline $14: 07$ & 47.72 & 45.10 & 5.47 & 54.59 & -14.40 \\
\hline $14: 08$ & 50.45 & 45.46 & 9.89 & 58.32 & -15.60 \\
\hline $14: 09$ & 52.80 & 47.73 & 9.60 & 59.70 & -13.08 \\
\hline $14: 10$ & 55.02 & 42.29 & 23.15 & 55.56 & -0.98 \\
\hline $14: 11$ & 52.74 & 43.22 & 18.05 & 48.04 & 8.91 \\
\hline $14: 12$ & 50.44 & 46.44 & 7.93 & 54.08 & -7.20 \\
\hline $14: 13$ & 50.32 & 49.89 & 0.85 & 57.16 & -13.60 \\
\hline $14: 14$ & 50.38 & 44.69 & 11.29 & 52.85 & -4.90 \\
\hline $14: 15$ & 52.60 & 45.46 & 13.58 & 52.05 & 1.03 \\
\hline $14: 16$ & 45.81 & 39.91 & 12.87 & 46.33 & -1.14 \\
\hline $14: 17$ & 50.52 & 51.53 & -2.00 & 46.02 & -10.89 \\
\hline $14: 18$ & 50.54 & 48.47 & 4.10 & 51.41 & -1.72 \\
\hline $14: 19$ & 54.99 & 51.86 & 5.71 & 60.28 & -9.61 \\
\hline $14: 20$ & 56.69 & 54.95 & 3.07 & 50.29 & 11.64 \\
\hline $14: 21$ & 45.34 & 39.56 & 12.76 & 52.06 & -14.81 \\
\hline $14: 22$ & 45.62 & 44.70 & 2.00 & 41.33 & 9.39 \\
\hline Averages & 50.17 & 45.28 & 9.95 & 52.07 & -3.62 \\
\hline Absolute Averages & 50.17 & 45.28 & 10.16 & 52.07 & 9.44 \\
\hline
\end{tabular}




\begin{tabular}{|c|c|c|}
\hline \multicolumn{3}{|c|}{ METAR CYUL 151700Z 02008KT 15SM SCT160 BKN200 09/04 A2997 RMK AC4CI3 SLP150= } \\
\hline METAR & $\begin{array}{c}\text { LOCATION } \\
\text { CYUL - MONTREAL/PIERRE-ELLIOTT-TRUDEAU } \\
\text { INT }\end{array}$ & $\begin{array}{c}\text { DATE - TIME } \\
15 \text { NOVEMBER } 2016 \text { - } \\
1700 \text { UTC }\end{array}$ \\
\hline $\begin{array}{l}\text { WIND } \\
20 \text { TRUE @ } 8 \\
\text { KNOTS }\end{array}$ & $\begin{array}{c}\text { VISIBILITY } \\
\text { 15 STAT. MILES }\end{array}$ & RUNWAY VISUAL RANGE \\
\hline WEATHER & $\begin{array}{c}\text { CLOUDINESS } \\
\text { SCATTERED CLOUDS }(3 / 8-4 / 8) 16000 \mathrm{FT} \\
\text { BROKEN CLOUDS }(5 / 8-7 / 8) 20000 \mathrm{FT}\end{array}$ & $\begin{array}{l}\text { TEMP / DEWPOINT } \\
9 \mathrm{C} / 4 \mathrm{C}\end{array}$ \\
\hline $\begin{array}{l}\text { ALTIMETER } \\
29.97 \text { IN HG }\end{array}$ & RECENT WEATHER & WIND SHEAR \\
\hline
\end{tabular}

\begin{tabular}{|c|c|c|}
\hline \multicolumn{3}{|c|}{ METAR CYOW $151700 Z$ 08005KT 15SM FEW180 FEW220 BKN240 10/04 A2994 RMK AC1Cl1Cl3 SLP143= } \\
\hline METAR & $\begin{array}{c}\text { LOCATION } \\
\text { CYOW - OTTAWA/MACDONALD-CARTIER } \\
\text { INTL/ON }\end{array}$ & $\begin{array}{c}\text { DATE - TIME } \\
15 \text { NOVEMBER } 2016- \\
1700 \text { UTC }\end{array}$ \\
\hline $\begin{array}{l}\text { WIND } \\
80 \text { TRUE @ } 5 \\
\text { KNOTS }\end{array}$ & $\begin{array}{c}\text { VISIBILITY } \\
15 \text { STAT. MILES }\end{array}$ & RUNWAY VISUAL RANGE \\
\hline WEATHER & $\begin{array}{c}\text { CLOUDINESS } \\
\text { FEW CLOUDS }(1 / 8-2 / 8) 18000 \mathrm{FT} \\
\text { FEW CLOUDS }(1 / 8-2 / 8) 22000 \mathrm{FT} \\
\text { BROKEN CLOUDS }(5 / 8-7 / 8) 24000 \mathrm{FT}\end{array}$ & $\begin{array}{l}\text { TEMP / DEWPOINT } \\
10 \mathrm{C} / 4 \mathrm{C}\end{array}$ \\
\hline $\begin{array}{l}\text { ALTIMETER } \\
29.94 \text { IN HG }\end{array}$ & RECENT WEATHER & WIND SHEAR \\
\hline
\end{tabular}

Figure 6.11: Weather During the Fourth Test Flight [12]

cable and the laptop during this flight. The airspeed was again manually recorded by an observer reading the airspeed indicator every 60 seconds for validation of the airspeed equation post-flight. The observations were recorded in a spreadsheet and Table 6.6 shows the observed airspeed in $\mathrm{mph}$ and its conversion to $\mathrm{m} / \mathrm{s}$ as well as the maneuver being performed by the aircraft at that time. Due to the takeoff procedure requiring flaps, the relevant data only begins once the flaps are raise. This is once again due to the flaps changing the shape, size and angle of attack of the wing. The day of the flight was chosen based on the lack of gusts or wind variation. The wind conditions described by the METARs preceding the flight are shown in Figure 6.11. The flight was once again a standard sightseeing flight at 1000 feet AGL or 1300 feet MSL.

\section{Fourth Flight Test Results}

The fourth flight test was fairly successful and as such it was the final flight test. The parameters measured by the Pixhawk and the weight of the aircraft are shown in Table 6.7.

Once again, the measured parameters from the Pixhawk were averaged over 10 seconds, 
Table 6.6: Fourth Flight's Recorded Airspeed

\begin{tabular}{|c|c|c|c|}
\hline Local Time & Maneuver & Indicated Airspeed (mph) & Indicated Airspeed $(\mathrm{m} / \mathrm{s})$ \\
\hline $12: 35$ & Climb & 90 & 40.23 \\
\hline $12: 36$ & Climb & 102 & 46.11 \\
\hline $12: 37$ & Straight and Level & 115 & 51.41 \\
\hline $12: 38$ & Straight and Level & 125 & 55.88 \\
\hline $12: 39$ & Straight and Level & 120 & 53.64 \\
\hline $12: 40$ & Straight and Level & 110 & 49.17 \\
\hline $12: 41$ & Straight and Level & 110 & 49.17 \\
\hline $12: 42$ & Straight and Level & 105 & 46.94 \\
\hline $12: 43$ & Straight and Level & 111 & 49.62 \\
\hline $12: 44$ & Straight and Level & 115 & 51.41 \\
\hline $12: 45$ & Straight and Level & 114 & 50.96 \\
\hline $12: 46$ & $5^{o}$ Bank & 110 & 49.17 \\
\hline $12: 47$ & $5^{o}$ Bank & 109 & 48.73 \\
\hline $12: 48$ & Straight and Level & 107 & 47.83 \\
\hline $12: 49$ & $10^{\circ}$ Bank & 110 & 49.17 \\
\hline $12: 50$ & Straight and Level & 111 & 49.62 \\
\hline $12: 51$ & $20^{\circ}$ Bank & 105 & 46.94 \\
\hline $12: 52$ & Straight and Level & 107 & 47.83 \\
\hline $12: 53$ & Straight and Level & 104 & 46.49 \\
\hline $12: 54$ & $5^{\circ}$ Bank & 106 & 47.39 \\
\hline
\end{tabular}


the two accelerometers were averaged for the $\mathrm{z}$ acceleration value and the two gyroscopes were averaged for the pitch value. Table 6.7 is mostly similar to the table for the previous flight test's parameters except for the constant temperature. During this flight test, it was determined that the temperature indicator of the Pixhawk unit was reading significantly higher than the temperature of the aircraft's cockpit. This error could be due to the Pixhawk giving off excess heat or the unit being in the sunlight on a black rubber pad. For the purposes of this test's calculations, the METAR temperature in Figure 6.9 was used after adjusting for the altitude with an assumed adiabatic lapse rate of $-2{ }^{\circ} \mathrm{C} / 1000$ '. This lapse rate is the average temperature change per altitude ascended. Basically, the temperature decreases $1^{\circ} \mathrm{C}$ for each 500 feet of elevation climbed. Since the METAR showed the observed temperature to be 10 degrees and the flight took place at 1000 feet AGL, the temperature was assumed to be $8^{\circ}$ Celsius. The pitch is still an average taken from the two gyroscopes and the $\mathrm{z}$ acceleration is still an average taken from the two accelerometers. The mass of the aircraft was calculated the same way as before by using the POH's weight and balance sheet shown in Figure 6.12.

The results of the airspeed calculations and their errors are shown in Figure 6.8. The average error of the calculated true airspeed was approximately $4.5 \%$ and the average absolute error was approximately $5.5 \%$ when compared to the true airspeed derived from the observations. These errors could be attributed to various factors such as accuracy of the observer, accuracy of the airspeed indicator, assumptions made with the algorithm, or errors made when measuring the aircraft information. 
Table 6.7: The Measured Parameters of the Fourth Flight Test

\begin{tabular}{|c|c|c|c|c|c|c|}
\hline Time & $\begin{array}{c}\text { Pitch } \\
\text { (Radians) }\end{array}$ & $\begin{array}{c}\text { Pressure } \\
(\mathrm{Pa})\end{array}$ & $\begin{array}{l}\text { Temperature } \\
\qquad\left({ }^{o} C\right)\end{array}$ & $\begin{array}{c}\mathrm{Z} \text { acceleration } \\
\left(\mathrm{m} / \mathrm{s}^{2}\right)\end{array}$ & $\begin{array}{l}\text { Mass } \\
(\mathrm{kg})\end{array}$ & $\begin{array}{l}\text { Heading } \\
\text { Degrees }\end{array}$ \\
\hline $12: 35$ & 0.230 & 97191 & 8 & -9.47 & 949.1 & 276 \\
\hline $12: 36$ & 0.221 & 96621 & 8 & -9.68 & 948.7 & 273 \\
\hline $12: 37$ & 0.145 & 97258 & 8 & -9.44 & 948.3 & 258 \\
\hline $12: 38$ & 0.162 & 98095 & 8 & -10.13 & 947.9 & 149 \\
\hline $12: 39$ & 0.162 & 97977 & 8 & -9.76 & 947.5 & 319 \\
\hline $12: 40$ & 0.188 & 97354 & 8 & -9.82 & 947.1 & 248 \\
\hline $12: 41$ & 0.189 & 96769 & 8 & -9.70 & 946.7 & 278 \\
\hline $12: 42$ & 0.187 & 96433 & 8 & -9.56 & 946.3 & 284 \\
\hline $12: 43$ & 0.188 & 96161 & 8 & -9.63 & 945.9 & 298 \\
\hline $12: 44$ & 0.171 & 96086 & 8 & -9.45 & 945.5 & 274 \\
\hline $12: 45$ & 0.170 & 96397 & 8 & -9.78 & 945.0 & 230 \\
\hline $12: 46$ & 0.161 & 96440 & 8 & -9.35 & 944.6 & 106 \\
\hline $12: 47$ & 0.175 & 96705 & 8 & -9.52 & 944.2 & 240 \\
\hline $12: 48$ & 0.179 & 96946 & 8 & -9.69 & 943.8 & 197 \\
\hline $12: 49$ & 0.245 & 97221 & 8 & -10.25 & 943.4 & 138 \\
\hline $12: 50$ & 0.173 & 97058 & 8 & -9.82 & 943.0 & 47 \\
\hline $12: 51$ & 0.154 & 97012 & 8 & -9.63 & 942.6 & 271 \\
\hline $12: 52$ & 0.178 & 97004 & 8 & -9.44 & 942.2 & 78 \\
\hline $12: 53$ & 0.166 & 97165 & 8 & -9.50 & 941.8 & 76 \\
\hline $12: 54$ & 0.166 & 97165 & 8 & -9.50 & 941.4 & 76 \\
\hline
\end{tabular}




\section{BEECHCRAFT}

Musketeer A23, A23A

Section VI

Wt and Bal/Equip List

WEIGHT AND BALANCE LOADING FORM

MODEL A23A DATE 2016-11-15

SERIAL NO. C-GBFZ REG NO. NXXX

\begin{tabular}{|l|c|c|}
\hline ITEM & WEIGHT & MOM/100 \\
\hline 1. BASIC EMPTY CONDITION & $\mathbf{1 4 2 0 . 9 9}$ & $\mathbf{1 5 8 0}$ \\
\hline 2. FRONT SEAT OCCUPANTS & $\mathbf{2 2 0}$ & $\mathbf{2 4 2}$ \\
\hline 3. 3rd \& 4th SEAT OCCUPANTS & $\mathbf{1 5 0}$ & $\mathbf{2 1 3}$ \\
\hline 4. BAGGAGE OR CARGO & $\mathbf{3 0}$ & $\mathbf{5 0}$ \\
\hline $\begin{array}{l}\text { 5. SUB TOTAL } \\
\text { ZERO FUEL CONDITION }\end{array}$ & $\mathbf{1 8 2 1}$ & $\mathbf{2 0 8 5}$ \\
\hline 6. FUEL LOADING ( GAL) & $\mathbf{3 7 3}$ & $\mathbf{4 3 6}$ \\
\hline $\begin{array}{l}\text { 7. SUB TOTAL } \\
\text { RAMP CONDITION }\end{array}$ & $\mathbf{2 1 9 4}$ & $\mathbf{2 5 2 1}$ \\
\hline $\begin{array}{l}\text { 8. *LESS FUEL FOR START, } \\
\text { TAXI, AND TAKE-OFF }\end{array}$ & 6 & 7 \\
\hline $\begin{array}{l}\text { 9. SUB TOTAL } \\
\text { TAKE-OFF CONDITION }\end{array}$ & $\mathbf{2 1 8 8}$ & $\mathbf{2 5 1 4}$ \\
\hline $\begin{array}{l}\text { 10. LESS FUEL TO } \\
\text { DESTINATION ( GAL) }\end{array}$ & 17 & $\mathbf{2 0}$ \\
\hline 11. LANDING CONDITION & $\mathbf{2 1 7 1}$ & $\mathbf{2 4 9 4}$ \\
\hline
\end{tabular}

*Fuel for start, taxi and take-off is normally $5 \mathrm{lbs}$ at an average $\mathrm{mom} / 100$ of 6 .

Figure 6.12: The Weight and Balance of the Aircraft for the Fourth Flight Test 
Table 6.8: Calculated Results of the Fourth Flight Test

\begin{tabular}{|c|c|c|c|c|c|}
\hline \multirow[t]{2}{*}{ Time } & TAS $(\mathrm{m} / \mathrm{s})$ & TAS $(\mathrm{m} / \mathrm{s})$ & Error (\%) & TAS $(\mathrm{m} / \mathrm{s})$ & Error (\%) \\
\hline & Observed & Algorithm & Algorithm & GS method & GS method \\
\hline $12: 35$ & 40.57 & 42.46 & -4.67 & No Data & $\mathrm{N} / \mathrm{A}$ \\
\hline $12: 36$ & 46.11 & 43.52 & 5.62 & 47.40 & -2.80 \\
\hline $12: 37$ & 51.82 & 50.48 & 2.58 & 48.44 & 6.53 \\
\hline $12: 38$ & 56.08 & 49.12 & 12.41 & 54.62 & 2.60 \\
\hline $12: 39$ & 53.87 & 48.76 & 9.48 & 51.21 & 4.95 \\
\hline $12: 40$ & 49.54 & 46.25 & 6.65 & 55.00 & -11.02 \\
\hline $12: 41$ & 49.69 & 46.17 & 7.09 & 52.03 & -4.71 \\
\hline $12: 42$ & 47.51 & 46.25 & 2.65 & 52.97 & -11.47 \\
\hline $12: 43$ & 50.30 & 46.27 & 8.01 & 52.78 & -4.93 \\
\hline $12: 44$ & 52.13 & 47.79 & 8.32 & 55.86 & -7.16 \\
\hline $12: 45$ & 51.60 & 48.18 & 6.63 & 54.26 & -5.16 \\
\hline $12: 46$ & 49.78 & 48.64 & 2.28 & 45.71 & 8.16 \\
\hline $12: 47$ & 49.26 & 47.31 & 3.95 & 52.79 & -7.18 \\
\hline $12: 48$ & 48.29 & 47.01 & 2.66 & 54.18 & -12.19 \\
\hline $12: 49$ & 49.58 & 42.04 & 15.19 & 52.14 & -5.17 \\
\hline $12: 50$ & 50.07 & 47.72 & 4.68 & 42.81 & 14.50 \\
\hline $12: 51$ & 47.37 & 49.57 & -4.63 & 50.90 & -7.45 \\
\hline $12: 52$ & 48.28 & 46.79 & 3.08 & 43.09 & 10.73 \\
\hline $12: 53$ & 26.88 & 47.99 & -2.37 & 42.06 & 10.30 \\
\hline $12: 54$ & 47.79 & 47.98 & -0.41 & 41.64 & 12.87 \\
\hline Averages & 49.82 & 47.02 & 4.46 & 49.99 & -0.45 \\
\hline Absolute Averages & 49.82 & 47.02 & 5.67 & 49.99 & 7.89 \\
\hline
\end{tabular}




\section{Chapter 7}

\section{Conclusion and Future Work}

\subsection{Conclusion}

An algorithm was created to determine airspeed using non-invasive method using a Pixhawk autopilot system. The Pixhawk has several internal sensors which allow it to measure accelerations, angles, pressure and temperature. There is also an external GPS antenna which can be connected to the Pixhawk to give it position and grounspeed data. These particular pieces of hardware were use based on their low cost and high availability. In an attempt to avoid the expenses of modifying aircraft and obtaining government approval, the airspeed was determined computationally using other recorded parameters and stability derivatives. This made the FDR unit a non-invasive alternative to large and costly traditional FDRs.

There have previously not been any FDRs available to general aviation. This is primarily due to their expense and the difficulty of determining airspeed without taping into the pitotstatic system or relying on inaccurate forecasts of atmospheric conditions aloft. There have been several attempts to create a GA FDR in the recent past. Most of these previous attempts have relied on using the forcasted winds aloft in combination with groudspeed to determine the airspeed. Some other attempts at GA FDRs have had invasive modifications to the aircraft. These modifications require a long and expensive paper trail before the aircraft can be used with a normal certification.

In the past, large associations such as the Canadian Owners and Pilots Association have heavily resisted and opposed new mandatory equipment legislations in the country. This 
is primarily due to the cost and time required when implementing hardware changes to an aircraft. These large associations may be more likely to accept a mandatory FDR with such a low cost like the one outlined in this thesis. What may make it even more attractive to these large groups of pilots is the ability to install it themselves thereby reducing the costs even more.

The Ardu-Pilot can be powered in a variety of ways. The APM was powered using a small battery pack during the first flight test. This small battery pack is typically used to recharge cellphones but it has been shown to power the APM for an excess of twelve hours. In the second flight test, the APM was powered via USB cable to the aircraft's 12 Volt cigarette outlet using a USB to 12 Volt adaptor. This method of powering an FDR is attractive due to the fact that it is always and only on if the aircraft has electrical power. The battery pack would have to be connected and disconnected for each flight, whereas, if the APM was powered via the aircraft's power outlet, it would simply power down when the electrical master switch is turned off. The drawback to powering it in such a way would mean that if the aircraft were to lose electrical power in-flight, the FDR would stop recording.

The FDR outlined in this thesis has gone through several air tests and the airspeed algorithm has proven capable of calculating airspeed during normal flight operations. There was significantly larger error margins on the computationally derived airspeed when the FDR was flown in gusty wind conditions with turbulence. The error margins in the adverse weather averaged to approximately $10 \%$. These poor weather conditions were particularly difficult to work with as the winds were gusting and changing directions. The FDR was taken on a flight test where the weather conditions which involved only very light turbulence and no gusting winds. During the test on the day with the better weather, the errors averaged to approximately $5 \%$. This result shows that the airspeed algorithm is fairly accurate under the tested conditions. The errors demonstrate that the calculations are typically accurate when the aircraft is in cruise, turning, climbing or descending. Further study is required to determine the results of the airspeed algorithm in unsual attitudes.

The Airspeed algorithm and it's errors were compared to the method of determining 
airspeed using the recorded grounspeed of the aircraft and the observed windspeed on the ground. The groundspeed method showed similar error margin in both cases. However, the weather observations used for the groundspeed method were observed ground winds as opposed to upper wind data. The reason that observed ground winds were used is due to the altitude of the aircraft. These wind measurements are much more frequent and accurate than the upper wind data which would be required for nay aircraft flying at an altitude over 3000 feet. This means that if the aircraft was flying at a higher altitude, the errors on the groundspeed method would increase.

\section{2 $\quad$ Future Work}

The future work section outlines additional effort which could be performed with respect to the testing, validation, hardware modifications and additions to the equation.

\subsubsection{Further Testing}

There are several steps to be taken to validate the algorithm further. Most importantly, the FDR unit must be taken on other aircrafts to prove its functionality and versatility. This would have been done but due to hardware difficulties and the constant reforming of the aircraft, the time constraints became an issue. The tests on other aircraft should be done on different types of aircraft that are used in the GA sector, particularly twin engine aircraft and high-wing aircraft. If the airspeed equation proved accurate on different types of aircraft in the GA sector, it would show that the equation is versatile and capable of being used for the majority of GA aircraft. Another good method to improve the validation

of the FDR unit could be to use on an aircraft with a pre-existing FDR equipped. If the airspeed algorithm was compared to a direct airspeed measurement output from a different FDR already equipped on an aircraft, many more data points could be examined in a single flight. This would lead to a more thorough validation of the algorithm and increase the confidence that it functions properly.

The airspeed algorithm needs to be tested with unusual flight maneuvers such as stalls, 
spins and spirals. Stall, spins and spirals are frequent causes of aircraft accidents and it would be very useful to investigators if they could confirm that the aircraft was in such an attitude. The airspeed algorithm in its current form may not be able to accurately calculate the airspeed in a stall configuration, the reason for this is that the algorithm has no information on critical angle of attack. The critical angle of attack is when the angle is so great that the flow of the air over the wing becomes turbulent and the wing no longer produces lift. A slow-flight configuration is the same effect but to a lesser extent over a more prolonged period of time. It is suspected that the algorithm would not be able to determine the airspeed in this configuration either. A Spin is when one wing of the aircraft is more stalled than the other, this creates a corkscrew pattern but the airspeed is also near zero. A spin is known to be one of the more difficult attitudes to recover from, for this reason it is a common situation leading up to an accident. A spiral is a simpler manuver, it is when an aircraft is in a steep turn and there is not enough elevator input to maintain lift, causing the nose of the aircraft to lower and the aircraft then gains a large increase in airspeed. All of these flight configurations are easily detectable with the other sensors onboard the Pixhawk but if the specific airspeed was known, it could help the accident investigators know more about the events leading up to collision with the ground.

Taking the FDR at a higher altitude to compare the error between the airspeed algorithm and the GS method would be another good test for the future. This would allow for a direct comparison between the two methods. Such a test would be fairly simple to implement and would solidify the reasoning behind such an algorithm's existence. The higher altitude would also keep the aircraft away from the mechanical turbulence which may or may not have caused error differences in the algorithm's output.

\subsubsection{Hardware Considerations}

Calibration of the Ardu-pilot system could be performed in order to determine the inaccuracies of its internal sensors. The calibration would be done using equipment with known and small uncertainties. The calibration tests would include locating any drift over time or whether the innacuracies of the Ardu-Pilot change every time it is powered up. The 
calibration process would generate a better understanding of the errors associated with the measurement instruments and allow for error-bars to be placed on the data.

Since there was a temperature sensor malfunction on the Pixhawk, it would be wise to have an external thermometer used to determine the temperature. This external sensor could easily be placed in a part of the aircraft which would be less likely to be within the effective operating range of the climate control such as the luggage compartment or the tail section if it's accessible. A location in the aircraft that is not the cockpit would have a smaller temperature difference with the outside air. These temperature sensors are inexpensive and a quick search on the internet can locate several of them for under $\$ 20$.

\subsubsection{Additions to the Equation}

With more research it would be possible to include airspeed data when the flaps are used. Flaps are used for short field takeoff and are use for most approaches and landings. A typical GA pilot, if their aircraft is equipped with flaps, will have the flaps extended for a short portion of every flight. Flaps change the camber, or curvature, of the airfoil as well as it's angle of attack. The effect of flaps on the camber and angle of attack of an airfoil is shown in Figure 7.1. An airfoil with extended flaps could would have different lift characteristics which would need to be applied when the flaps are extended. The largest issue with attempting to determine flap position with the current type of recorder is determining when the flaps are extended. This determination of flap position would be difficult because sensors cannot be placed on the flight controls without approval. The only other way to determine flap position is with visual cues such as position of the flap extension handle, a flap position indicator or simply looking at the flaps. It could be possible to use a camera with one of these visual cues and process the video for the flap information. This process would be similar to what the Research Professor's group did previously [16]. The issue with this kind of approach is that pilots have always argued against video recordings of the cockpit and many of them will refuse to have it.

The primary test in which the airspeed algorithm was computed involved using the telemetry logs because the data from those logs were easier to manipulate than the dataflash 


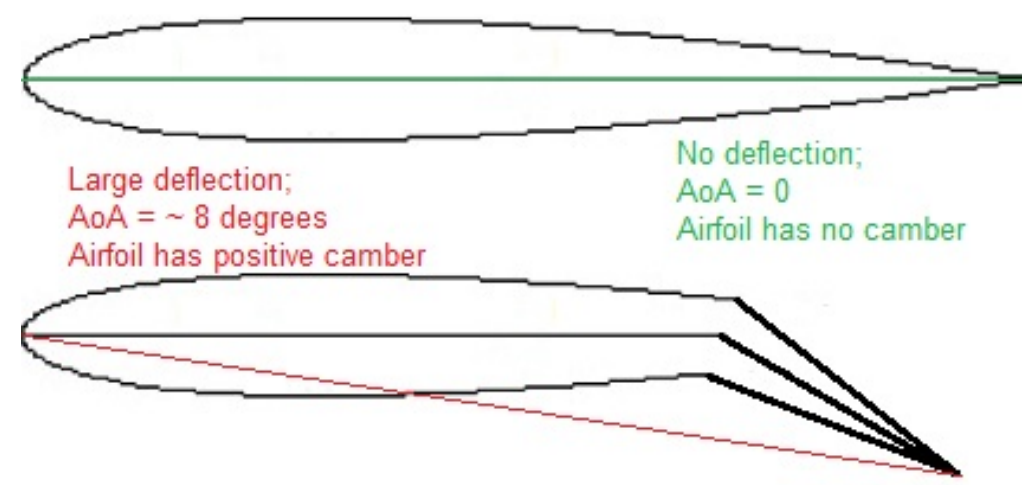

Figure 7.1: The Effect of Flaps on an Airfoil [44]

logs. The telemetry logs involve the FDR unit to be connected to a computer or tablet, while the dataflash logs are simply internal. There is no particular difference between the two types of logs other than formatting; they hold the same information. Work that could be done in the future is writing an algorithm to easily access the dataflash log information in a more accessible format. If the Pixhawk were to be used as an FDR, the dataflash logs would be the logs available. The dataflash logs are workable, it's just tedious to get all of the necessary information out of them to calculate airspeed.

Once there is a way to implement the airspeed algorithm using the dataflash logs, the Pixhawk could be programmed to compute the airspeed internally. The Pixhawk's microcontroller is more than powerful enough to calculate the airspeed internally. This internal computation of the airspeed would allow for the output to be a direct value as opposed to forcing the algorithm and the parameters into a tablet computer or other similar device. The direct output of the airspeed calculation result would allow for simpler integration with other hardware and software which would require an airspeed parameter such as an EFB.

In 1997, there was research done on estimating control surface deflections based on a limited number of available flight recorded parameters [45]. That study was because airlines who were facing a very expensive upgrade from an older type of FDR to a newer one. The older type of FDR did not have control surface deflections as a recordable parameters while the newer one did. This computation of control surface deflections was done using a Neural Network Simulator (NNS) and a Neural Network Reconstructor (NNR). A Neural 
Network Simulator is an approximated mathematical model of the human brain's problem solving activities [45]. The NNS requires off-line training with the FDR parameters and with measured control surface deflections. This training determines the control surface deflections with respect to other parameters. A Neural Network Reconstructor uses an iterative minimization technique in order to approximate the control surface deflections based on the NNS and the parameters recorded by the less sophisticated FDR. Figure 7.2 shows the conceptual block diagram of the virtual flight data recorder proposed in 1997 which uses an NNS and an NNR. This minimizing approximation by the NNR is done at each discrete time step and has proven that it is capable of accurately approximating control surface deflections when tested on a Boeing 737 [45]. The parameters recorded by the less sophisticated FDR are the three accelerations, the three Euler angles, the altitude and the calibrated airspeed. These parameters can be determined using the Arduino-based FDR with the airspeed algorithm. If one was ambitious enough to attempt an NNRbased approach, control surface deflections could also be estimated using the Pixhawk FDR proposed in this thesis. Control surface deflection information can narrow down the accident investigation and allow for it to be carried out in a quicker and most cost-effective manner. 
NNR = Neural Network Reconstructor

NNS $=$ Neural Network Simulator

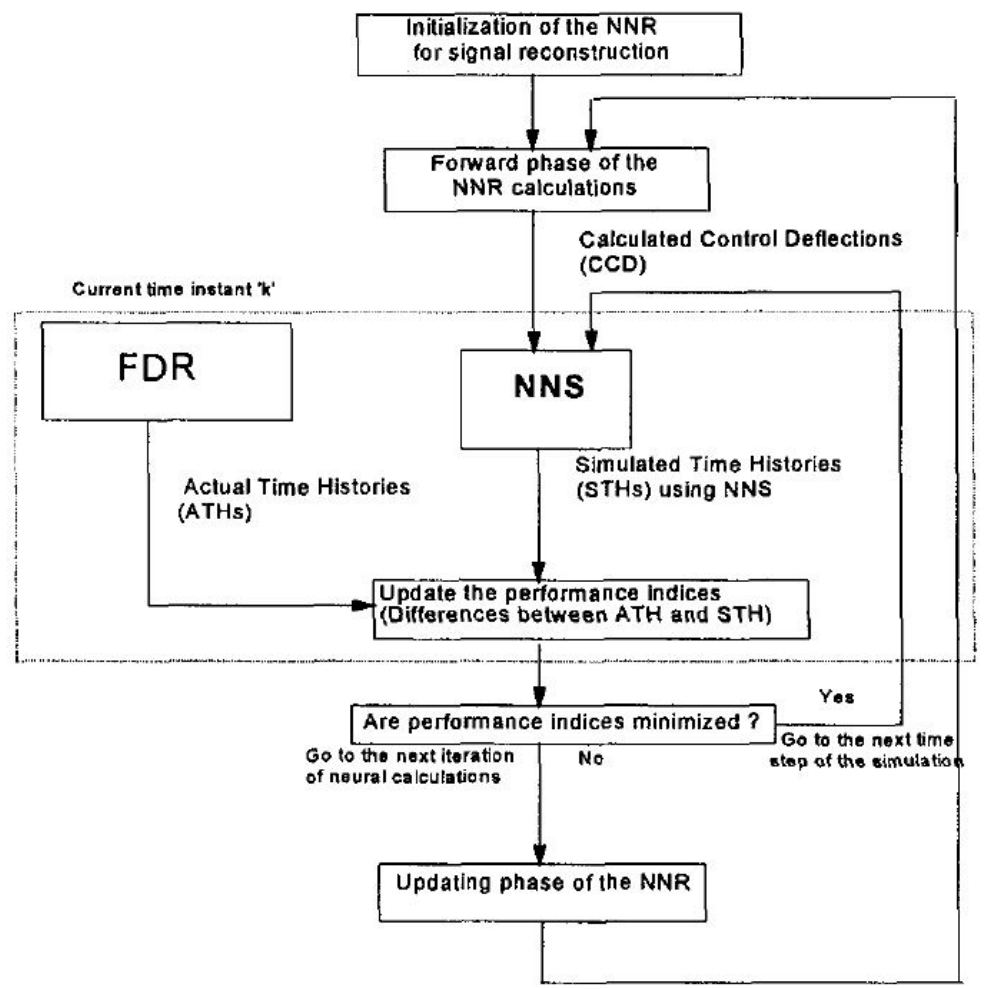

Figure 7.2: Block Digram of a Virtual Flight Data Recorder Using an NNR [45] 


\section{List of References}

[1] “2015 General Aviation Statistical Databook \& 2016 Industry Outlook," General Aviation Manufacturers Association, (Washington, DC,) March 2016.

[2] "Simplified flow chart of report and safety recommendation processes," Transport Accident Investigation Commission, (Wellington, New Zealand,) November 2016.

[3] “Atmega640/v-1280/v-1281/v-2560/v-2561/v." Atmel Corporation, February 2014.

[4] J. O'Callaghan, "Analysis of a Stall-and-Spin Accident Using Recorded Avionics Data," in AIAA Atmospheric Flight Mechanics Conference and Exhibit, no. AIAA-2008-6572, (Honolulu, Hawaii), 2008.

[5] R. Bach and R. Wingrove, "Equation for Determining Aircraft Motions for Accident Data." National Aeronautics and Space Administration, (Moffett Field, California), June 1980.

[6] "Air Taxis Prompt Ottawa Probe After 175 Crash Deaths," CBC News, November 2014.

[7] "Canadian Mining Air Accident (Cessna 208b Caravan)," Aerossurance, June 2014.

[8] "Easa Launch Rule Making Team on In-Flight Recording for Light Aircraft," Aerossurance, August 2014

[9] B. Cox, "Flight Recorder for the Little Guy," Plane \& Pilot Magazine, February 2011.

[10] A. Barclay, "Miniature Flight Data Recorders," in International Helicopter Safety Symposium, (Montreal, Quebec), 2005.

[11] J. Slane, R. Butler, J. Emmerling, S. Morris, R. Winn, and K. Kumley, "Evaluation of a General Aviation Flight Data Recorder," in AIAA Modeling and Simulation Technologies Conference and Exhibit, no. AIAA-2007-6365, (Hilton Head, South Carolina), 2007.

[12] “AWWS Forecasts and Observations," NAV Canada, (Ottawa, Ontario) 2016 
[13] K. Mitchell, B. Sholy, and A. J. Stolzer, "General Aviation Aircraft Flight Operations Quality Assurance," IEEE A\&E Systems Magazine, June 2007.

[14] H. Hurt, "Aerodynamics for Naval Aviators, " Naval Air Systems Command, no NAVAIR 00-801-80, January 1965.

[15] R. Neuhart, D. Gingras, R. Hultberg, R. Oltman, and N. Graybeal, "Flight Data Collection for General Aviation Aircraft Simulation Validation," in AIAA Atmospheric Flight Mechanics Conference, no. AIAA-2009-5731, (Chicago, Illinois), 2009.

[16] S. Abraham-Doman and C. Merrett, "Development of a Flight Data System and experimental Determination of Aerodynamic Loads on a Wing Spar," in AIAA Atmospheric Flight Mechanics Conference, no. AIAA-2014-0194, (National Harbor, Maryland), 2014.

[17] "Extending the Electronic Flight Bag (EFB)," Aircraft Data Fusion, (Farmington, Minnesota), 2013

[18] K. Kavi, and M. Aborizka, "Glass Box: An Intelligent Flight Data Recorder," in 39th AIAA Aerospace Sciences Meeting \& Exhibit, (Reno, Nevada,) January 2001.

[19] M. Anderson, D. French, R. Newman, and M. Phillips, "Flight Testing a General Aviation Head-Up Display," in J. Aircraft, VOL. 33, NO. 1, pages 235-238, 1996

[20] D. B. Chad Bonadonna and A. Lopez, "Design of a Low-Cost General Aviation Flight Data Recording and Analysis System," in IEEE Systems and Information Engineering Design Symposium, 2015.

[21] M. J. Glasgow and G. A. Niehus, "Improving general Aviation Safety Using Low-Cost Iridium Devices," in IEEE Digital Avionics Systems Conference, 2012.

[22] “APM 2.5 Block Diagram,” Ning Interactive Incorporated, November 2015.

[23] "Pixhawk Overview," Ardupilot, November 2016.

[24] “APM 2.5+ - Ardupilot Mega 2.5 Assembled,” JDrone, October 2016.

[25] "Pixhawk," 3DR Robotics, October 2016.

[26] "Pelican 1020," Pelican Cases, October 2016.

[27] "Hkpilot Transceiver Telemetry Radio Set v2 (915mhz)," Hobby King, October 2016.

[28] "STM32f427xx, STM32f429xx," ST Microelectronics, November 2016.

[29] "MPU-6000 and MPU-6050 Product Specification Revision 3.4," InvenSense, November 2015 . 
[30] "L3GD20H," ST Microelectronics, March 2013.

[31] "MS5611-01BA03 Barometric Pressure Sensor, with Stainless Steel Cap," Measurement Specialties Incorporated, November 2015.

[32] "3-Axis Digital Compass IC HMC58831," Honeywell International Incorporated, November 2015.

[33] "FGPMMOPA6B datasheet," Globe Top, November 2016.

[34] “1020 Micro Case,” Pelican Products Incorporated, November 2015.

[35] “3DR RadioV2 Quick Start Guide," 3D Robotics, October 2013.

[36] B. Etkin, L. Reid, "Dynamics of Flight: Stability and Control," Third Edition, John Wiley \& Sons Incorporated, (Toronto, Ontario), 1996.

[37] J. Anderson, "Fundamentals of Aerodynamics," Third Edition, McGraw-Hill, (New York, New York), 2001.

[38] W. Gracey, "Measurement of Aircraft Speed and Altitude," National Aeronautics and Space Administration, (Hampton, Virginia), 1980.

[39] E. Lhotellier, "Airspeeds Definition," International Virtual Aviation Organisation, September 2015.

[40] "Beechcraft Musketeer II A23 and Custom III A23A: Pilot's Operating Handbook and FAA Approved Airplane Flight Manual," RayTheon Aircraft Company, (Wichita, Kansas), July 1994.

[41] H. Glauert, "The Elements of Aerofoil and Airscrew Theory," Cambridge University Press, London, 1926.

[42] D. Lednicer, "The Incomplete Guide to Airfoil Usage," University of Illinois at UrbanaChampaign, (Champaign, Illinois), September 2010

[43] R. Zagull, M. Bragg, G. Gregorek, "Results of an Experimental Program Investigating The Effects of Simulated Ice on the Performance of the NACA 63A415 Airfoil," The Ohio State University (Columbus, Ohio), January 1984.

[44] "Control surfaces and supersonic flight [FAR]" Kerbal Space Program Forums, 2013

[45] M. Napolitanon, D. Windon, J. Casanova, B. Seanor, and D. Matinelli, "The Virtual Flight Data Recorder : a Neural Extension of Existing Data Recording Capabilities," American Institute of Aeronautics and Astronautics, no. A97-37043, 1997. 